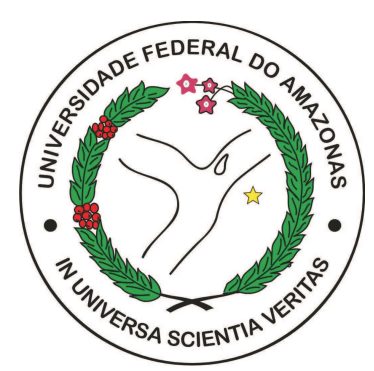

UNIVERSIDADE FEDERAL DO AMAZONAS

FACULDADE DE TECNOLOGIA

PROGRAMA DE PÓS-GRADUAÇÃO EM ENGENHARIA ELÉTRICA TÉCNICAS BIDIMENSIONAIS

Wheidima Carneiro de Melo

Manaus - Amazonas

Junho de 2014 
Wheidima Carneiro de Melo

COMPRESSÃO DE SINAIS ELETROMIOGRÁFICOS BASEADA EM TÉCNICAS BIDIMENSIONAIS

Dissertação apresentada ao Programa de Pós-Graduação em Engenharia Elétrica da Universidade Federal do Amazonas, como requisito para obtenção do título de Mestre em Engenharia Elétrica. Área de concentração: Controle e Automação de Sistemas.

Orientadores: Prof. D.Sc. Eddie Batista de Lima Filho Prof. D.Sc. Waldir Sabino da Silva Júnior 


\section{Ficha Catalográfica}

Ficha catalográfica elaborada automaticamente de acordo com os dados fornecidos pelo(a) autor(a).

\begin{tabular}{|l|}
\hline Melo, Wheidima Carneiro de \\
Compressão de sinais eletromiográficos baseada em técnicas \\
bidimensionais / Wheidima Carneiro de Melo. 2014 \\
83 f.: il. color; $31 \mathrm{~cm}$. \\
Orientador: Eddie Batista de Lima Filho \\
Coorientador: Waldir Sabino da Silva Júnior \\
Dissertação (Mestrado em Engenharia Elétrica) - Universidade \\
Federal do Amazonas. \\
1. Sinais eletromiográficos. 2. Casamento de padrões multiescala. \\
3. Pré-processamento. 4. Codificador HEVC. I. Lima Filho, Eddie \\
Batista de II. Universidade Federal do Amazonas III. Título \\
\end{tabular}


COMPRESSÃO DE SINAIS ELETROMIOGRÁFICOS BASEADA EM TÉCNICAS BIDIMENSIONAIS

Wheidima Carneiro de Melo

DISSERTAÇÃO SUBMETIDA AO CORPO DOCENTE DO PROGRAMA DE PÓS-GRADUAÇÃO EM ENGENHARIA ELÉTRICA DA UNIVERSIDADE FEDERAL DO AMAZONAS COMO PARTE DOS REQUISITOS NECESSÁRIOS PARA A OBTENÇÃO DO GRAU DE MESTRE EM ENGENHARIA ELÉTRICA.

Aprovada por:

Prof. Eddie Batista de Lima Filho, D.Sc.

Prof. Rogério Caetano, D.Sc.

Prof. Jozias Parente de Oliveira, D.Sc.

MANAUS, AM - BRASIL

JUNHO DE 2014 


\section{Agradecimentos}

- Primeiramente, a Deus pelo seu amor incondicional.

- A minha esposa pela sua paciência, compreensão, carinho e apoio durante todo o período do Mestrado.

- A minha mãe pelo suporte durante toda minha vida e pelo seu esforço para garantir a minha formação acadêmica.

- Ao meu orientador Prof. Eddie por ter me incentivado a fazer o curso de mestrado, por ser um exemplo de profissional, pelas suas orientações e pela sua amizade.

- Ao meu co-orientador Prof. Waldir pelos seus bons conselhos, pela sua ajuda ao longo do mestrado e pela sua amizade.

- Aos amigos do Ceteli pela amizade e apoio. 
Resumo da Dissertação apresentada à UFAM como parte dos requisitos necessários para a obtenção do grau de Mestre em Engenharia Elétrica

\title{
COMPRESSÃO DE SINAIS ELETROMIOGRÁFICOS BASEADA EM TÉCNICAS BIDIMENSIONAIS
}

\author{
Wheidima Carneiro de Melo \\ Orientador: Eddie Batista de Lima Filho
}

Programa: Pós-Graduação em Engenharia Elétrica

Tradicionalmente, sinais eletromiográficos são comprimidos com técnicas unidimensionais, que são desenvolvidas especificamente para esse fim. Entretanto, alguns trabalhos têm demonstrado que a compressão de sinais biológicos como imagens, através do seu pré-processamento e rearranjo em uma matriz bidimensional, pode levar a bons resultados. O presente trabalho apresenta uma investigação sobre a compressão de sinais eletromiográficos como imagens, com três principais contribuições: a utilização de novos codificadores, o desenvolvimento de novas técnicas de pré-processamento e a modificação do núcleo de codificação de um compressor específico, de modo que as redundâncias existentes sejam melhor exploradas. No que diz respeito ao pré-processamento do sinal, duas novas técnicas são introduzidas: a ordenação por diferença percentual e a segmentação por similaridade, que apresentam o potencial de aumentar o desempenho do codificador de imagens. Como opção para compressão de sinais eletromiográficos, propõem-se o codificador high efficiency video coding, que representa o estado da arte em compressão de vídeo. Além disso, uma investigação do paradigma que utiliza recorrência de padrões multiescalas, conhecido como multidimensional multiscale parser, também é apresentada. Em resumo, adapta-se o codificador para trabalhar com o sinal biológico, através da substituição das suas técnicas de predição, de modo a melhorar a exploração de redundâncias, cujo resultado é denominado de MMP-Bio. Os experimentos realizados com sinais eletromiográficos reais mostram que as técnicas propostas são eficazes, proporcionando resultados superiores ao estado da arte presente na literatura. 
Abstract of Dissertation presented to UFAM as a partial fulfillment of the requirements for the degree of Master in Electrical Engineering

\title{
ELECTROMYOGRAPHIC SIGNAL COMPRESSION BASED ON TWO-DIMENSIONAL TECHNIQUES
}

\author{
Wheidima Carneiro de Melo \\ Advisor: Eddie Batista de Lima Filho
}

Department: Postgraduate in Electrical Engineering

Traditionally, electromyographic signals are compressed to one-dimensional techniques, which are specifically developed for this purpose. However, some works have shown that the compression of biological signals such as images, by mean preprocessing and rearrangement in a two-dimensional matrix, can lead to good results. This work presents an investigation about the compression of electromyographic signals such as images, with three main contributions: the use of new encoders, the development of new techniques for preprocessing and the modification of the framework of a specific compressor, so that existing redundancies are better exploited. With regard to the preprocessing of the signal, two new techniques are introduced: ordering by percentage difference and similarity segmentation which have the potential to improve the performance of encoding images. As an option for compression of electromyographic signals, are proposed encoder high efficiency video coding, which represents the state-of-the-art video compression. Furthermore, an investigation of the paradigm that uses multiscale recurrent patterns, known as multidimensional multiscale parser is also presented. In summary, we adapted the encoder to work with the biological signal by replacing its prediction techniques in order to improve the exploitation of redundancy, the result is named MMP-Bio. The experiments carried out with real electromyographic signals show that the proposed techniques are effective, providing superior results to state-of-the-art in the literature. 


\section{Sumário}

1 Introdução 1

2 Fundamentos Teóricos $\quad 7$

2.1 Técnicas de compressão de sinais . . . . . . . . . . . . . . . 7

2.1.1 Compressão de sinais sem perdas . . . . . . . . . . . . 8

2.1.2 Compressão de sinais com perdas . . . . . . . . . . . . 9

2.2 Sinais Eletromiográficos . . . . . . . . . . . . . . 12

2.3 Trabalhos Relacionados . . . . . . . . . . . . . . . . . 15

$\begin{array}{lll}3 & \text { O algoritmo MMP-II } & 17\end{array}$

3.1 Introdução . . . . . . . . . . . . . . . . . . . . . . . 17

3.2 O algoritmo MMP . . . . . . . . . . . . . . . . . . . . . 19

3.2.1 O algoritmo MMP com técnicas de predição . . . . . . . . . . 21

3.2 .2 Atualização do dicionário . . . . . . . . . . . . . . . . . . . 24

3.2.3 Formação do stream de saída do MMP . . . . . . . . . . . . 28

3.3 Considerações Finais . . . . . . . . . . . . . . . . . . . . . . . . . 29

4 Otimização do MMP para codificação de sinais de S-EMG 31

4.1 Introdução . . . . . . . . . . . . . . . . . . . . . . . . . 31

4.2 Adaptação do MMP . . . . . . . . . . . . . . . . . . . . . . . . . 32

4.3 Melhoria nas técnicas de predição . . . . . . . . . . . . . . . . 34

4.3.1 Análise de blocos com escalas maiores . . . . . . . . . . . . . 37

4.4 Considerações Finais . . . . . . . . . . . . . . . . . . . . 39

5 Compressão de Sinais Eletromiográficos Baseada em Técnicas de $\begin{array}{ll}\text { Pré-processamento } & 40\end{array}$ 
5.1 Compressão de sinais eletromiográficos com codificadores bidimensio-

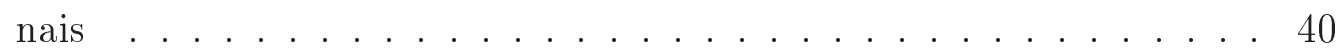

5.2 Técnicas de pré-processamento . . . . . . . . . . . . . . . . 42

5.2.1 A ordenação por diferença percentual . . . . . . . . . . . . . 42

5.2 .2 A segmentação por similaridade . . . . . . . . . . . . 44

5.3 Esquema de Compressão de Sinais Eletromiográficos Proposto . . . . 45

5.4 Considerações Finais . . . . . . . . . . . . . . . . . . . . . . . . 46

6 Resultados e Discussões 48

6.1 Procedimento . . . . . . . . . . . . . . . . . . . . . 48

6.2 Codificadores Utilizados . . . . . . . . . . . . . . . . . . . . 49

6.3 Base de Dados . . . . . . . . . . . . . . . . . . . . . . . . . 49

6.4 Métrica de Desempenho . . . . . . . . . . . . . . . 50

6.5 Análise de Desempenho . . . . . . . . . . . . . . . 50

6.5.1 Análise de Desempenho entre as Técnicas de Pré-processamento 51

6.5.2 Análise de Desempenho do Codificador HEVC . . . . . . . . . 56

6.5.3 Análise de Desempenho do Codificador MMP-Bio . . . . . . . 56

6.5.4 Análise de Desempenho com outros Métodos . . . . . . . . . 57

6.5.5 Análise do Envelope do Sinal Reconstruído . . . . . . . . . . 58

6.6 Considerações Finais . . . . . . . . . . . . . . . . . . . . . . . 59

$\begin{array}{lll}7 & \text { Conclusões } & 67\end{array}$

7.1 Considerações Finais da Dissertação . . . . . . . . . . . . . . . 67

7.2 Propostas para Trabalhos Futuros . . . . . . . . . . . . . 68

$\begin{array}{ll}\text { Referências Bibliográficas } & 70\end{array}$

$\begin{array}{ll}\text { A Sinais de S-EMG } & 78\end{array}$

B Artigos Desenvolvidos nesta Dissertação 83 


\section{Lista de Figuras}

1.1 (a) Sinal de EMG formatado em sinal bidimensional (b) espectro do

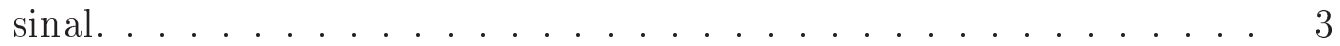

2.1 Diagrama de um esquema de compressão com perdas. . . . . . . . . . 9

2.2 Função taxa-distorção $R(D) \ldots \ldots \ldots$. . . . . . . . . . . 11

2.3 Estrutura do músculo esquelético [43] . . . . . . . . . . . . . . 13

2.4 Unidade motora e seus componentes [43] . . . . . . . . . . . . . . 14

2.5 Sinal de S-EMG. . . . . . . . . . . . . . . . . . . . 14

3.1 (a) Imagem Lena. (b) Espectro do sinal. . . . . . . . . . . . . . . . 17

3.2 Espectro da imagem gerada a partir do sinal de EMG. . . . . . . . . 18

3.3 (a) Esquema de segmentação do MMP. . . . . . . . . . . . . . . . . 20

3.4 Representação do dicionário do MMP. . . . . . . . . . . . . . . . . . . 21

3.5 (a) Segmentação de um bloco da imagem e (b) a sua correspondente árvore ótima. . . . . . . . . . . . . . . . . . . . . 22

3.6 Modos de predição do MMP-I. . . . . . . . . . . . . . . . . . 23

3.7 Segmentação de um bloco da imagem com técnicas de predição. . . . 23

3.8 Procedimento de atualização do dicionário. . . . . . . . . . . . . 25

3.9 Procedimento de atualização do dicionário com uso da condição de distância mínima. . . . . . . . . . . . . . . . 26

4.1 Técnicas de predição proposta para MMP-II. . . . . . . . . . . . . 34

4.2 Exemplo de predição utilizando amostras localizadas à esquerda/abaixo. 35

4.3 Imagem gerada a partir de um dos sinais de teste (a) e o seu histograma (b). O histograma do erro de predição para: (c) predições do MMP-II e $(\mathrm{d})$ técnica proposta. . . . . . . . . . . . . . . 36

4.4 Bloco codificado com o MMP-II utilizando 36 escalas. . . . . . . . . . 38 
5.1 Um sinal de EMG formatado em um sinal bidimensional. . . . . . . . 41

5.2 Resultado da ordenação por diferença percentual: (a) sinal bidimensional original e (b) sinal bidimensional reordenado. . . . . . . . . . . 43

5.3 Esquema de compressão proposto: diagrama em blocos do codificador

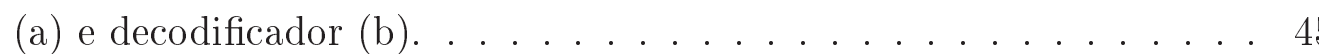

6.1 Resultados experimentais para o codificador JPEG2000: (a) sem técnica de pré-processamento, (b) com a ordenação por diferença percentual e (c) com a segmentação por similaridade. . . . . . . . . . . . 52

6.2 Resultados experimentais para o codificador H.264/AVC: (a) sem técnica de pré-processamento, (b) com a ordenação por diferença percentual e (c) com a segmentação por similaridade. . . . . . . . . . . 53

6.3 Resultados experimentais para o codificador HEVC: (a) sem técnica de pré-processamento, (b) com a ordenação por diferença percentual e (c) com a segmentação por similaridade. . . . . . . . . . . . 54

6.4 Resultados experimentais para o codificador MMP-Bio. . . . . . . . . 55

6.5 Inspeção visual da qualidade do sinal reconstruído a partir do codificador MMP-Bio: (a) sinal original, (b) sinal reconstruído a um $C F$ de $87,5 \%$ e (c) diferença entre sinal original e o reconstruído. . . . . . 60

6.6 Inspeção visual da qualidade do sinal reconstruído a partir da s.s.+HEVC: (a) sinal original, (b) sinal reconstruído a um $C F$ de $87,5 \%$ e (c) diferença entre sinal original e o reconstruído. . . . . . . 61

6.7 Inspeção visual da qualidade do sinal reconstruído a partir da o.d.p.+HEVC: (a) sinal original, (b) sinal reconstruído a um $C F$ de $87,5 \%$ e (c) diferença entre sinal original e o reconstruído. . . . . . . 62

6.8 Inspeção visual da qualidade do sinal reconstruído a partir da s.s. + H264: (a) sinal original, (b) sinal reconstruído a um $C F$ de $87,5 \%$ e (c) diferença entre sinal original e o reconstruído. . . . . . . 63

6.9 Inspeção visual da qualidade do sinal reconstruído a partir da o.d.p.+H264: (a) sinal original, (b) sinal reconstruído a um $C F$ de $87,5 \%$ e (c) diferença entre sinal original e o reconstruído. . . . . . . 64 
6.10 Inspeção visual da qualidade do sinal reconstruído a partir da s.S.+JPEG2000: (a) sinal original, (b) sinal reconstruído a um $C F$ de $87,5 \%$ e (c) diferença entre sinal original e o reconstruído. . . . . 65

6.11 Inspeção visual da qualidade do sinal reconstruído a partir da o.d.p.+JPEG2000: (a) sinal original, (b) sinal reconstruído a um $C F$ de $87,5 \%$ e (c) diferença entre sinal original e o reconstruído. . . . . . 66

A.1 Sinal teste.01. . . . . . . . . . . . . . . . . 78

A.2 Sinal teste.02. . . . . . . . . . . . . . . . 78

A.3 Sinal teste.03. . . . . . . . . . . . . . . . . . . . 79

A.4 Sinal teste.04. . . . . . . . . . . . . . . . . . . 79

A.5 Sinal teste.05. . . . . . . . . . . . . . . . . . 79

A.6 Sinal teste.06. . . . . . . . . . . . . . . . . . 80

A.7 Sinal teste.07. . . . . . . . . . . . . . . . . . . . . . . 80

A.8 Sinal teste.08. . . . . . . . . . . . . . . . . . . . 80

A.9 Sinal teste.09. . . . . . . . . . . . . . . . . 81

A.10 Sinal teste.10. . . . . . . . . . . . . . . . . . . 81

A.11 Sinal teste.11. . . . . . . . . . . . . . . . . . . . 81

A.12 Sinal teste.12. . . . . . . . . . . . . . . . . . . 82

A.13 Sinal teste.13. . . . . . . . . . . . . . . . . . . 82 


\section{Lista de Tabelas}

6.1 Valores de $P R D(\%)$ médios para metodologia proposta . . . . . 55

6.2 Valores de $P R D(\%)$ médios para sinais de EMG codificados com diferentes esquemas de compressão . . . . . . . . . . . . . . 58 


\section{Capítulo 1}

\section{Introdução}

O processamento de sinais biológicos é uma área dinâmica e de grande interesse da comunidade científica, principalmente devido aos seus diversos campos de pesquisa, como fisioterapia, medicina, processamento de sinais e imagens, entre outros. Dentre as suas aplicações de grande relevância pode-se citar: detecção de patologias [1-3], reconhecimento de padrões [4-6] e sistemas de reabilitação [7,8].

Os principais sinais biológicos pesquisados são o eletrocardiograma (ECG) [9], que mede a variação dos estímulos elétricos aplicados aos átrios e ventrículos, o eletromiograma (EMG) [10], que registra a atividade elétrica relacionada à contração dos músculos do corpo humano, e o eletroencefalograma (EEG) [11], que representa a atividade elétrica do cérebro humano, ou seja, padrões elétricos conhecidos como ritmos.

Dentro os principais sinais biológicos destacam-se o EMG e o EEG, pois estes sinais além de contribuírem para o tratamento e diagnósticos de patologias, também podem ser utilizados com interfaces, que interpretam o sinal, para controlar dispositivos. Por exemplo, estes sinais podem acionar próteses biônicas [12], [13], [14], devolvendo movimento a vítimas de acidentes ou a pacientes com alguma disfunção muscular. Em especial, o sinal de EMG representa diretamente os impulsos elétricos enviados pelo sistema nervosos às fibras musculares, estando presente mesmo que o membro tenha sido perdido [12]. Além disso, este sinal pode ser facilmente captado com a ajuda de eletrodos de superfície (S-EMG), sem causar qualquer dano ao paciente.

Os sinais de EMG podem ser adquiridos por múltiplos eletrodos e os registros 
de cada de sinal podem ser de longa duração. Em algumas aplicações, comparações de parâmetros do sinal e análises do desenvolvimento de patologias tornam o uso de banco de dados indispensável [15,16]. Além disso, os sinais podem ser usados em sistemas wireless, onde acrescenta-se um módulo receptor na interface de controle [17]. Essa necessidade de armazenamento e/ou transmissão do sinal, resulta em pesquisas por métodos de compressão eficientes. Entretanto, além de uma representação com um número menor de bits, tais métodos devem preservar a informação clínica presente no sinal.

Normalmente, os sinais biológicos são representados por variáveis unidimensionais. Entretanto, alguns métodos utilizam um esquema diferente para compressão de sinais biológicos: formatá-los em um sinal bidimensional [18], [19], [20], empregando um compressor de imagens para explorar as dependências intrasegmento e intersegmento. Adicionalmente, técnicas de pré-processamento são utilizadas, com o objetivo de aumentar as correlações do sinal bidimensional e, consequentemente, o desempenho do compressor de imagens.

Alguns autores apresentam resultados que comprovam as redundâncias do sinal de S-EMG formatado em um sinal bidimensional [19], evidenciando as técnicas de compressão de imagens como meio de codificação de sinais biológicos. Além disso, mostra-se a existência de correlação entre as colunas do sinal bidimensional (imagem), onde as mesmas podem ser rearranjadas de maneira a aumentar a correlação intersegmento. Para essa finalidade, propõe-se a utilização de uma técnica de pré-processamento denominada ordenação por correlação.

Geralmente, as técnicas de compressão de imagens empregadas na compressão de sinais biológicos são baseadas em transformadas. Estes métodos são eficientes na compressão de imagens que possuem alta correlação bidirecional, denominadas imagens suaves, onde através das transformadas compacta-se a energia do sinal nos componentes de baixa frequência, com isso os componentes de alta frequência podem ser fortemente atenuados ou até mesmo eliminados pelo processo de quantização. Entretanto as imagens geradas a partir do sinal de S-EMG possuem o aspecto similar à de uma imagem de ruído (Figura 1.1(a)), e o seu espectro (Figura 1.1(b)) possui energia distribuída de maneira uniforme entre os componentes de frequência. Com isso, o desempenho dos compressores baseados nestes métodos tende a piorar. 


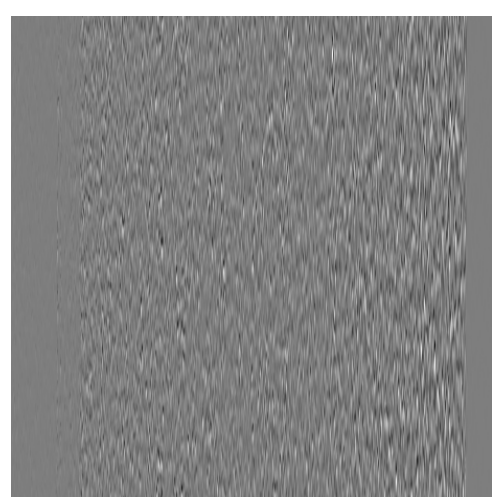

(a)

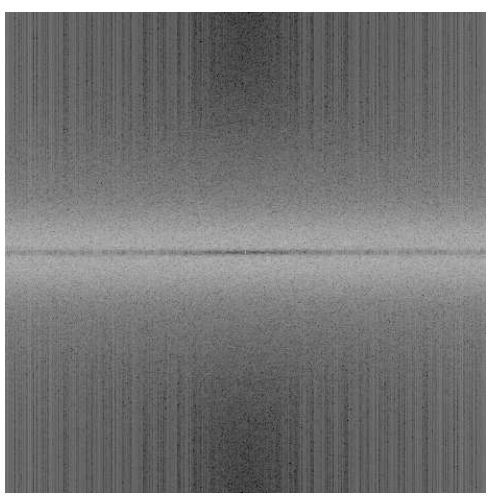

(b)

Figura 1.1: (a) Sinal de EMG formatado em sinal bidimensional (b) espectro do sinal.

Em resumo, codificar sinais biológicos, em específico os sinais de EMG, por meio de técnicas de compressão de imagens é eficiente, porém métodos baseados em transformadas podem ter uma eficiência menor. Além disso, o desempenho dos compressores de imagens podem ser melhorados através da utilização de técnicas de pré-processamento. Estes resultados estimulam: a pesquisa por novas técnicas de pré-processamento, a avaliação de compressores de imagens ainda não utilizados na compressão de sinais eletromiográficos e uma investigação de codificadores com paradigma diferente para compressão de sinais eletromiográficos.

Este trabalho propõe duas novas técnicas de pré-processamento para a codificação de sinais eletromiográficos como imagem: a ordenação por diferença percentual e a segmentação por similaridade. A primeira, reorganiza os segmentos do sinal de entrada com base em sua semelhança. A seguinte, particiona o sinal de forma adaptativa, alterando o número de amostras dentro dos segmentos. O objetivo das técnicas é facilitar a exploração das dependências intrasegmento e intersegmento, por meio do aumento da correlação nos segmentos adjacentes e entre as amostras dentro de um segmento, produzindo um aumento no desempenho do compressor de imagem.

Os codificadores JPEG2000 [21] e H.264/AVC [22] são empregados para compressão dos sinais de EMG. Do mesmo modo, propõe-se a compressão desses sinais utilizando o codificador HEVC (do inglês, high efficiency video coding) [23]. Este codificador visa suprir as necessidades de transmissão de vídeos de alta resolução [24]. O seu desempenho permite, em alguns casos, uma redução de metade da taxa de 
bits, proporcionando qualidade visual equivalente ao do seu antecessor, o codificador H.264/AVC [24]. O codificador HEVC pode ser utilizado na compressão de imagens [23,25], por isso uma investigação do desempenho deste codificador na compressão de sinais eletromiográficos é apropriada.

Adicionalmente, um codificador com paradigma alternativo para compressão de imagens baseado no casamento aproximado de padrões multiescalas, que utiliza um dicionário adaptativo e técnicas de codificação preditivas, é apresentado para compressão de sinais eletromiográficos. O compressor é denominado MMP-II (do inglês, multidimensional multiscale parser) [26]. A codificação é realizada pela predição dos blocos da imagem e representação dos mesmos por padrões existentes no dicionário. O algoritmo atualiza o dicionário à medida que comprime o sinal, por isso o codificador MMP-II possui a característica universal, ou seja, não se necessita de nenhum conhecimento prévio do sinal a ser codificado, esse comportamento supera a limitação dos métodos baseados em transformadas que pressupõem, normalmente, que o sinal de entrada é uma imagem suave. Além disso, o codificador apresenta eficiência na compressão de sinais com distribuições Gaussianas [26], característica dos sinais de S-EMG [27]. Esses fatos tornam o MMP-II um bom candidato à compressão de sinais eletromiográficos.

Os sinais de EMG formatados em uma matriz bidimensional apresentam correlação bidirecional. As técnicas de predição exploram estas correlações de modo a gerar um sinal de resíduo com menor quantidade de energia e uma distribuição de probabilidade Gaussiana [26]. Neste contexto, propõe-se uma melhoria no desempenho do codificador, para isso, as técnicas de predição são substituídas pelo método de predição presente no codificador HEVC, o qual é constituído por 33 modos direcionais de predição [23]. O esquema também utiliza as técnicas MFV (do inglês Most Frequent Value) e Planar como modos de predição não direcionais. As técnicas propostas favorecem o desempenho do codificador, pois os sinais de resíduo gerados são mais homogêneos, melhorando a adaptação do dicionário. Adicionalmente, para utilizar o MMP-II na compressão dos sinais eletromiográficos, realiza-se uma adaptação no compressor, de modo que a codificação possa ser realizada de acordo com as características do sinal. Estas modificações no codificador dão origem a um novo compressor denominado MMP-Bio. Por fim, como o algoritmo particiona a 
imagem em blocos para codificá-los, análisa-se o emprego de blocos de entrada com dimensões superiores.

Os desempenhos das técnicas propostas foram avaliados através de sinais eletromiográficos de superfície. Os codificadores JPEG2000, H.264/AVC e HEVC são utilizados para geração dos resultados, assim como, a combinação destes codificadores com a técnicas de pré-processamento propostas. Além disso, emprega-se o codificador MMP-Bio para compressão dos sinais. A análise dos resultados comprova que a ordenação por diferença percentual e a segmentação por similaridade aumentam os desempenhos dos compressores e os codificadores HEVC e MMP-Bio são eficientes na compressão de sinais eletromiográficos.

A dissertação é constituída por 7 capítulos que estão organizados da seguinte maneira:

- No Capítulo 2, são apresentados conceitos referentes à compressão de sinais, definindo os principais fundamentos e comentando as técnicas existentes. Adicionalmente, uma breve revisão sobre sinais biológicos é realizada, destacandose o sinal de EMG.

- No Capítulo 3, descreve-se o algoritmo de compressão de sinais MMP-II. Iniciase apresentando o algoritmo MMP, posteriormente comenta-se as técnicas de predição e o esquema de atualização do dicionário.

- No Capítulo 4, descreve-se de forma detalhada a adaptação do algoritmo MMP-II para compressão de sinais de EMG e o novo esquema de predição do compressor, como resultado define-se um novo compressor denominado MMPBio. Após isso, analisa-se o funcionamento do compressor para blocos com escalas superiores.

- As técnicas de pré-processamento são apresentadas no Capítulo 5, juntamente com a descrição do esquema de compressão proposto.

- O Capítulo 6 provê resultados experimentais, com sinais de EMG reais adquiridos em laboratório, para esquema de compressão proposto. Destaque para o desempenho do codificador MMP-Bio e HEVC, assim como para os resultados com as técnicas de pré-processamento. 
- Finalmente, as conclusões são apresentadas no Capítulo 7, além de sugestões para trabalhos futuros. 


\section{Capítulo 2}

\section{Fundamentos Teóricos}

Neste capítulo são discutidos os fundamentos de compressão de sinais como classificação das técnicas, principais métodos existentes e conceitos de teoria da informação. Além disso, apresenta-se uma breve descrição dos sinais eletromiográficos.

\subsection{Técnicas de compressão de sinais}

As técnicas de compressão de sinais consistem em representar um sinal de maneira eficiente, otimizando o processamento, a transmissão e o armazenamento do sinal. Tais técnicas exploram as redundâncias do sinal, de modo que sua representação torna-se mais compacta, onde o sinal original pode ser recuperado no processo inverso denominado descompressão.

A base para compressão de sinais é obtida na teoria da informação. Através deste ramo da ciência analisa-se de forma quantitativa a informação e assim, podese explorar as redundâncias do sinal. No trabalho de Claude Shannon [28], definese uma medida para quantidade de informação e desta forma, pode-se analisar a eficiência da compressão do sinal.

Durante a compressão, um algoritmo de codificação, definido como codifica-

dor, comprime uma entrada $X$ e gera uma versão codificada, definida como $\hat{X}$, a qual necessita de uma quantidade de bits menor para sua representação. No processo de descompressão, um algoritmo de decodificação, definido como decodificador, interpreta os bits gerados na saída do codificador e produz uma versão da entrada $X$, definida como $Y$. 
A versão produzida pelo decodificador pode ser exatamente igual ou diferente do sinal original. Desta maneira, podem-se classificar as técnicas de compressão de sinais como: sem perdas, em que não existe diferença entre o sinal original e o sinal reconstruído, e com perdas, em que o sinal reconstruído é uma versão aproximada do sinal original.

\subsubsection{Compressão de sinais sem perdas}

Na compressão sem perdas, a saída $Y$ do decodificador é exatamente igual a entrada $X$ do codificador, isso significa que não há perda de informação considerando o processo completo de compressão. Essa característica permite que essa técnica de compressão seja utilizada em aplicações de compressão de imagens médicas, textos e arquivos de áudio.

Uma forma de avaliação do desempenho do codificador é a razão entre o número de bits da entrada $X$ e o número de bits da saída $\hat{X}$, denominada de taxa de compressão. Para as técnicas de compressão sem perdas, as taxas de compressão não são altas, sendo esta a grande desvantagem deste tipo de codificador.

Entre várias técnicas de compressão sem perdas, destaca-se: codificação Run-length [29], codificação Huffman [30], codificação aritmética [31] e codificação Lempel-Ziv [32,33] que é baseada em dicionário.

Para determinar a taxa de compressão máxima teórica para este tipo de codificador, deve-se recorrer aos estudos iniciados por Shannon. Em [28], é realizada a definição do termo auto-informação, $I(\alpha)$, associada a probabilidade de um evento aleatório $\alpha$, como

$$
I(\alpha)=\log _{2} \frac{1}{P(\alpha)}
$$

A equação 2.1 evidência, em bits, a quantidade de informação $I(\alpha)$ contida no evento $\alpha$, perceba que se a probabilidade do evento aleatório $\alpha$ for baixa, a quantidade de informação $I(\alpha)$ é alta, em contrapartida, se a quantidade de informação $I(\alpha)$ é baixa, a probabilidade do evento aleatório $\alpha$ é alta.

O termo auto-informação média, conhecido como entropia, é outro importante conceito definido por Shannon que pode ser entendido matematicamente da 
seguinte maneira: seja uma fonte $S$ com alfabeto $A=\left\{a_{1}, a_{2}, \ldots, a_{n}\right\}$ e $s_{i}$, com $i=1,2, \ldots, n$, um elemento gerado por $S$ com probabilidades de ocorrências $P\left(s_{i}\right)$, então a entropia é definida por:

$$
H(S)=\sum_{k=1}^{n} P\left(s_{k}\right) I\left(s_{k}\right)
$$

A entropia é definida em bits/símbolo e substituindo-se a equação (2.1) na equação (2.2), obtém-se:

$$
H(S)=-\sum_{k=1}^{n} P\left(s_{k}\right) \log _{2}\left(s_{k}\right)
$$

A entropia da fonte define a taxa de compressão máxima que pode ser alcançada por codificadores que utilizam técnicas de compressão sem perdas. Por isso, os codificadores de tais técnicas procuram atingir taxas que se aproximem da entropia da fonte $S$.

\subsubsection{Compressão de sinais com perdas}

Durante a compressão com perdas, a saída $Y$ do decodificador difere da entrada $X$ do codificador. Este processo é categorizado como irreversível, pois no decorrer da codificação perde-se informação, e por esse motivo, o decodificador não é capaz de reproduzir o sinal original de forma exata. A diferença entre o sinal de saída, do processo completo de compressão, e o sinal de entrada é denominada distorção. O diagrama da Figura 2.1 ilustra um esquema de compressão com perdas.

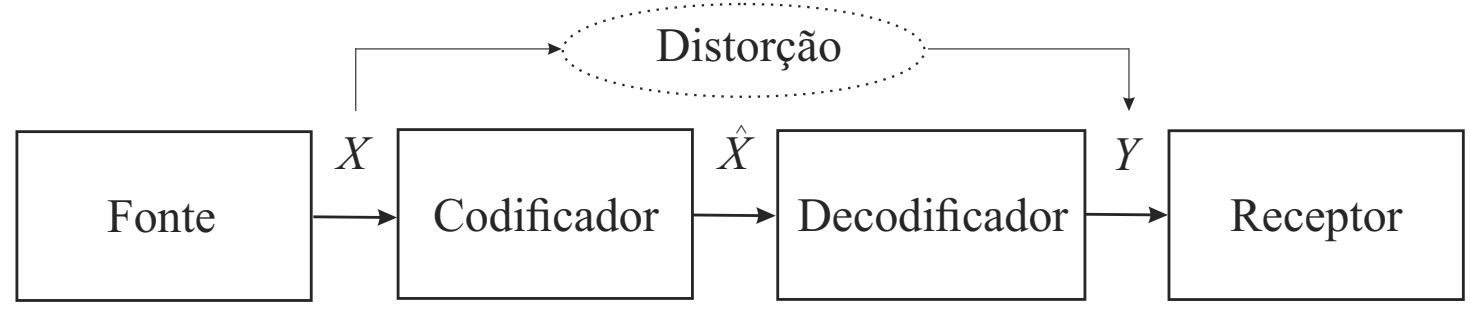

Figura 2.1: Diagrama de um esquema de compressão com perdas.

As técnicas de compressão com perdas são utilizadas em aplicações que toleram distorção no sinal decodificado. Porém, os codificadores são utilizados de 
maneira a não deteriorarem significativamente o sinal de entrada para que não afete a sua interpretação. Como exemplo, pode-se citar a compressão de imagens que explora a percepção humana para interpretar uma imagem. Nestes casos, eliminam-se informações na imagem com pouca ou nenhuma contribuição para o sistema visual humano.

Com relação aos sinais biológicos, é possível classificar as técnicas de compressão com perdas existentes na literatura em três grupos [34-36]: métodos diretos, paramétricos e baseados em transformadas. Nos métodos diretos são empregadas técnicas de predição para a estimação de amostras futuras, baseado no que foi codificado anteriormente. Os paramétricos, por sua vez, criam um modelo e extraem os parâmetros necessários para excitar o codificador, reconstruindo o sinal original. Para as técnicas baseadas em transformada, o sinal de entrada é transformado para outro domínio e então é quantizado e codificado. Neste último, se as características da transformada escolhida forem corretamente exploradas, o desempenho do codificador tende a ser superior ao apresentado pelos demais grupos [34].

As técnicas de compressão com perdas possuem uma relação de compromisso entre a compressão requerida e a distorção. A base teórica de tal relação é encontrada na teoria taxa-distorção, em que se obtém a taxa $R$ (número de bits) mínima para representar um sinal para uma determinada distorção $D$. Para obter estes resultados, necessita-se dos conceitos de entropia condicional e informação mútua que podem ser conceituadas da seguinte maneira: seja uma fonte $X$ constituída pelo alfabeto $\tilde{X}=\left\{x_{1}, x_{2}, \ldots, x_{n}\right\}$ e uma saída $Y$ formada pelo alfabeto $\tilde{Y}=\left\{y_{1}, y_{2}, \ldots, y_{m}\right\}$, a entropia condicional $H(Y \mid X)$ é dada por:

$$
\begin{array}{r}
H(Y \mid X)=\sum_{i=1}^{n} P\left(x_{i}\right) H\left(Y \mid X=x_{i}\right) \\
H(Y \mid X)=-\sum_{i=1}^{n} \sum_{j=1}^{m} P\left(y_{j} \mid x_{i}\right) P\left(x_{i}\right) \log _{2} P\left(y_{j} \mid x_{i}\right)
\end{array}
$$

A informação mútua [37], que determina a quantidade de informação de $X$ em $Y$, é definida por:

$$
I(X ; Y)=H(Y)-H(Y \mid X)
$$


A partir dos conceitos de entropia condicional e informação mútua pode-se encontrar a função taxa-distorção $R(D)$, esta função específica, para uma distorção menor ou igual a $D$, a menor taxa para representar o sinal original.

Para um método de compressão com fonte $X$, probabilidade $P\left(x_{i}\right)$ e saída $Y$, a distorção média é obtida por:

$$
D=\sum_{i=1}^{n} \sum_{j=1}^{m} P\left(x_{i}\right) P\left(y_{j} \mid x_{i}\right) d\left(x_{i}, y_{j}\right)
$$

A função taxa-distorção para uma medida de distorção $d\left(x_{i}, y_{j}\right)$ limitada é dada por:

$$
R(D)=\min _{P\left(y_{j} \mid x_{i}\right) \mid D \leq D^{*}} I(X ; Y)
$$

onde $D^{*}$ é a distorção alvo.

A equação 2.7 fornece, para um valor de distorção menor ou igual a uma distorção alvo $D^{*}$, a menor taxa de codificação do sinal.

A função $R(D)$ é não negativa, decrescente e definida para $D \in\left(D_{\min }, D_{\max }\right)$, onde $R(D)=0$, se $D>D_{\max }$. Na Figura 2.2, apresenta-se um gráfico que representa a função descrita na equação 2.7. Observe que para o ponto $\left(R_{\max }, 0\right)$ tem-se a compressão sem perdas pois a distorção é zero. Para o ponto $\left(0, D_{\max }\right)$, a taxa é igual a zero, ou seja, nenhuma informação é transmitida.

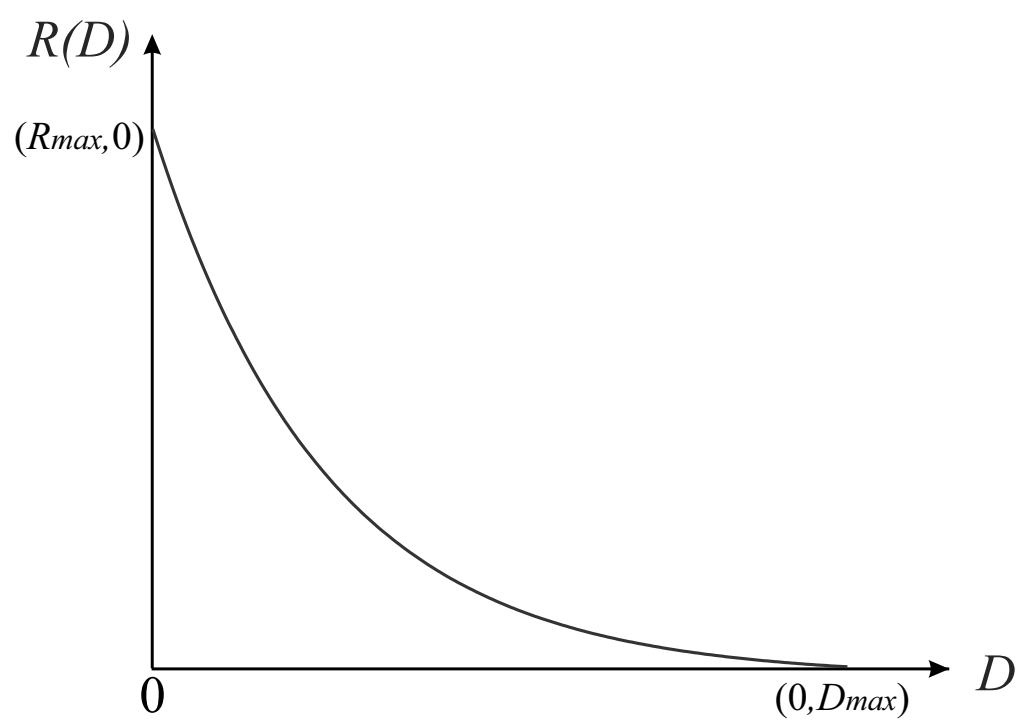

Figura 2.2: Função taxa-distorção $R(D)$. 


\subsection{Sinais Eletromiográficos}

Sinais biológicos consistem em sinais produzidos por diversos processos fisiológicos no corpo humano. A natureza destes sinais pode ser elétrica, acústica ou química e a interpretação das suas informações contribuem para tratamento e/ou compreensão de patologias do corpo humano [38].

Entre os sinais de natureza elétrica, pode-se citar o sinal de eletrocardiograma (ECG) [9], registra as atividades elétricas do músculos do coração, eletromiograma (EMG) [10], registra as atividades elétricas dos músculos, e eletroencefalograma (EEG) [11,39], registra as atividades elétricas do cérebro. Os sinais de EMG e EEG se destacam, pois, além de contribuírem em aplicações clínicas, podem ser utilizados com interfaces de controle, ampliando as aplicações destes sinais [40] [41]. A seguir apresenta-se uma breve descrição da geração e do comportamento dos sinais de EMG.

O sinal eletromiográfico (EMG) é muito importante para a área de engenharia biomédica, pois o mesmo é gerado pela contração dos músculos do corpo humano quando uma pessoa está consciente (movimentos similares resultam em formas similares), podendo ser diretamente utilizado como sinalizador de intenção de movimento [13] ou como ferramenta de diagnóstico para músculos com funcionamento irregular [42].

A eletromiografia é um método de avaliação e registro das atividades elétricas produzidas no músculo do corpo humano. Os registros são denominados eletromiogramas e o instrumento que adquiri o sinal de EMG é o eletromiógrafo [10].

Os sinais de EMG são adquiridos da musculatura humana, especificamente, dos músculos esqueléticos, responsáveis por contrações voluntárias. Estes músculos dispõem de uma grande quantidade de vasos sanguíneos e nervos. As células nervosas transmitem o impulso elétrico para executar a contração, e os vasos provêem nutrientes e oxigênio necessário para realizá-la.

Os músculos esqueléticos (Figura 2.3) são constituídos por fascículos musculares [43]. Estes são compostos por fibras musculares, que são células multinucleadas com estruturas alongadas e cilíndricas, envolvidas em uma membrana plasmática, denominada sarcolema [43].

As fibras musculares são, em grande parte, responsáveis pelo sinal de EMG, 


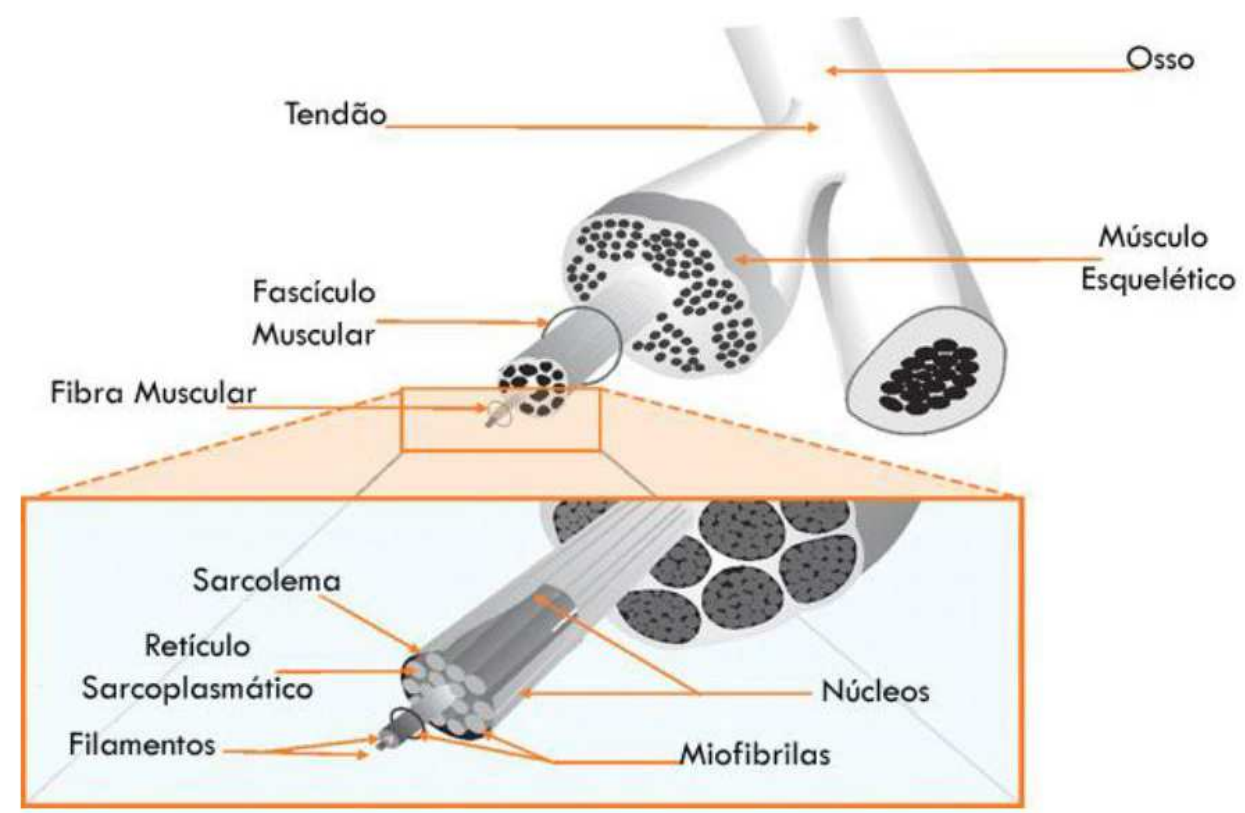

Figura 2.3: Estrutura do músculo esquelético [43].

pois são inervadas pelos neurônios motores, para que seja produzido um potencial de ação. Um único neurônio motor pode inervar várias fibras musculares constituindo uma unidade motora (MU, do inglês Motor Unit) que é a menor unidade funcional dos músculos esqueléticos [44] (Figura 2.4).

Quando o sistema nervoso estimula um neurônio motor, todas as fibras musculares sob o seu controle produzem um sinal conhecido como potencial de ação da unidade motora (MUAP, do inglês Motor Unit Action Potential). O sinal de EMG é então definido como a soma dos MUAPs de todas as unidades motoras próximas aos eletrodos de medição [44].

Após ser captado pelo elétrodo, o sinal de EMG é amplificado e filtrado, para que ruídos ou interferências capazes de modificar a saída sejam atenuados. A amplitude do sinal varia de 0 a $10 \mathrm{mV}$ (pico a pico), com frequências entre 0 a $500 \mathrm{~Hz}$, porém, a maior parte da energia do sinal de EMG está concentrada entre 50 e $150 \mathrm{~Hz}[45]$.

Existem dois métodos básicos de aquisição do sinal de EMG: invasivo e nãoinvasivo. O primeiro, denominado eletromiografia intramuscular (I-EMG), obtém os registros utilizando elétrodos de fio ou elétrodos de agulha. Por último, o método de aquisição que utiliza eletrodos de superfície é denominado eletromiografia de superfície (S-EMG), sendo este uma alternativa muito interessante, pois possui uma 


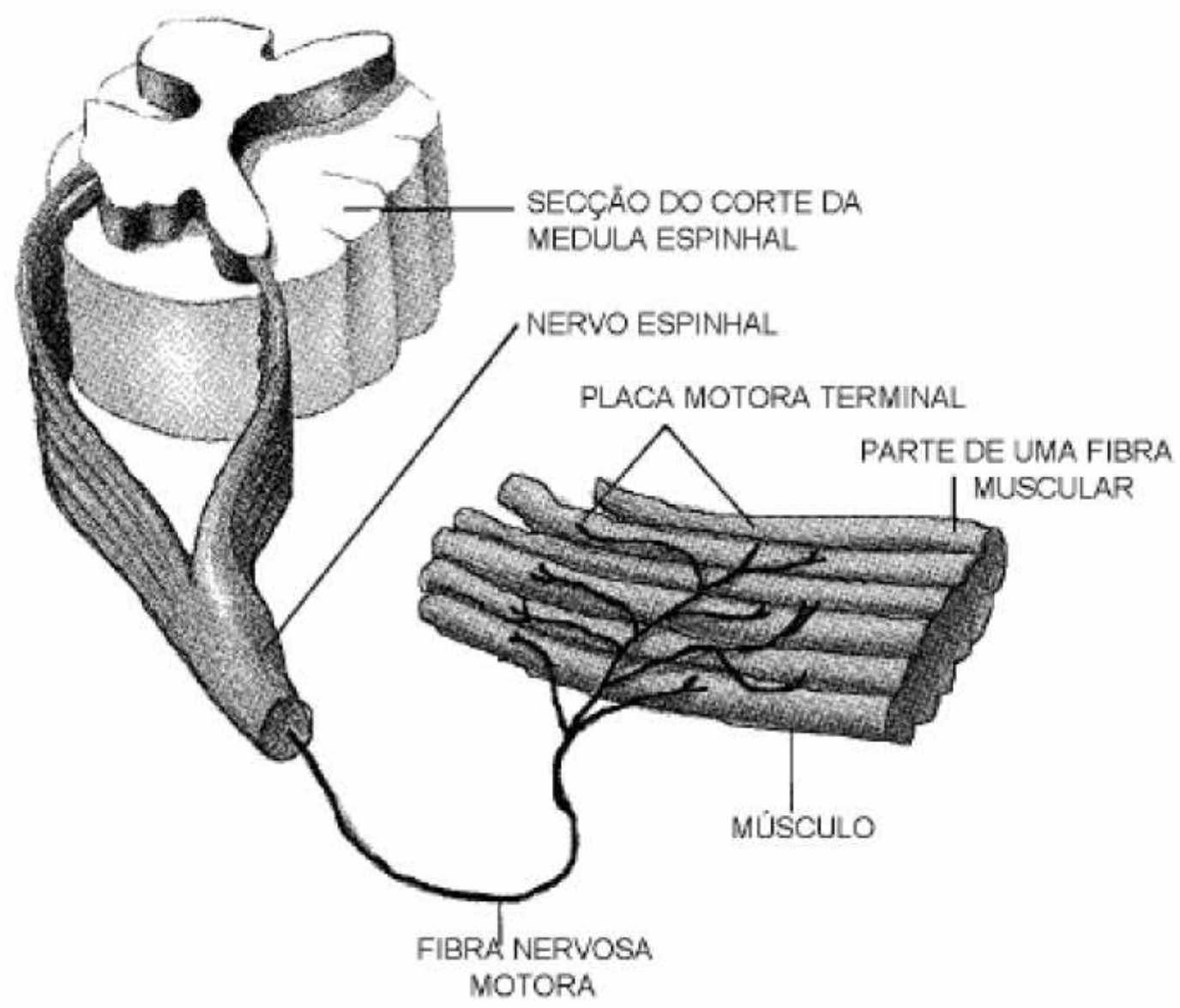

Figura 2.4: Unidade motora e seus componentes [43].

abordagem que não causa qualquer dano ao corpo do paciente.

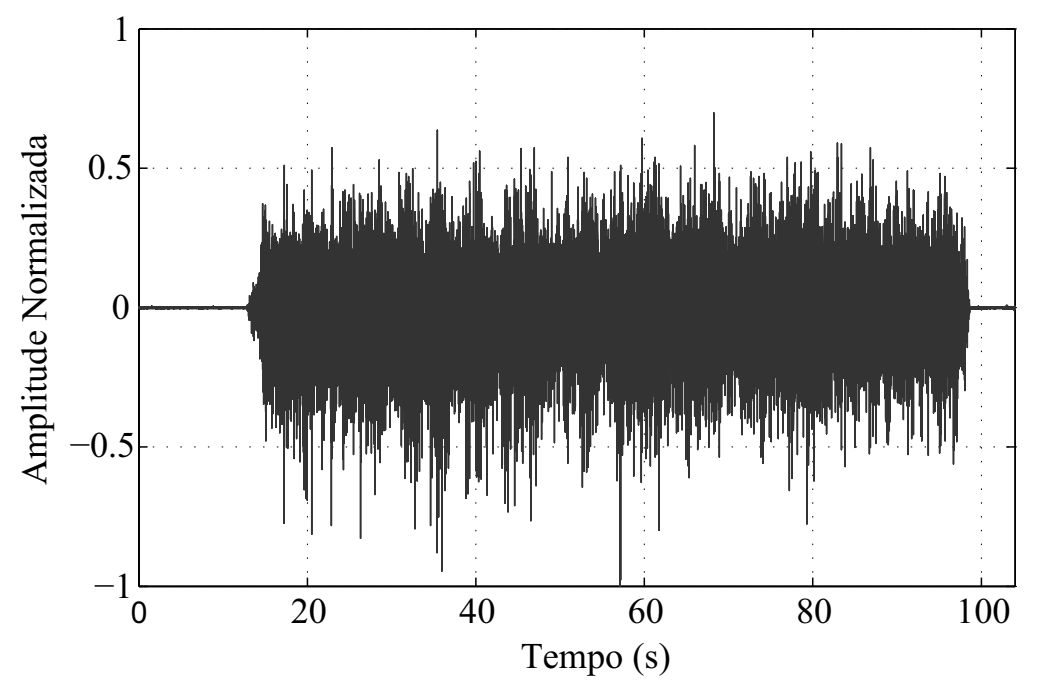

Figura 2.5: Sinal de S-EMG.

O S-EMG não apresenta uma qualidade tão boa quanto o I-EMG, sendo similar a um sinal de ruído, como pode ser visto na Figura 2.5. Em resumo, sabe-se 
que o sinal de S-EMG capturado durante contrações de esforço e ângulo constantes, com uma compressão voluntária máxima (MVC, do inglês Maximum Voluntary Compression) maior que 30\%, pode ser modelado como um processo ergódico com distribuição Gaussiana [27]. Tal resultado é importante, pois permite afirmar que amostras adjacentes apresentam correlação, que pode ser explorada por um compressor unidimensional.

\subsection{Trabalhos Relacionados}

Na literatura técnica de compressão de sinais eletromiográficos podem ser encontrados trabalhos envolvendo métodos diretos, paramétricos e baseados em transformadas. Norris et. al. [46] emprega a modulação por código de pulso diferencial adaptativa (ADPCM, do inglês Adaptive Differential Pulse Code Modulation) para codificar os sinais de EMG, onde a amostra atual é estimada por uma combinação das amostras passadas, diminuindo a quantidade de energia do sinal. O sinal de erro gerado é transmitido após ser quantizado de forma adaptativa. Esta técnica pode ser considerada um exemplo de método direto.

O método apresentado por Carotti et. al. [47] é baseado em predição linear excitada por código algébrico (ACELP, do inglês algebraic code excited linear prediction), onde o codificador obtém os parâmetros de um modelo auto-regressivo (AR, do inglês autoregressive) através da autocorrelação do sinal. Este codificador apresenta a característica de representar com qualidade o espectro do sinal.

Normalmente, os codificadores baseados em transformada possuem um desempenho superior aos dos codificadores baseados em métodos paramétricos e diretos. Norris et al. [48] emprega o algoritmo EZW (do inglês, Embedded Zero-Tree Wavelet) para produzir a melhor representação dos coeficientes da transformada $w a-$ velet. Berger et al. utiliza um algoritmo que otimiza a alocação dinâmica de bits na quantização dos coeficientes da transformada wavelet [16]. Por fim, Chaffim et al. emprega os codificadores JPEG2000 e o H.264/AVC, que utilizam a transformada wavelet e a transformada do cosseno, respectivamente [19].

Algumas técnicas utilizam uma abordagem híbrida. Por exemplo, Jain et al. emprega a transformada wavelet para converter o sinal para outro domínio, e arranja 
os coeficientes gerados em um conjunto de vetores. A quantização vetorial [49] codifica este conjunto de vetores com um dicionário, o qual é atualizado dinamicamente. O sinal codificado consiste de índices do dicionário [50].

Compressão de sinais de S-EMG utilizando recorrência de padrões multiescalas é apresentado por Filho et al. [51]. O algoritmo emprega uma abordagem unidimensional, codificando cada segmento do sinal de entrada através de padrões armazenados em um dicionário. Os segmentos previamente codificados são utilizados para atualizar o dicionário através da contração e expansão desses segmentos tornando o dicionário adaptativo. Este codificador apresenta um bom desempenho na codificação dos sinais de S-EMG. 


\section{Capítulo 3}

\section{O algoritmo MMP-II}

\subsection{Introdução}

A maioria dos codificadores de sinais bidimensionais utilizam codificação por transformada. Quando aplicados na compressão de sinais biológicos unidimensionais, estes métodos utilizam transformadas para explorar as redundâncias intrasegmento e intersegmento. Estes esquemas adicionam dois processos: quantização e codificação. O primeiro quantiza os coeficientes da transformada, permitindo uma representação com menor quantidade de símbolos e o segundo é um codificador por entropia que explora as dependências estatísticas dos símbolos gerados pelo quantizador.

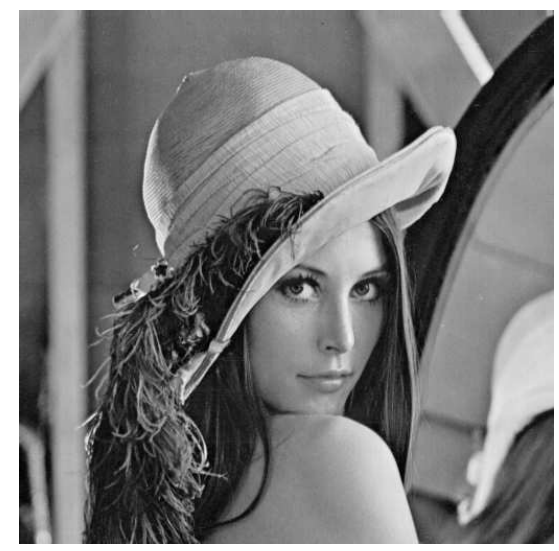

(a)

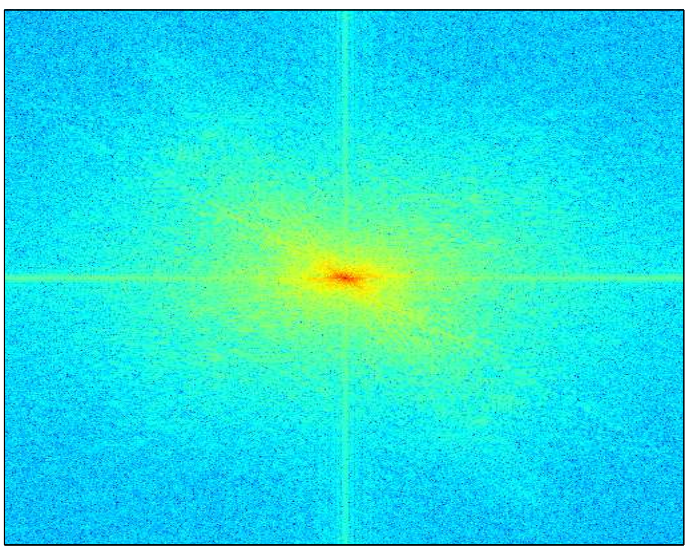

(b)

Figura 3.1: (a) Imagem Lena. (b) Espectro do sinal.

Estes codificadores possuem bom desempenho para imagens suaves, que con- 
centram a maior parte da energia em baixas frequências. Um exemplo de imagem suave é exibido na Figura 3.1, bem como o seu espectro, onde pode-se observar que a energia está concentrada nas baixas frequências. Entretanto, a imagem gerada a partir do sinal de EMG possui energia distribuída entre os componentes de frequência (Figura 3.2), o que tende a diminuir o desempenho do algoritmo. Um paradigma alternativo para codificação destes sinais é o baseado em casamento de padrões [26]. Estes algoritmos operam no domínio espacial, e a sua principal característica consiste em dividir a imagem de entrada em blocos que são aproximados, seguindo algum critério de distorção, por padrões existentes em um dicionário.

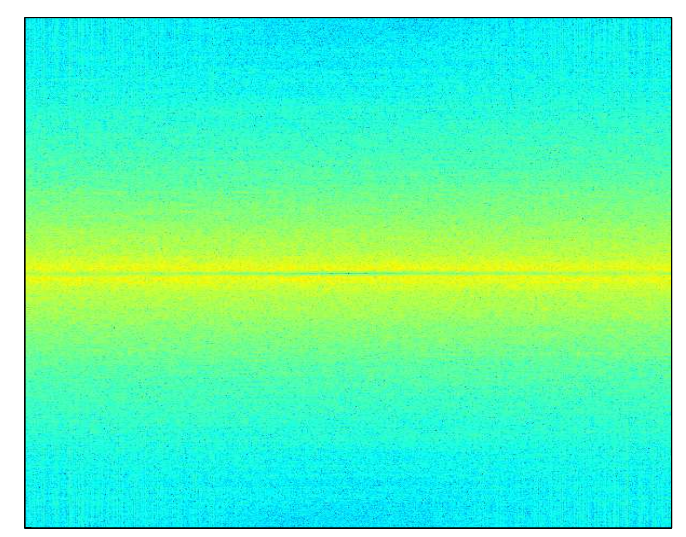

Figura 3.2: Espectro da imagem gerada a partir do sinal de EMG.

Um algoritmo de compressão de sinais com perdas, baseado em casamento de padrões, denominado MMP (do inglês, Multidimensional Multiscale Parser), ou recorrência de padrões multiescalas, é apresentado por de Carvalho et al. [52]. O método segmenta a imagem de entrada e aproxima cada segmento por blocos do dicionário. Porém, o dicionário é formado por concatenações de blocos que codificaram os segmentos da entrada. Dessa forma, pode-se considerar que o algoritmo MMP combina as técnicas dos codificadores Lempel-Ziv e quantização vetorial (VQ) [49].

O MMP possui um dicionário adaptativo e esta particularidade o diferencia dos outros métodos baseados em casamento de padrões. O algoritmo, adicionalmente, incrementa o número de blocos do dicionário com concatenações e dilatações de blocos previamente codificados através da transformação de escalas, permitindo que blocos com diferentes dimensões possam ser utilizados para efetuar o casamento de blocos. O processo de atualização do dicionário torna o MMP um codificador universal, ou seja, não é necessário nenhum conhecimento prévio do sinal de entrada 
para realizar a codificação.

Técnicas de predição e algoritmos de atualização do dicionário são adicionados ao MMP em [26], melhorando o desempenho do algoritmo, de modo a alcançar o nível dos codificadores de estado da arte como HEVC, JPEG2000 e H.264/AVC, na compressão de imagens suaves [26]. O algoritmo é renomeado para MMP-II e aplicado na codificação de documentos compostos [26], imagens estereoscópicas [53], video [54] e sinal de voz [55] apresentando bons resultados, comprovando a característica universal do codificador.

Neste capítulo, são apresentadas as características mais relevantes do MMPII, iniciando com a operação básica do MMP, para então descrever outras técnicas do codificador. Uma descrição detalhada do algoritmo pode ser encontrada em [26].

\section{$3.2 \mathrm{O}$ algoritmo MMP}

O MMP é um algoritmo que aproxima blocos da imagem, de escala $l$, usando elementos de um dicionário adaptativo $\mathcal{D}$. O algoritmo segmenta a imagem em blocos e os processa de forma sequencial, da esquerda para direita, e procura para cada bloco $X^{l}$ da imagem, um elemento $S_{i}^{l}$ do dicionário $\mathcal{D}^{l}$ com índice $i$ que minimiza o Custo Lagrangiano J, definido por:

$$
J\left(X^{l}\right)=D\left(X^{l}, S_{i}^{l}\right)+\lambda R\left(S_{i}^{l}\right)
$$

onde $D\left(X^{l}, S_{i}^{l}\right)$ é a soma das diferenças quadradas (SSD, do inglês Sum of Squared Differences) entre o bloco original e o elemento do dicionário, $\lambda$ é um multiplicador Lagrangiano [56] e $R\left(S_{i}^{l}\right)$ é a taxa para codificar o índice da representação.

Depois de selecionar o elemento de melhor representação, o bloco original é segmentado na direção vertical e, posteriormente, o mesmo bloco é segmentado na direção horizontal [57]. A segmentação vertical produz dois novos sub-blocos, $X_{0}^{l-1}$ e $X_{1}^{l-1}$, cada um com metade do número de pixels do bloco original, e os elementos $S_{i 0}^{l-1}$ e $S_{i 1}^{l-1}$, que minimizam o custo lagrangiano para cada sub-bloco, são encontrados no dicionário de nível $l-1, \mathcal{D}^{l-1}$. Os sub-blocos $X_{2}^{l-2}$ e $X_{3}^{l-2}$ são gerados na segmentação horizontal e o mesmo procedimento é aplicado. Quando um bloco é segmentado, o algoritmo aplica o mesmo processo recursivamente, especificamente, 


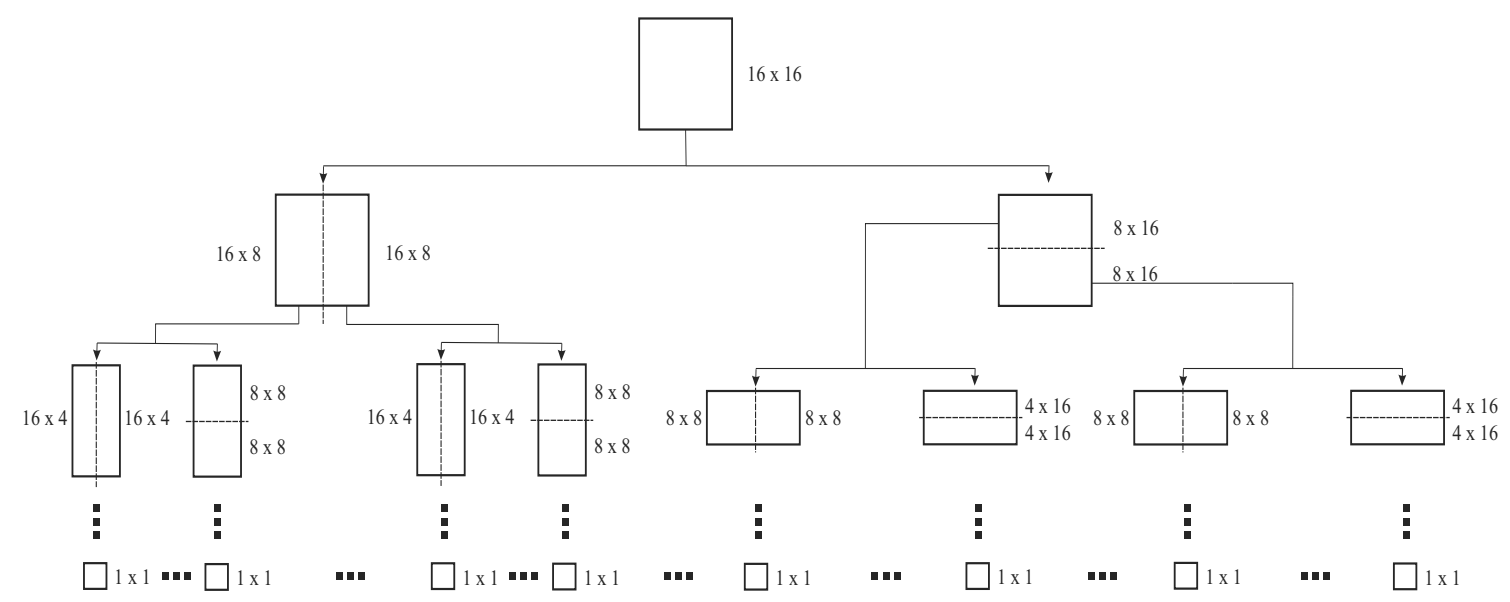

Figura 3.3: (a) Esquema de segmentação do MMP.

o MMP trabalha com bloco inicial com dimensões $16 \times 16$, que corresponde ao nível $l=25$, e realiza a segmentação até o menor nível $(l=1)$, que corresponde a blocos com dimensão $1 \times 1$. O resultado final deste procedimento é ilustrado na Figura 3.3.

Nesse processo, pode-se observar que o dicionário do MMP é composto por sub-dicionários de blocos com escalas distintas. O número de sub-dicionários é igual a 25, que corresponde ao número de escalas do algoritmo, onde as dimensões dos blocos são iguais a $2^{m} \times 2^{n}$, com $m$ e $n$ variando entre $0,1,2,3,4$ (Figura 3.4). O número de elementos dentro de um sub-dicionário é limitado e determinado de forma empírica.

O procedimento seguinte é o processo de otimização, onde o custo lagrangeano de representação de cada bloco é comparado com o custo lagrangeano das partições originadas da segmentação vertical e horizontal de forma a optar-se pela direção da segmentação do bloco, ou pela manutenção do bloco. Por exemplo, se o custo de codificar o bloco de nível $l$ é menor que o de codificar dois blocos de nível $l-1$ e dois do nível $l-2$, o bloco não será segmentado. O custo lagrangeano para um bloco não segmentado é definido por:

$$
J\left(X^{l}\right)=J\left(X^{l}\right)+\lambda R(\text { flag })
$$

onde $R($ flag $)$ é a taxa para codificar o flag que informa a não segmentação do bloco. O custo Lagrangiano da codificação dos sub-blocos é definido por:

$$
J\left(X^{l}\right)=J\left(X_{j}^{l-1}\right)+J\left(X_{j+1}^{l-1}\right)+\lambda R(\text { flag })
$$




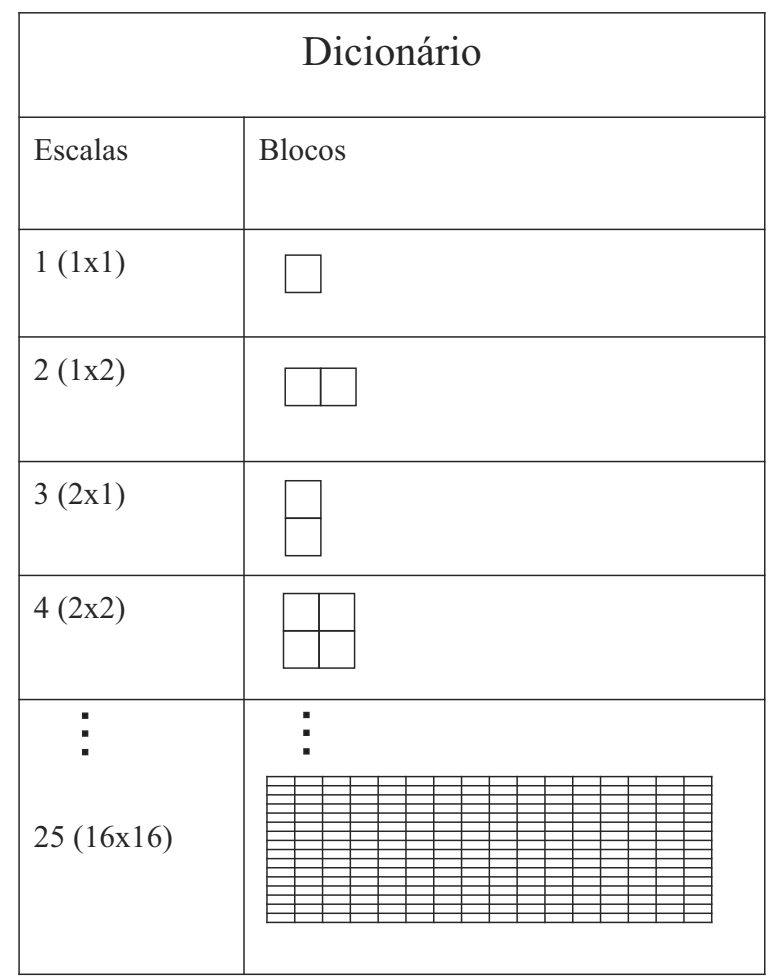

Figura 3.4: Representação do dicionário do MMP.

onde $R(f l a g)$ é a taxa para codificar o flag que informa a direção da segmentação.

O resultado do processo de otimização é a melhor representação do bloco inicial, bloco com escala igual a 25 , e pode ser representado por uma árvore ótima que foi obtida após o processo de podagem da árvore completa, que simboliza todas as opções de segmentação do bloco inicial até a escala de nível 1. A Figura 3.5 é um exemplo de árvore ótima, onde cada folha corresponde a um bloco não segmentado, o qual é aproximado por um único elemento de dicionário. Cada nó corresponde a um bloco segmentado, podendo ser na direção vertical ou horizontal, o qual é representado pela concatenação de dois elementos dos dicionários subsequentes. Por fim, cada nível da árvore possui uma correlação com a escala do bloco em análise.

\subsubsection{O algoritmo MMP com técnicas de predição}

Em [26], é desenvolvido um novo algoritmo para codificação de imagens chamado MMP-Intra, o objetivo dos autores é melhorar o desempenho do algoritmo na compressão de imagens suaves. Este algoritmo emprega técnicas de codificação preditivas para explorar a correlação espacial dentro da imagem, gerando o sinal de resíduo, que é codificado pelo MMP. 


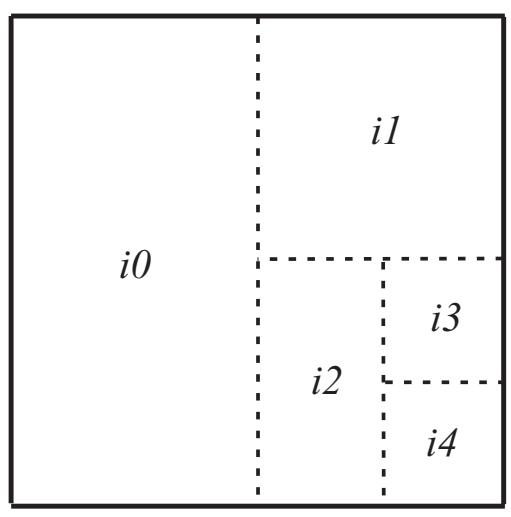

(a)

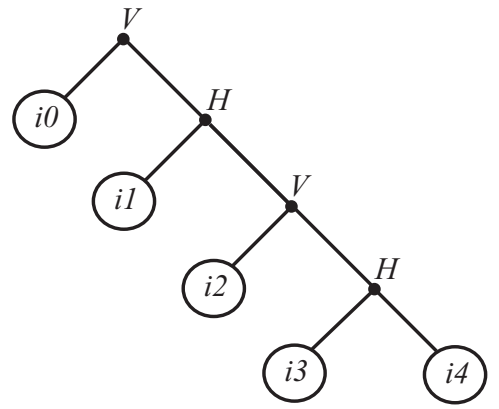

(b)

Figura 3.5: (a) Segmentação de um bloco da imagem e (b) a sua correspondente árvore ótima.

As técnicas de predição reduzem a quantidade de energia do sinal de entrada. O sinal resultante deste processo possui como característica uma função de distribuição de probabilidade com picos ao redor de zero [26]. Este fato é importante, pois o desempenho do codificador melhora para essa classe de sinais, devido à menor variação de amplitude dos blocos de entrada do MMP [26].

Para gerar o bloco de resíduo, o MMP-Intra subtrai o bloco de entrada do bloco de predição, que é obtido a partir das amostras vizinhas previamente codificadas:

$$
R_{P_{M}}^{l}=X^{l}-P_{M}^{l}
$$

onde $P_{M}^{l}$ refere-se ao bloco de predição de escala $l$ e $M$ é o modo de predição selecionado para gerar o resíduo.

Os modos de predição usados no padrão H.264/AVC [22] são adotados no MMP-Intra. Entre eles estão as oito predições direcionais, conforme Figura 3.6, que basicamente fazem uma extrapolação e interpolação (através de uma combinação linear dos valores de pixels vizinhos, estima-se o valor do pixel em determinada posição) das amostras vizinhas previamente codificadas de acordo com a direção do modo.

O MMP-Intra substitui o modo DC utilizado no codificador H.264/AVC pelo modo MFV (do inglês, Most Frequent Value) [26]. Nestes casos, o modo de predição produz blocos homogêneos, porém no modo DC, o valor da predição é a média dos 


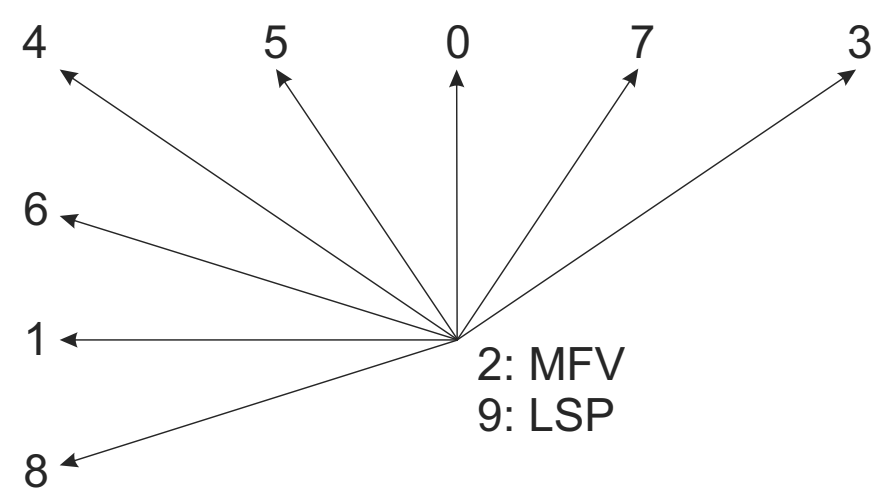

Figura 3.6: Modos de predição do MMP-I.

valores das amostras vizinhas, enquanto que no modo MFV, o valor predito é o valor de intensidade mais frequente na vizinhança do bloco. Além disso, o modo LSP (do inglês, Least Square Prediction) foi adicionado por Graziosi et al. [58]. Neste método, cada pixel de predição é obtido através de uma filtragem adaptativa da vizinhança, onde os coeficientes do filtro são definidos a partir de um processo baseado no critério dos mínimos quadrados, e a vizinhança é definida a partir de um modelo Markoviano [58].

O algoritmo avalia todos os modos de predição durante a análise de cada bloco, com o objetivo de encontrar o modo que obtém o melhor compromisso taxadistorção. Cada modo de predição possui um custo lagrangiano de reconstrução do resíduo, que é dado pelo custo de codificação do resíduo pelo MMP, de acordo com a equação 3.2, e a taxa requirida para transmitir o modo de predição, ou seja:

$$
J_{P_{M}}\left(X^{l}\right)=J\left(R_{P_{M}}^{l}\right)+\lambda R\left(P_{M}\right)
$$

o modo que possuir o menor custo $J_{P_{M}}\left(X^{l}\right)$ será selecionado neste processo.

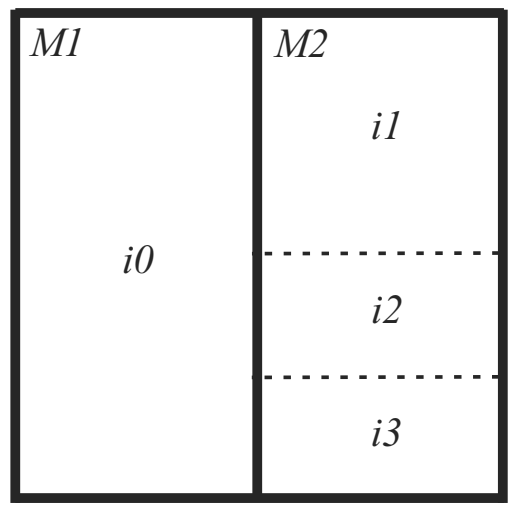

Figura 3.7: Segmentação de um bloco da imagem com técnicas de predição. 
O processo de codificação do MMP-Intra permanece sendo executado de forma hierárquica assim como no MMP. Os blocos de entrada são de dimensões iguais a $16 \times 16$, e o modo de predição, que gera o bloco de resíduo com melhor representação pelo MMP, é escolhido. No próximo passo, o bloco de entrada é segmentado na vertical, e posteriormente na horizontal, e os modos de predição que produzem os quatro blocos de resíduo com melhor representação são encontrados. O processo é recursivo e as técnicas de predição são aplicadas até a escala de nível 9, o que corresponde a blocos com dimensões dadas por $2^{m} \times 2^{n}$, com $m$ e $n$ variando entre $2,3,4$.

Uma árvore de segmentação representa o resultado deste procedimento e o processo de otimização gera uma árvore ótima. No exemplo da Figura 3.7, o bloco original é segmentado na direção vertical e realiza-se a predição em ambos subblocos, gerando os blocos de resíduo, onde os modos de predição foram M1 e M2. O sub-bloco direito é adicionalmente segmentado pelo MMP para alcançar a sua representação ótima.

A combinação do algoritmo de otimização taxa-distorção com as técnicas de predição possibilita o MMP encontrar um bom compromisso entre melhor representação do bloco e alocação de bits. Em outras palavras, o algoritmo considera a melhor combinação de sub-blocos e modos de predição para representar o bloco original, o que leva a um melhor desempenho do codificador.

\subsubsection{Atualização do dicionário}

O algoritmo de atualização do dicionário é um dos procedimentos mais importantes do MMP-Intra, isto porque este processo é responsável pela geração de novos padrões e, consequentemente, pelo aumento do poder de representação do algoritmo. À medida que o MMP-Intra codifica os blocos, novos padrões são inseridos no dicionário, por isso classifica-se o dicionário como adaptativo.

O dicionário não necessita de qualquer conhecimento do sinal de entrada, por isso diz-se que o MMP-Intra possui um comportamento universal. Os elementos iniciais do dicionário são blocos homogêneos, obtidos dentro da faixa compreendida entre $[-255,255]$ de maneira não uniforme e divididos dentre as diferentes escalas do algoritmo. Porém, a exceção é o sub-dicionário de nível zero $\left(\mathcal{D}^{0}\right)$, onde todos 
os blocos possuem um único elemento, que é inicializado com todos os valores da faixa. Com isto, qualquer elemento do bloco pode ser representado, permitindo a compressão sem perdas, a qual é habilitada quando lambda é igual a zero (equações $3.23 .3)$.

Quando um bloco $X^{l}$ de escala $l$ é segmentado, um novo padrão é formado pela concatenação de dois elementos do sub-dicionário de nível inferior. Este padrão é utilizado para atualizar o dicionário em todas as outras escalas. Para isso, o MMP-Intra utiliza uma transformação de escala, $T_{l}^{s}$, que adapta as dimensões do novo padrão, através de contrações, quando a escala do sub-dicionário é inferior, e dilatações, quando o novo padrão possui escala inferior a do sub-dicionário. A Figura 3.8 representa este procedimento.

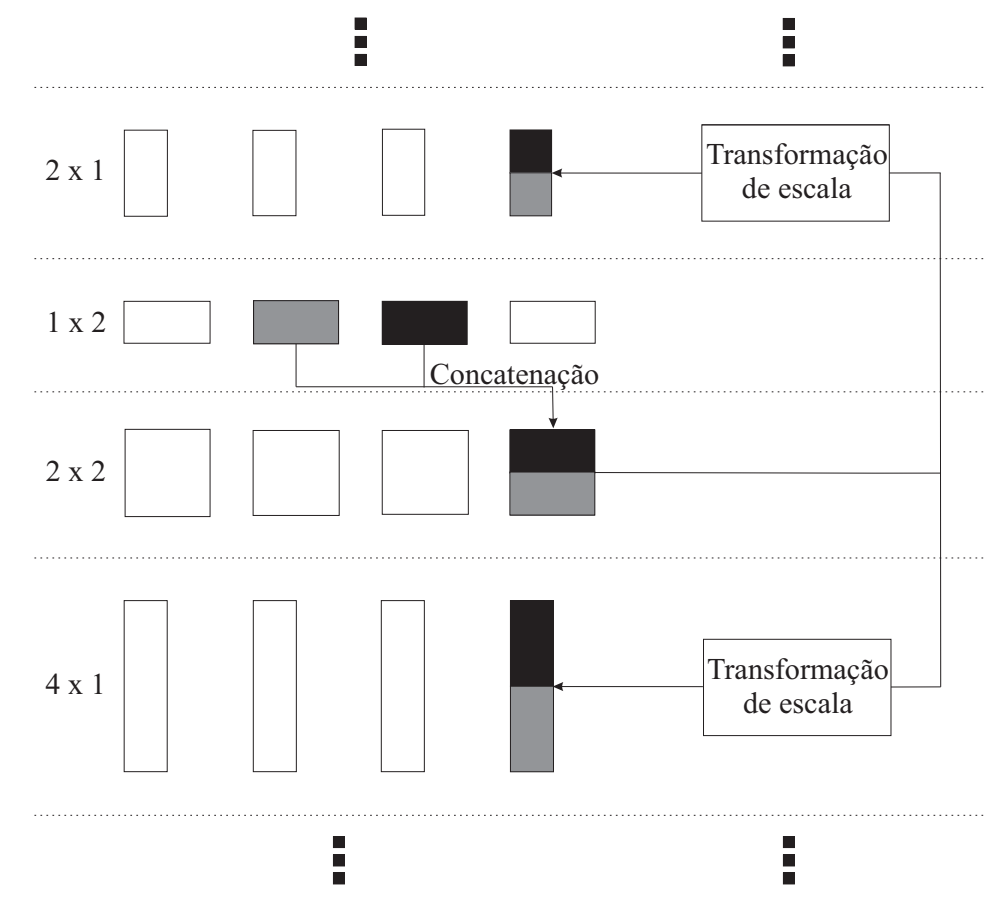

Figura 3.8: Procedimento de atualização do dicionário.

Para realizar o processo de atualização do dicionário no decodificador, o MMP-Intra utiliza os flags de segmentação e os índices do dicionário para manter uma cópia sincronizada do dicionário. Por isso, durante a codificação, o MMPIntra não precisa enviar nenhuma informação extra para que o decodificador possa atualizar o dicionário.

Em [26], N. Rodrigues et. al. propõem técnicas de atualização do dicionário que melhoram o desempenho do codificador. A combinação do MMP-Intra com estas técnicas adicionais originam um novo algoritmo chamado de MMP-II. O algoritmo 
pode ser descrito, em termos dos métodos projetados para o dicionário, como segue.

O MMP-II introduz um critério de distorção mínimo para o processo de atualização do dicionário. Cada vez que um novo elemento é inserido no dicionário, um novo índice é criado e, consequentemente, a entropia média dos índices do dicionário aumenta, o que reduz o desempenho da codificação. O critério de distorção mínimo é um eficiente esquema de controle de redundância que limita o aumento de elementos no dicionário. O esquema permite a inserção de elementos no dicionário de escala $l$, se a distância relativa entre o novo elemento, $X^{l}$, e qualquer bloco existente de $\mathcal{D}^{l}$ for superior a um dado limiar $d^{2}$, definido por:

$$
d^{2}=\sum_{m, n}\left(X^{l}(m, n)-S^{l}(m, n)\right)^{2}
$$

Este processo é análogo a um preenchimento de um espaço de dimensão $l$ por hiperesferas de raio $d$ sem sobreposição de áreas, onde cada elemento do dicionário ocupa a área de uma hiperesfera, garantindo, assim, o critério de distorção mínima entre os elementos do dicionário, com isso evita-se a criação de blocos que contribuem pouco para a codificação. O processo para o caso de um espaço bidimensional, onde o bloco $A$ não é inserido no dicionário é ilustrado na Figura 3.9.

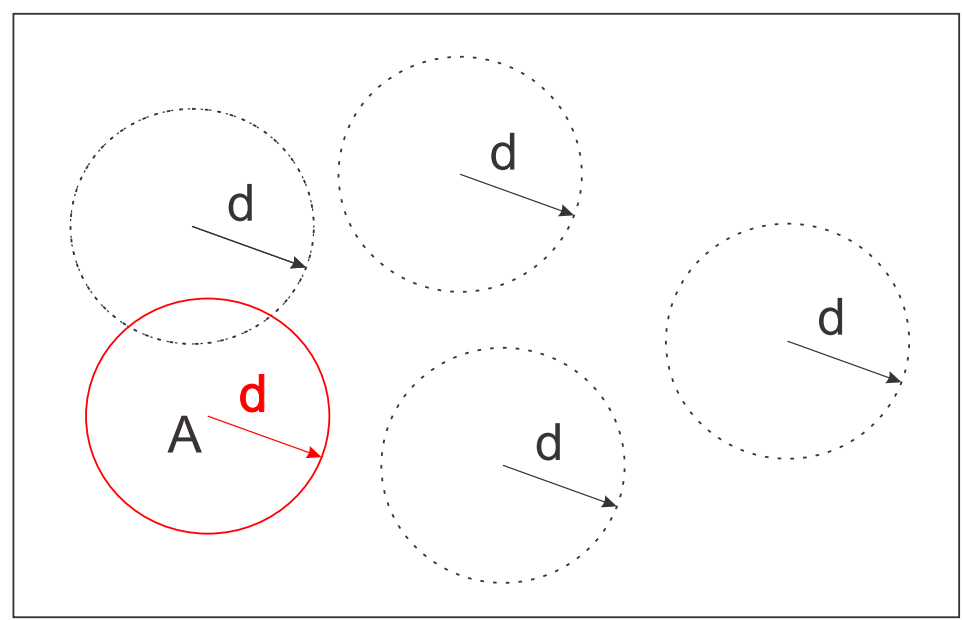

Figura 3.9: Procedimento de atualização do dicionário com uso da condição de distância mínima.

A transformação de escala é um procedimento que distingui o MMP-Intra de outros codificadores baseados em casamento de padrões. O motivo é que o poder de representação do algoritmo aumenta, e isso, é devido à geração de mais padrões 
que são inseridos no dicionário. Baseado nesse fato, o MMP-II propõe técnicas para melhorar o poder de representação do algoritmo. As técnicas geram novos padrões a partir do bloco de resíduo de entrada e, se a condição do esquema de controle de redundância for satisfeita, estes padrões são inseridos no dicionário.

A primeira técnica chama-se transformação geométrica, esta gera quatro novos padrões a partir da rotação de $90^{\circ}$ e $270^{\circ}$, e espelhamento na vertical e horizontal do bloco de entrada. A outra técnica é nomeada de additive symmetric, e a atualização do dicionário é realizada através da multiplicação dos elementos do bloco de entrada por -1 , isso porque os valores dos elementos do bloco de resíduo podem ter valores simétricos a um elemento do dicionário.

Outra importante melhoria do MMP-II foi arranjar os elementos do dicionário dentro de partições. Neste método, os índices são inseridos em partições que possuem diferentes contextos de probabilidade. Consequentemente, é necessário transmitir duas informações, uma a respeito da partição do dicionário e a outra que especifica o índice dentro da partição. Este processo melhora o desempenho do codificador por explorar as distribuições estatísticas destas informações.

O MMP-II possui o procedimento de equalização de norma ${ }^{1}$. Quando um novo bloco é gerado e a transformação de escala o atualiza para os outros subdicionários, a norma, para escalas superiores a do novo bloco, é incrementada e a distribuição de probabilidade do sinal residual perde a característica de apresentar médias próximas de zero. Por isso, o procedimento tem a finalidade de manter a norma do novo bloco nas versões dilatadas obtidas após a transformação de escala do mesmo. A transformação de escala é dada por:

$$
R^{l}=T_{l_{0}}^{l}\left(R^{l_{0}}\right)
$$

adicionando o procedimento de equalização, a transformação de escala, para blocos $R^{l}$ com escala $l$ superiores ao bloco de entrada $R^{l_{0}}$ com escala $l_{0}$, passa a ser definida por:

$$
R^{l}=s_{\alpha}^{l_{0}, l} T_{l_{0}}^{l}\left(R^{l_{0}}\right)
$$

\footnotetext{
${ }^{1} \mathrm{~A}$ norma $L^{\alpha}$ de um vetor $\mathbf{x}=\left(x_{0}, x_{1}, \ldots, x_{n-1}\right)$ é definida por $|x|_{\alpha}=\left(\sum_{i}\left|x_{i}\right|\right)^{1 / \alpha}$
} 
onde o fator de equalização $s_{\alpha}^{l_{0}, l}$ é dado por:

$$
s_{\alpha}^{l_{0}, l}=\frac{\left|R^{l_{0}}\right|_{\alpha}}{\left|R^{l}\right|_{\alpha}}
$$

Os resultados do procedimento de equalização de norma são blocos com uma melhor distribuição estatística contribuindo para um aumento da eficiência da codificação [26].

\subsubsection{Formação do stream de saída do MMP}

Uma vez que o codificador obtém, para cada bloco da imagem, a árvore de segmentação ótima, um conjunto de símbolos é gerado a partir desta árvore, o qual será transmitido e utilizado no processo de decodificação.

Para codificar a árvore de segmentação ótima, o algoritmo identifica a folha da árvore e os nós com flags. Entretanto, como o codificador utiliza o procedimento de predição hierárquico, a árvore ótima possui nós oriundos de diferentes processos. Um nó é produzido a partir da predição hierárquica e o outro é fornecido pelo processo de segmentação do resíduo. Portanto, cinco diferentes flags deverão ser utilizados para identificar os nós:

- Flag "0" representa uma folha da árvore. Este flag é seguido pelo índice do elemento do dicionário. Entretanto, se nenhum modo de predição tem sido enviado para este bloco, este flag é, adicionalmente, seguido pelo modo de predição.

- Flag "1" representa um nó da árvore para qual uma segmentação vertical do bloco de resíduo é realizada.

- Flag "2" representa um nó da árvore para qual uma segmentação horizontal do bloco de resíduo é realizada.

- Flag "3" representa um nó da árvore para qual uma segmentação vertical é feita no processo de predição hierárquico.

- Flag “4” representa um nó da árvore para qual uma segmentação horizontal é feita no processo de predição hierárquico. 
A árvore de segmentação ótima é convertida dentro de um conjunto de símbolos através de uma abordagem de cima para baixo, ou seja, da raiz até as folhas. Toda vez que ocorrer um nó na árvore, duas sub-árvores serão geradas, logo, quando uma segmentação vertical ocorrer, a sub-árvore do ramo à esquerda é primeiramente codificada, seguida da sub-árvore do ramo à direita. A codificação de um nó que simboliza uma segmentação horizontal é realizada primeiramente na sub-árvore que corresponde ao ramo acima, seguida da sub-árvore que corresponde ao ramo abaixo.

No exemplo da Figura 3.7, o MMP-II gerou o seguinte conjunto de símbolos:

$$
\begin{array}{lllllllllllll}
3 & 0 & M 1 & i 0 & 2 & M 2 & 0 & i 1 & 2 & 0 & i 2 & 0 & i 3
\end{array}
$$

onde $M 1$ e $M 2$ são os modo de predição.

O codificador aritmético adaptativo é usado para codificar os símbolos gerados [26]. Os símbolos são codificados de acordo com os seus modelos de probabilidades. Por exemplo, os flags de identificação dos nós possuem probabilidades distintas de acordo com o nível da árvore (dimensões do bloco), pois em alguns casos não é possível fazer segmentações verticais ou horizontais. Quando os blocos são de dimensões $1 \times 1$ nenhuma segmentação é realizada e nenhum flag é enviado, já que durante a decodificação, o algoritmo conhece o nível da árvore.

Para codificar os índices do dicionário, o algoritmo considera a escala do bloco e a do elemento que deu origem a este padrão. Isto porque o dicionário é particionado de acordo com a escala do bloco que deu origem ao padrão do dicionário. Logo, o contexto para o índice do dicionário é condicionado ao conhecimento do bloco que deu origem ao mesmo e ao nível do bloco.

\subsection{Considerações Finais}

Neste capítulo, apresentou-se o algoritmo de recorrência de padrões multiescalas. Primeiramente, o algoritmo MMP foi descrito, em seguida o algoritmo MMPIntra, constituído pela combinação do algoritmo MMP com técnicas de predição, que geram sinais residuais com função de distribuição que favorecem o desempenho do codificador. Finalmente, descreveu-se o algoritmo MMP-II, que é formado pelo MMP-Intra adicionado de técnicas de atualização do dicionário, que aumentam o poder de representação e a eficiência da utilização do dicionário. 
No próximo capítulo, apresenta-se uma das contribuições da dissertação. O objetivo é adaptar e otimizar o algoritmo MMP-II para compressão de sinais eletromiográficos. Estes procedimentos dão origem ao codificador MMP-Bio. 


\section{Capítulo 4}

\section{Otimização do MMP para}

\section{codificação de sinais de S-EMG}

\subsection{Introdução}

Em um dos trabalhos relacionados a codificação de sinais biológicos, em particular os sinais de EMG, encontra-se o trabalho produzido por Filho et al. em [51]. Os autores utilizam uma versão unidimensional do algoritmo MMP e obtém bons resultados. As justificativas de tais resultados são a característica universal do codificador e o bom desempenho na compressão de sinais que podem ser modelados como uma fonte de distribuição Gaussiana [59], e este é o caso dos sinais de S-EMG [27].

A versão unidimensional do algoritmo MMP não apresenta resultados competitivos na compressão de imagens naturais [26] e nem utiliza técnicas de predição e métodos de atualização do dicionário descritos na Seção 3.2.2. Os resultados apresentados por Rodrigues et al. [26], indicam que o MMP-II possui um bom desempenho na codificação de sinais com distribuições Gaussianas. Esses fatos sugerem que o MMP-II pode obter um desempenho mais eficiente do que a sua versão unidimensional [51] na compressão de sinais de S-EMG.

Com o objetivo de utilizar o MMP-II na compressão de sinais de S-EMG e melhorar o desempenho do codificador, uma adaptação do MMP-II para codificar estes sinais é proposta e uma investigação de um diferente esquema de predição, com o intuito de melhorar a exploração das correlações intrasegmento e intersegmento, é realizada, este esquema é o mesmo utilizado pelo codificador HEVC (do inglês, High 


\subsection{Adaptação do MMP}

O algoritmo MMP-II codifica imagens no formato PGM (do inglês, Portable Gray Map) com 8 bits de profundidade. Considerando que o processo de predição pode produzir amplitudes de níveis de cinza negativas, o codificador constrói padrões no dicionário com valores dentro da faixa $[-255,255]$. Entretanto, as imagens geradas a partir da formatação do sinal eletromiográfico, normalmente, tem profundidade de bits maior que 8, o que não permite a codificação sem erros, produzindo uma redução do desempenho do codificador. Para superar esta limitação, o algoritmo foi adaptado para codificar valores maiores de amplitude na imagem e uma consequência imediata reside no fato de que os valores dos elementos do dicionário ficam em função do maior nível de cinza, ou seja, dentro da faixa $[-a, a]$, onde $a$ refere-se à maior amplitude dentro da imagem. Com isso, o algoritmo torna-se um codificador adaptativo a profundidade de bits do sinal eletromiográfico.

O codificador possui uma etapa de reconstrução do bloco de entrada necessária para o processo de predição. O algoritmo soma o bloco de predição e o elemento do dicionário que representa o bloco de resíduo para obter o bloco de entrada. Durante esta operação, o algoritmo limita a amplitude máxima de cada pixel para 255, com a finalidade de evitar erros. Com a adaptação do algoritmo para codificar de acordo com a profundidade de bits do sinal eletromiográfico, a amplitude máxima de cada pixel é limitada pelo maior valor de nível de cinza da imagem.

O procedimento de inicialização do dicionário é modificado. Os elementos dos blocos iniciais dos sub-dicionários são determinados de maneira não uniforme como no MMP-II, porém com uma diferença. Especificamente, o primeiro bloco do dicionário é uniforme com elementos $f\left(S_{0 i}^{l}\right)$ iguais a $-a$. O próximo bloco do dicionário é determinado pelo valor do bloco anterior mais o passo $(p)$, onde o valor do passo muda de acordo com a alteração dos elementos do bloco. Assim, os blocos iniciais do dicionário são expressos por: 


$$
\left\{\begin{array}{l}
p=1, \quad \text { se } \quad\left|f\left(S_{0 i}^{l}\right)\right| \leq 10 \\
p=4, \quad \text { se } \quad 10<\left|f\left(S_{0 i}^{l}\right)\right| \leq 22 \\
p=8, \quad \text { se } \quad 22<\left|f\left(S_{0 i}^{l}\right)\right| \leq 86 \\
p=13, \quad \text { se }\left|f\left(S_{0 i}^{l}\right)\right|>86
\end{array}\right.
$$

O esquema de controle de redundância, descrito na Seção 3.2, introduz um valor de distorção mínimo, definido pela variável $d$, entre dois blocos de um dado subdicionário. A distorção mínima $d$ deve ser determinada de maneira cuidadosa, pois esta influência no desempenho da codificação. Por exemplo, quando o valor é muito alto, os padrões não podem ser representados de maneira mais acurada, pois um menor número de blocos é inserido no dicionário e existe uma grande variação entre eles, perceba que este fato pode ser utilizado quando se objetiva uma codificação com taxas baixas de bits. Adicionalmente, para taxas altas, $d$ deve ser baixo, pois desta maneira, um maior número de blocos é inserido no dicionário, com pequenas variações entre eles, permitindo uma representação mais acurada. Finalmente, como a taxa de bits é determinada através de $\lambda$, define-se a função que relaciona $d$ e $\lambda$ por:

$$
d(\lambda)=\left\{\begin{array}{lll}
20, & \text { se } \quad \lambda \leq 4 \\
40, & \text { se } \quad 4<\lambda \leq 22 \\
60, & \text { se } \quad 22<\lambda \leq 50 \\
80, & \text { se } \quad \lambda>50
\end{array}\right.
$$

A equação (4.2) foi determinada de maneira heurística, e a relação taxadistorção é estabelecida em função destes valores.

Um dos parâmetros do algoritmo MMP-II é o número limite de blocos em cada sub-dicionário. Quando o procedimento de atualização do dicionário produz a inserção do último elemento no sub-dicionário, de acordo com o valor limite, os novos padrões gerados são descartados, e isso impacta na eficiência do codificador. Por isso, o número limite deve ser definido de modo a não comprometer a compressão. Como a profundidade de bits da imagem gerada a partir de um sinal eletromiográfico é maior, o valor limite deve ser alterado, pois a faixa de amplitude se dilata o que 
aumenta a possibilidade de blocos. Neste trabalho, define-se o valor limite igual a 200.000 (duzentos mil).

\subsection{Melhoria nas técnicas de predição}

Em pesquisas anteriores [26,60], as técnicas de predição são utilizadas com sucesso no algoritmo MMP-II. Os resultados evidenciam um aumento no desempenho do codificador para imagens suaves e não suaves [26]. O sucesso dessa estratégia é originado pela conversão do sinal de entrada em amostras residuais com distribuição de probabilidade Gaussiana. Isso faz com que o processo de adaptação do dicionário seja favorecido, ou seja, diminui-se o número de elementos no dicionário e aumentase a probabilidade de uso dos mesmos, resultando em uma codificação mais eficiente em termos de taxa-distorção.

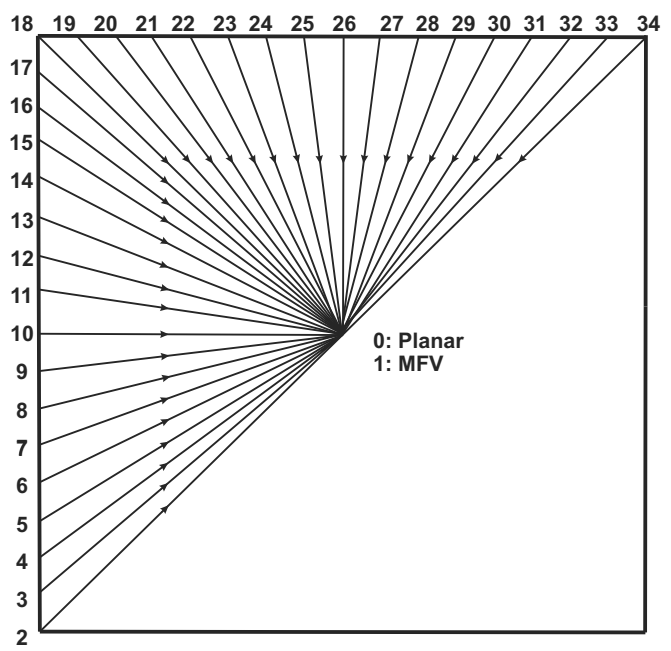

Figura 4.1: Técnicas de predição proposta para MMP-II.

A imagem gerada a partir do sinal de EMG, possui correlação intrasegmento e intersegmento. Estas correlações podem ser exploradas pelas técnicas de predição, de modo que o sinal residual gerado possua menor energia e uma melhor distribuição de probabilidade. Os algoritmos de predição, basicamente, estimam os blocos de entrada através da direção da predição. Métodos com maior número de modos de predição direcionais podem explorar de forma eficiente as correlações do sinal bidimensional, produzindo uma melhor estimação do bloco. Por este motivo, propõese, neste trabalho, a adoção dos modos angulares de predição usados no codificador HEVC [23]. O novo esquema substitui os 8 modos de predições direcionais usado no 
MMP-II pelos 33 modos direcionais mostrados na Figura 4.1. Além disso, o MMP-II utiliza amostras vizinhas, já previamente codificadas, localizadas acima, à esquerda e acima/direita do bloco atual, enquanto que o esquema proposto utiliza blocos à esquerda/abaixo, adicionalmente (Figura 4.2), de acordo com as dimensões do bloco a ser codificado.

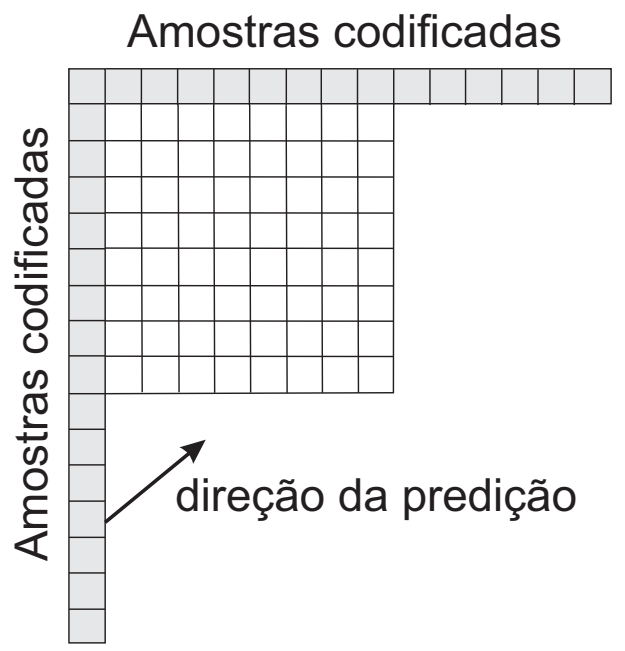

Figura 4.2: Exemplo de predição utilizando amostras localizadas à esquerda/abaixo.

Uma importante informação é que o HEVC é baseado no método de transformadas, com a utilização de um esquema flexível de particionamento dos blocos e técnicas de predição [23]. O H.264 é um codificador similar, porém com um esquema menos flexível de particionamento espacial e um número menor de predições direcionais [22]. Quando compara-se o desempenho dos codificadores H.264 e HEVC para compressão de imagens, verifica-se que os resultados obtidos pelo codificador HEVC são superiores [25]. Para o caso de compressão de imagens, pode-se concluir que um esquema flexível de segmentação espacial e um número maior de técnicas de predição são duas características desejáveis, pois a primeira contribui para encontrar regiões mais homogêneas na imagem, e a última explora de maneira mais eficiente as redundâncias do sinal. O algoritmo MMP-II possui um esquema de segmentação mais flexível quando comparado ao do codificador HEVC, porém um número de predições menor, fazendo com que o MMP-II explore pouco as redundâncias da imagem.

O MMP-II utiliza blocos de diferentes escalas. Dessa forma, durante as predições angulares, em algumas escalas, será necessário fazer uma extrapolação do bloco em análise. Para otimizar esse processo, duas referências são criadas para o 
procedimento de predição, onde estas referências são usadas para todas as escalas. A primeira referência contém todas as amostras vizinhas previamente codificadas à esquerda sendo necessárias para fazer a predição do bloco com a maior escala, enquanto que a segunda referência contém todas as amostras vizinhas dos blocos acima.

Em adição as predições angulares, o esquema proposto usa os modos planar e MFV como modos não angulares de predição, normalmente usados em regiões suaves da imagem. O modo MFV usa o valor mais frequente dentro das duas referências para calcular a predição, e o modo planar gera a predição através do cálculo da média de duas interpolações, uma na horizontal e outra na vertical [61].

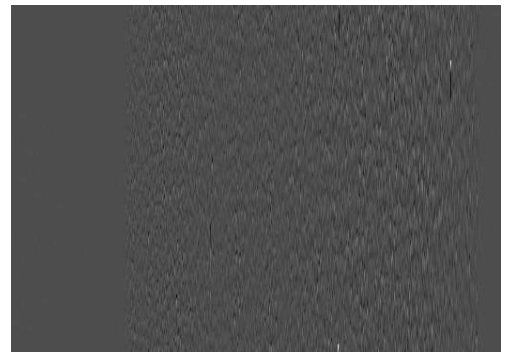

(a)

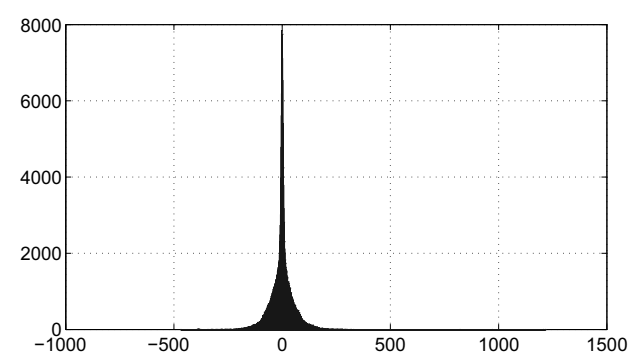

(c)

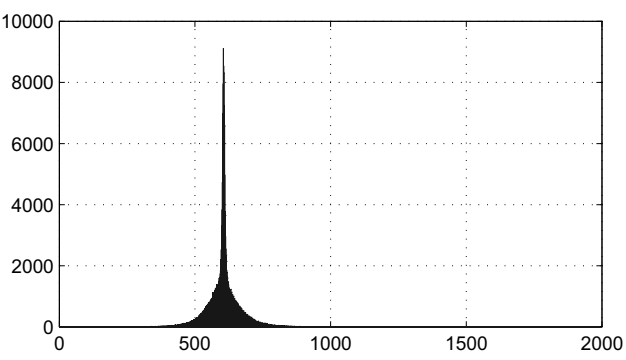

(b)

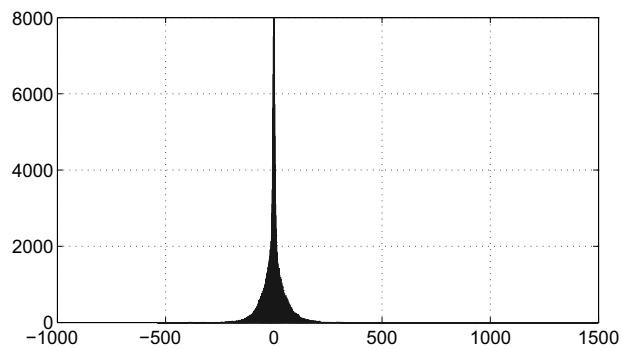

(d)

Figura 4.3: Imagem gerada a partir de um dos sinais de teste (a) e o seu histograma (b). O histograma do erro de predição para: (c) predições do MMP-II e (d) técnica proposta.

A característica da imagem gerada a partir do sinal de EMG é de alta correlação intrasegmento e baixa correlação intersegmento [19]. As técnicas de predição são aplicadas de maneira a explorar estas correlações. O resultado da predição da imagem do sinal de EMG é evidenciado na Figura 4.3, a qual mostra a imagem em análise (Figura 4.3(a)), bem como, os histogramas da imagem (Figura 4.3(b)) e do resíduo gerado pelas técnicas de predição do MMP-II (Figura 4.3(c)) e do esquema proposto (Figura 4.3(d)). Pode-se observar que a função de distribuição estatística 
da imagem pode ser representada por uma função Gaussiana, esta distribuição favorece o desempenho do codificador. Comparando o histograma gerado pelas técnicas de predição com o da imagem, observa-se que a energia do sinal residual está mais compacta, ou seja, um sinal com menor variação de amplitude e centrado próximo do zero, com isto, o processo de adaptação do dicionário é melhorado.

Comparado com a estrutura de predição do algoritmo MMP-II, o esquema proposto utiliza mais modos de predições angulares, com isto, os segmentos podem ser preditos através de outros segmentos, ou mais elementos de segmentos adjacentes são utilizados na predição, consequentemente, a exploração das dependências intersegmentos é beneficiada. Por este motivo, os histogramas gerados utilizando estes dois esquemas mostram uma melhor distribuição de probabilidade do método proposto (neste exemplo, a variância do sinal de resíduo gerado a partir do MMP-II é igual a 330534, 7, enquanto que o valor da variância para o esquema proposto é igual a 312958,7), isto contribui para blocos de resíduo mais homogêneos, melhorando, assim, o desempenho do codificador.

Normalmente, algumas das possíveis direções das predições angulares podem gerar valores similares para pequenos blocos, por isso opta-se por não utilizar alguns modos de predição para blocos com escalas menores, visando uma melhor codificação por entropia. Entretanto, como a imagem de EMG é similar a uma imagem de ruído, pequenas variações na predição podem produzir uma representação com maior distorção. Consequentemente, o esquema proposto adota a utilização de todos os modos possíveis da predição angular para blocos até a escala 4, blocos com dimensões de $2 \times 2$, para blocos com escalas menores, nenhum modo de predição é utilizado. Além disso, o modo planar é utilizado somente nas escalas $4,9,16,25$, porque este modo possui resultados similares aos do modo MFV para outras escalas.

O resultado final da adaptação do algoritmo MMP-II para codificar sinais eletromiográficos e da substituição das técnicas de predição é um novo codificador denominado MMP-Bio.

\subsubsection{Análise de blocos com escalas maiores}

Pode-se investigar codificadores baseados em recorrência de padrões multiescalas com blocos de entrada com dimensões $32 \times 32$ (atualmente, utiliza-se blocos de 
entrada com dimensões $16 \times 16$ ). Esta investigação é plausível, pois as técnicas de predição do codificador HEVC utilizam blocos de entrada com dimensões $64 \times 64$.

O primeiro impacto com a utilização de blocos com dimensões maiores é a inclusão de 11 escalas, por exemplo: $32 \times 16,16 \times 32$, gerando um total de 36 escalas (um bloco de entrada codificado com estas dimensões é mostrado na Figura 4.4). Deve-se notar que o codificador HEVC utiliza blocos com dimensões maiores por causa da mudança da definição de video para alta resolução, com isso as áreas suaves da imagem crescem, consequentemente blocos maiores melhoram a eficiência da codificação. Porém, isto não acontece com a imagem gerada a partir do sinal de S-EMG, uma vez que ela tende a ter o aspecto de um ruído, a representação de blocos maiores é mais difícil de ser realizada, gerando o particionamento do bloco, que por sua vez causa mais transmissão de flags de segmentação e modos de predição, o que diminui a eficiência da codificação.

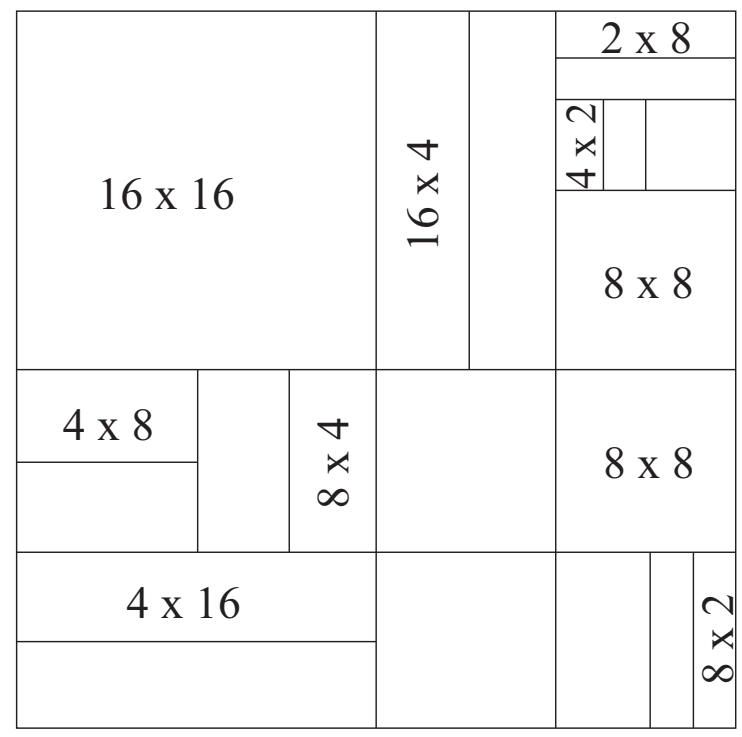

Figura 4.4: Bloco codificado com o MMP-II utilizando 36 escalas.

Outro ponto importante é a análise da complexidade quando se utiliza blocos de entrada com dimensões $32 \times 32$. Com mais escalas, maior o número de subdicionários e consequentemente maior o número de operações, pois a seleção de um bloco do dicionário envolve a análise do elemento que possui a menor distorção com o bloco em codificação. Se o número de amostras do sinal de S-EMG for elevado, a imagem gerada terá grandes dimensões, o que pode resultar numa codificação com alta latência, ou seja, o período de espera para geração do sinal codificado é alto.

Neste contexto, para cada bloco segmentado, o procedimento de predição 
é executado nos blocos gerados, envolvendo operações com 33 modos de predição angulares e com 2 modos não angulares, e os blocos de resíduo são, adicionalmente, codificados pelo MMP. Portanto, para dimensões maiores, a complexidade aumenta e a eficiência diminui, por isto, define-se que a maior escala utilizada no codificador é igual a 25.

\subsection{Considerações Finais}

Neste capítulo, apresentou-se uma das contribuições deste trabalho. O algoritmo MMP-II foi adaptado para codificar sinais eletromiográficos com diferentes resoluções de bits. As técnicas de predição foram substituídas pelos 33 modos direcionais de predição e 2 modos não direcionais. Estas técnicas permitem a exploração das correlações do sinal de maneira mais eficiente. Consequentemente, a função de distribuição de probabilidade do sinal de resíduo torna-se favorável a adaptação do dicionário. O resultado é um novo codificador de sinais eletromiográficos denominado MMP-Bio. Por fim, uma análise da codificação com blocos de entrada com dimensões maiores é feita, onde conclui-se que a complexidade aumenta e a eficiência diminui.

No próximo capítulo, apresenta-se outras contribuições da dissertação. O objetivo é utilizar técnicas de pré-processamento para melhorar o desempenho do compressor de imagens. 


\section{Capítulo 5}

\section{Compressão de Sinais}

\section{Eletromiográficos Baseada em}

\section{Técnicas de Pré-processamento}

Neste capítulo propõem-se duas novas técnicas de pré-processamento para melhorar o desempenho da codificação de sinais eletromiográficos. Além disso, descreve-se a metodologia para codificar sinais eletromiográficos utilizando compressores bidimensionais e apresenta-se o esquema de compressão proposto.

\subsection{Compressão de sinais eletromiográficos com co- dificadores bidimensionais}

Codificadores bidimensionais têm sido uma abordagem alternativa e eficiente para compressão de sinais biológicos [18-20]. Apesar de, usualmente, uma variável unidimensional ser capaz de representar um sinal biológico, é possível formatar estes sinais como matrizes bidimensionais e posteriormente codificá-los com compressores de imagens.

Normalmente, os compressores de imagens utilizados na codificação de sinais biológicos são baseados em transformadas. Por exemplo, o algoritmo de codificação JPEG2000 [21] é aplicado na compressão de sinais de EEG [20]. Neste caso, o algoritmo converte o sinal para outro domínio através da transformada wavelet. Chaffim et. al. [19] utilizam o padrão H.264/AVC no modo intra [22] para codificar sinais de 
EMG, onde a transformada do cosseno é empregada para realizar a conversão para outro domínio.

Para codificar sinais eletromiográficos utilizando compressores de imagem, é necessário particionar o sinal unidimensional em segmentos com número de amostras fixo. Cada segmento, produzido no processo de particionamento, deve ser inserido em uma linha ou coluna de uma matriz bidimensional. Este procedimento é ilustrado na Figura 5.1.

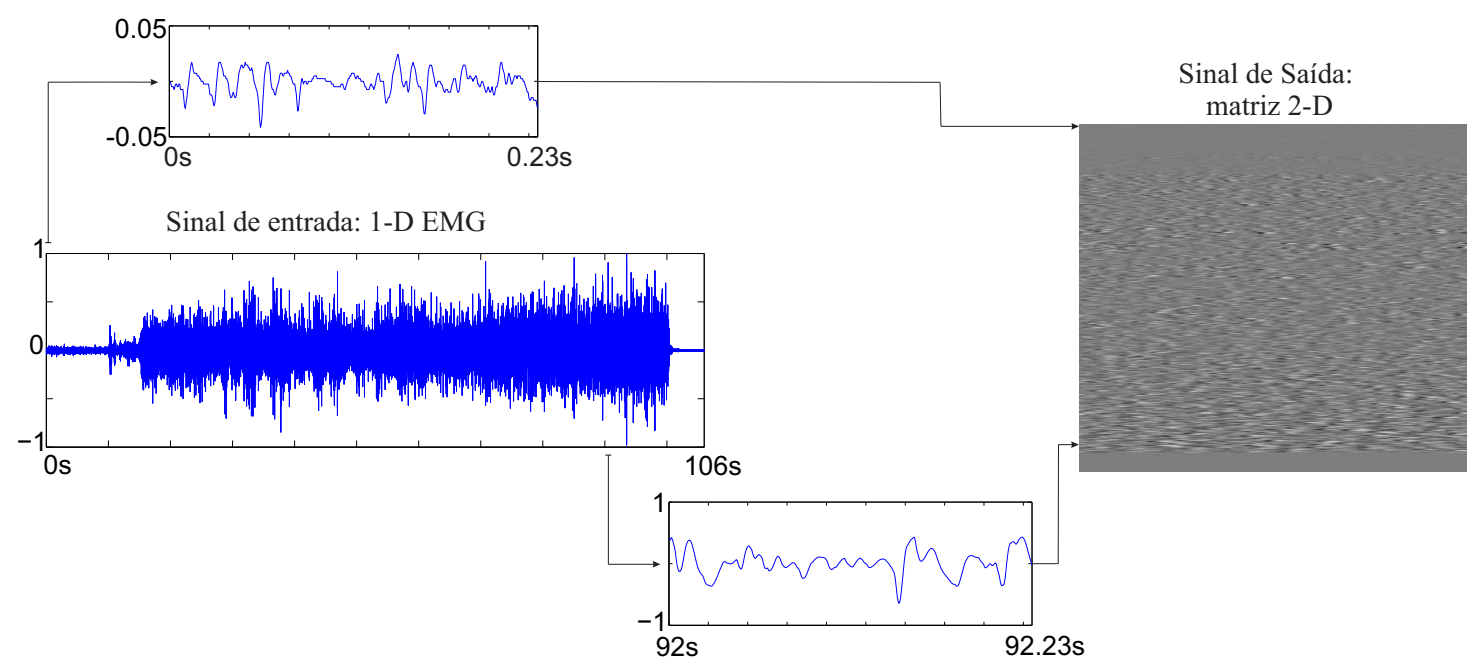

Figura 5.1: Um sinal de EMG formatado em um sinal bidimensional.

Com a geração da matriz, o compressor de imagem pode explorar as dependências intrasegmento e intersegmento. Entretanto, o procedimento de geração da matriz bidimensional resulta em um sinal com baixa correlação intersegmento [18-20], o que pode causar perda de desempenho do compressor de imagens.

Os segmentos de sinais eletromiográficos podem ser tratados como unidades independentes, sendo que estas apresentam alguma correlação, podendo ser maior entre segmentos não adjacentes, com isso, é possível aumentar a eficiência da compressão, acrescentando-se um estágio de processamento, imediatamente anterior à compressão bidimensional [18-20], onde pode-se modificar os segmentos ou simplesmente reordená-los, de forma que as dependências intersegmento sejam melhor exploradas. Este estágio é denominado pré-processamento. 


\subsection{Técnicas de pré-processamento}

Os sinais eletromiográficos podem possuir um comportamento não estacionário, a média e variância do sinal mudam com o tempo, com isso o processo de formatação do sinal em uma matriz bidimensional pode produzir um sinal com baixa correlação entre as amostras de um segmento e entre os segmentos, o que piora a exploração das dependências do sinal pelo codificador. As técnicas de préprocessamento podem segmentar o sinal de forma a aumentar a correlação entre as amostras de um segmento. Além disso, a reordenação dos segmentos do sinal pode produzir áreas mais homogêneas dentro da imagem contribuindo para o aumento da correlação intersegmento. Por isso, as técnicas de pré-processamento possuem o potencial para melhorar a exploração das dependências do sinal. A seguir, são apresentadas duas técnicas de pré-processamento: ordenação por diferença percentual e segmentação por similaridade.

\subsubsection{A ordenação por diferença percentual}

Chaffim et al. [19] propõem uma técnica de pré-processamento que reordena os segmentos de sinal baseada nos coeficientes de correlação. No entanto, tal estratégia permite descobrir se duas variáveis possuem uma relação linear ou não, podendo ser direta ou inversa. Logo, é possível haver dois segmentos com alta correlação, porém com amostras com amplitudes bastante distintas, o que pode comprometer a exploração das dependências intersegmento, deixando a codificação pouco eficiente.

Neste trabalho apresenta-se uma técnica de pré-processamento eficiente para a reordenação dos segmentos de sinais eletromiográficos, denominada ordenação por diferença percentual. Em vez de analisar a correlação linear dos segmentos, a técnica permite verificar a similaridade das amostras dos segmentos pela diferença percentual. O objetivo é ordenar os segmentos com base na semelhança, de modo que as redundâncias intersegmentos sejam aumentadas. Para tal, pode usar-se a seguinte métrica: 


$$
D P(x, m)=\frac{\sum_{n=0}^{N-1}(x[n]-m[n])^{2}}{\sum_{n=0}^{N-1} x^{2}[n]},
$$

onde $D P(x, m)$ representa a ordenação por diferença percentual para os segmentos $\mathbf{x}$ e $\mathbf{m}, x[n]$ é o $n$-ésimo elemento da última coluna posicionada, $m[n]$ é o $n$-ésimo elemento do segmento em análise e $N$ é o número de amostras em cada coluna.

Antes de utilizar a métrica, o segmento com menor variância é inserido na primeira coluna da matriz. A próxima coluna recebe o segmento com menor valor de diferença percentual em relação à primeira coluna. Os segmentos restantes são reordenados de acordo com o menor valor de diferença percentual. A Figura 5.2 mostra o resultado da técnica para um sinal de S-EMG.

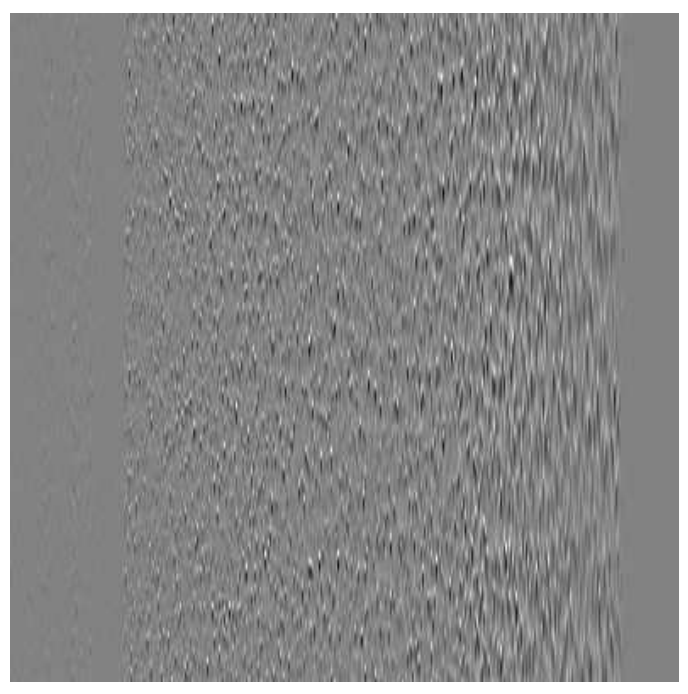

(a)

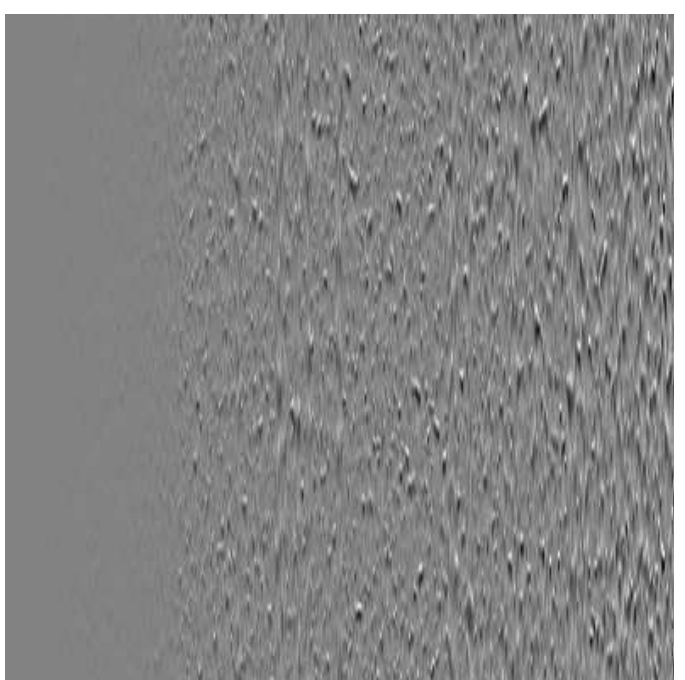

(b)

Figura 5.2: Resultado da ordenação por diferença percentual: (a) sinal bidimensional original e (b) sinal bidimensional reordenado.

Observe que a técnica de diferença percentual necessita transmitir a posição original dos segmentos dentro do sinal eletromiográfico, antes da aplicação da técnica, para que no processo de decodificação o sinal unidimensional possa ser reconstruído. 


\subsubsection{A segmentação por similaridade}

Conforme mencionado anteriormente, para realizar a compressão de sinais eletromiográficos com compressores de imagens, é necessário particionar o sinal, de modo que os segmentos gerados sejam inseridos nas colunas de uma matriz. Entretanto, o número de amostras em cada segmento, geralmente, influência no resultado das dependências intrasegmento e intersegmento, consequentemente a exploração das correlações do sinal pode ser comprometida [19].

Um outro aspecto importante é a necessidade de transmitir informação lateral. Embora a reordenação realizada pelas técnicas de pré-processamento melhore a eficiência da compressão dos sinais eletromiográficos, a exigência de transmissão das posições originais dos segmentos diminui os ganhos obtidos pela exploração das correlações do sinal. Assim, se a quantidade de informação lateral for elevada, os ganhos obtidos pelo aumento das correlações não conseguem compensar as perdas pela transmissão de informação lateral, tornando a etapa de pré-processamento dispendiosa.

Considerando esses fatos, pode-se argumentar que se o procedimento de segmentação for adaptativamente executado, a necessidade de reordenação dos segmentos pode ser reduzida. Por isso, propõe-se que a técnica de pré-processamento busque o melhor número de amostras dentro de um segmento, de modo a melhorar as correlações intrasegmento e intersegmento. Esta técnica é denominada segmentação por similaridade (SS).

A equação (5.1) é usada como métrica para verificar a similaridade entre segmentos adjacentes. A técnica inicia com um valor $N$ de amostras dentro de um segmento. O próximo passo consiste no cálculo dos valores de diferença percentual entre os segmentos adjacentes. Em seguida, a média destes valores é obtida e armazenada. O procedimento ocorre de maneira recursiva, onde o número de amostras dentro de um segmento é dado por $N=16 n$, com $n=\{2,3, \ldots, 64\}$. O segmento com número de amostras $N$ que possuir o menor valor de média de diferença percentual é escolhido para formatar o sinal eletromiográfico em uma matriz bidimensional.

Com o particionamento do sinal eletromiográfico sendo efetuado desta maneira, potencializam-se as correlações intrasegmento e intersegmento, podendo tornar desnecessário a aplicação das técnicas de ordenamento dos segmentos. 


\subsection{Esquema de Compressão de Sinais Eletromio- gráficos Proposto}

O esquema de compressão proposto é formado por três estágios: formatação de sinal, pré-processamento e codificação. Primeiramente, o sinal eletromiográfico de entrada é segmentado, de modo que o número de amostras em cada bloco seja igual ao número de blocos, inseridos nas colunas da matriz bidimensional quadrada. Caso o último segmento fique incompleto, as posições vagas são preenchidas com a repetição do último elemento. O número de amostras do sinal original é enviado como informação lateral. Após essa etapa, a matriz é reordenada, de acordo com a técnica de ordenação por diferença percentual (equação (5.1)), gerando uma lista de índices de coluna, que são então codificados com um compressor aritmético e incorporados ao cabeçalho do arquivo. Quando a técnica de pré-processamento for a segmentação por similaridade, os dois primeiros estágios são realizadas em uma única etapa. Finalmente, a matriz bidimensional resultante é processada por um compressor de imagens, gerando o feixe de bits comprimido.

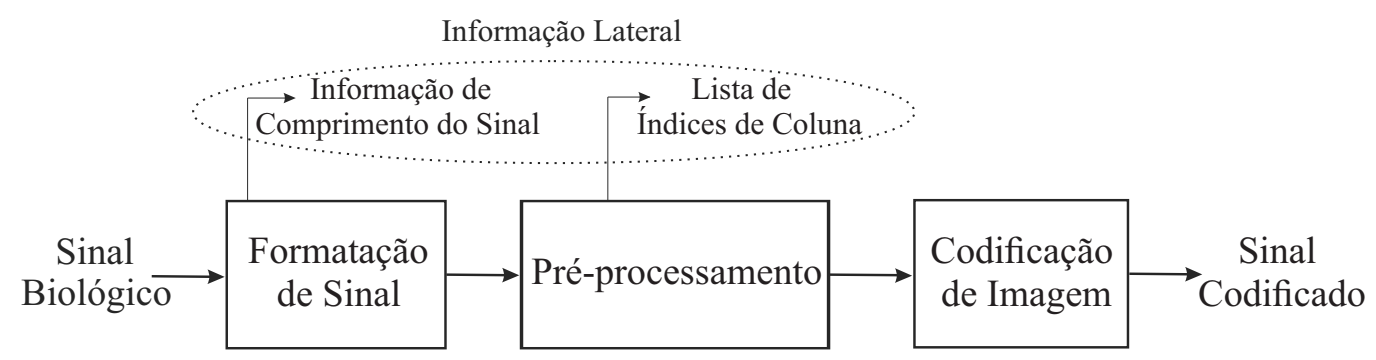

(a)

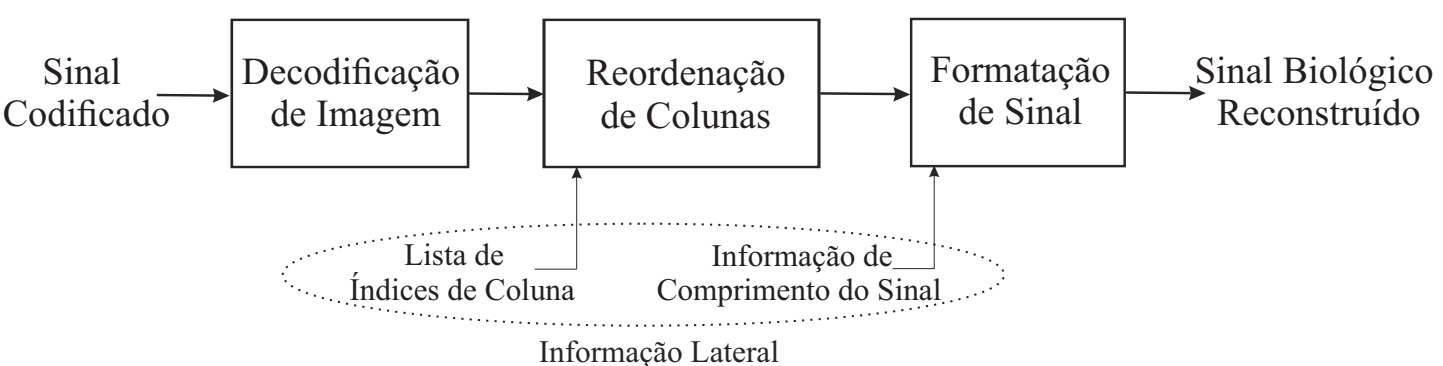

(b)

Figura 5.3: Esquema de compressão proposto: diagrama em blocos do codificador (a) e decodificador (b).

Os codificadores JPEG2000 [21], MMP-Bio, H.264/AVC [22] e HEVC [23] são utilizados no estágio de codificação de imagem, sendo que os dois últimos efetuam 
a compressão no modo intra. A Figura 5.3 ilustra o codificador e o decodificador proposto. Perceba que o esquema pode codificar diferentes sinais biológicos, além de possibilitar o emprego de outras técnicas de pré-processamento e compressores de imagens. Por exemplo, se um codificador alcança bons resultados na compressão de um sinal biológico, pode-se trabalhar apenas na elaboração de uma técnica de pré-processamento mais adequada para este sinal.

É importante mencionar que não se encontra na literatura uma investigação sobre a eficiência do codificador HEVC na compressão de sinais eletromiográficos. Este codificador é projetado para suprir as necessidades de transmissão e armazenamento de imagens de alta resolução [24] e superar, de forma considerável, o codificador H.264/AVC. Quando comparado ao codificador H.264/AVC na codificação de vídeos, verifica-se que, em alguns casos, o codificador HEVC reduz pela metade a taxa de bits necessária para uma mesma qualidade visual [24]. Desta forma, pode-se afirmar que é factível uma investigação do desempenho deste codificador na codificação de sinais eletromiográficos.

O decodificador interpreta o sinal codificado e o estágio de decodificação de imagem gera o sinal bidimensional. A etapa de reordenação das colunas utiliza a lista de índices de coluna para recuperar os segmentos na ordem original dentro da matriz. Se a técnica de pré-processamento utilizada é a segmentação por similaridade, os dois primeiros estágios são realizados em uma única etapa. Por fim, a formatação de sinal converte a matriz bidimensional no sinal eletromiográfico reconstruído.

\subsection{Considerações Finais}

Neste capítulo, duas das contribuições deste trabalho foram apresentadas. Mostrou-se como as técnicas de pré-processamento podem aumentar a correlação intrasegmento e intersegmento, de maneira que a perda de correlação resultante do processo de formatação do sinal eletromiográfico em uma matriz bidimensional possa ser resolvida. O esquema de compressão para sinais eletromiográficos foi definido, possuindo como uma das opções de compressor de imagem o codificador HEVC.

No próximo capítulo, apresentam-se os procedimentos experimentais utilizando sinais de S-EMG. Em seguida, é realizada uma análise do desempenho dos 
codificadores com as técnicas de pré-processamento, bem como uma avaliação do desempenho dos codificadores HEVC e MMP-Bio. Por fim, realiza-se uma comparação entre as técnicas de compressão propostas e os métodos presentes na literatura. 


\section{Capítulo 6}

\section{Resultados e Discussões}

Neste capítulo, apresentam-se os procedimentos experimentais utilizados para avaliar o método proposto. O esquema é utilizado com a técnica de ordenação por diferença percentual e a segmentação por similaridade, e com os codificadores JPEG2000, H.264/AVC e HEVC, de modo a saber a sua eficiência na codificação de sinais eletromiográficos. O desempenho destes codificadores, combinados com as técnicas de pré-processamento, e do codificador proposto MMP-Bio são discutidos e comparados com técnicas presentes na literatura.

\subsection{Procedimento}

Os algoritmos do método proposto são avaliados através de sinais de S-EMG. Os sinais são aplicados no codificador da Figura 5.3(a), onde são formatados e préprocessados pela técnica de ordenação por diferença percentual, ou pela técnica de segmentação por similaridade, em seguida o sinal é codificado por um compressor de imagem. Nesta etapa, utilizam-se os compressores de imagem com diferentes taxas de bits. O sinal codificado é aplicado no decodificador da Figura 5.3(b), este gera o sinal reconstruído que é comparado com o sinal original para se avaliar a distorção resultante do processo de codificação. Os resultados são, adicionalmente, gerados sem a etapa de pré-processamento, com a finalidade de verificação da eficiência das técnicas de pré-processamento propostas e de análise do desempenho do codificador HEVC.

O codificador proposto MMP-Bio é aplicado na codificação dos sinais de S- 
EMG. Para isto, não se utiliza técnicas de pré-processamento e fixa-se o número de amostras dentro de um segmento para 32. No estágio do compressor de imagem do codificador da Figura 5.3(a), utiliza-se o MMP-Bio, onde gera-se sinais codificados para diferentes taxas de bits. O decodificador da Figura 5.3(b) produz o sinal reconstruído utilizando o algoritmo proposto no estágio de decodificação da imagem.

\subsection{Codificadores Utilizados}

Os codificadores JPEG2000, H.264/AVC (modo intra), HEVC (modo intra) e o algoritmo proposto MMP-Bio são empregados para geração dos resultados. Para comprimir os sinais com o codificador JPEG2000, utiliza-se a versão disponibilizada pela Kakadu software [62]. O codificador é utilizado com passo de quantização fixado em 0,000025, e resolução de bits ajustada para 16. Os resultados da codificação com o H.264/AVC são obtidos com o software de referência JM 18.2 [63], no perfil FRExt High 100, com filtro de deblocagem, otimização taxa-distorção (RDO, do inglês Rate-Distortion Optimization) e a codificação binária aritmética adaptativa ao contexto (CABAC, do inglês Context Adaptive Binary Arithmetic Coding) habilitados. O software de referência HM 9.1 [64] é utilizado no modo de codificação de alta eficiência (HE, do inglês high efficiency), com RDOQ (do inglês, Rate-Distortion Optimized Quantization) e filtro de deblocagem habilitados, para gerar os resultados da codificação com o HEVC.

\subsection{Base de Dados}

A avaliação da metodologia proposta é realizada através de experimentos com sinais de S-EMG coletados no músculo biceps brachii de 13 voluntários, durante contrações isométricas. Os voluntários ficaram sentados, com o antebraço paralelo ao torso e sustentando um MVC de $60 \%$. Os sinais resultantes foram amostrados a uma taxa de $2000 \mathrm{~Hz}$ e quantizados a 12 bits, com uma duração variando de 1,3 a 3,0 minutos [51]. Cada sinal gerado é processado pelo esquema de compressão proposto (Figura 5.3). Os sinais utilizados podem ser vistos no apêndice A. 


\subsection{Métrica de Desempenho}

O sinal reconstruído é avaliado através da métrica de diferença quadrática média percentual (PRD, do inglês Percent Root Mean Square Difference), comumente adota na literatura, que é definida por:

$$
P R D=\sqrt{\frac{\sum_{i=0}^{N-1}(x[i]-\hat{x}[i])^{2}}{\sum_{i=0}^{N-1} x^{2}[i]}} \times 100,
$$

Na equação (6.1), $x[i]$ é o sinal original, $\hat{x}[i]$ é o sinal reconstruído e $N$ é o número de amostras. O fator de compressão (CF, do inglês Compression Factor) é definido como

$$
C F=\frac{B_{o}-B_{c}}{B_{o}} \times 100
$$

Na equação (6.2), $B_{o}$ é o número total de bits do sinal original e $B_{c}$ é o número total de bits do sinal comprimido, incluindo a informação de cabeçalho. Para cada sinal de EMG utilizado, $B_{o}=12 \times n$, correspondendo à resolução de 12 bits dos registros e às $n$ amostras de cada sinal.

\subsection{Análise de Desempenho}

Nesta seção, apresentam-se os resultados para os 13 sinais de S-EMG isométricos empregando o esquema proposto. Os resultados são obtidos utilizando um fator de compressão dentro da faixa de $75 \%$ a $90 \%$, verificando-se o $P R D$ gerado em cada caso. Desta forma, pode-se verificar o desempenho das técnicas propostas em função da qualidade do sinal reconstruído para uma mesma quantidade de bits.

Os resultados obtidos para todos os 13 sinais de S-EMG, bem como a média dos resultados, utilizando os codificadores JPEG2000, H.264/AVC e HEVC, juntamente com os resultados gerados a partir da combinação destes codificadores com as técnicas de pré-processamento propostas são apresentados nas Figuras 6.1, 6.2 e 6.3, respectivamente. Os resultados para o codificador proposto MMP-Bio são 
apresentados na Figura 6.4. As curvas mostram que à medida que se aumenta os valores de $C F$, a qualidade do sinal piora, ou seja, os valores de $P R D$ aumentam. É possível perceber que, para valores de $C F$ menores que $80 \%$, o esquema proposto mantém um resultado de $P R D$ razoável $(<7 \%)$, o que em geral é o suficiente para não comprometer o diagnóstico realizado pelo médico [51].

A seguir, analisa-se a eficiência de cada técnica proposta. Primeiramente, os resultados dos codificadores combinados com as técnicas de pré-processamento são comparados com os resultados gerados sem a utilização das mesmas, com objetivo de verificar o aumento no desempenho dos codificadores. Em seguida, observa-se os desempenhos dos codificadores HEVC e MMP-Bio, comparando-os com os outros codificadores utilizados, de modo a analisar a eficiência destes codificadores. Finalmente, a ordenação por diferença percentual e a segmentação por similaridade são comparadas com as técnicas de pré-processamento presentes na literatura, com a finalidade de descobrir a técnica que mais facilita a exploração das dependências do sinal, além disso, comparam-se os resultados dos codificadores HEVC e MMP-Bio com outros métodos presentes na literatura, de modo a validar estes dois codificadores como alternativa para codificação de sinais eletromiográficos.

\subsubsection{Análise de Desempenho entre as Técnicas de Pré- processamento}

Os valores médios de $P R D$ para as técnicas de pré-processamento propostas, com os diferentes codificadores, são apresentados na Tabela 6.1, juntamente com os resultados obtidos sem o emprego das técnicas (para gerar os resultados sem utilização das técnicas de pré-processamento, o sinal de S-EMG é segmentado de maneira a formar uma matriz bidimensional quadrada e então o sinal resultante é codificado por um compressor de imagem).

Os resultados produzidos pela combinação da técnica de ordenação por diferença percentual com o codificador JPEG2000 evidenciam um aumento no desempenho do codificador, o mesmo ocorre com o codificador H.264/AVC. Para o codificador HEVC, a técnica proporciona uma eficiência maior para fatores de compressão inferiores a 90\%, o motivo é que o aumento das correlações do sinal bidimensional, não consegue compensar a desvantagem do envio de informação lateral para tais fatores 


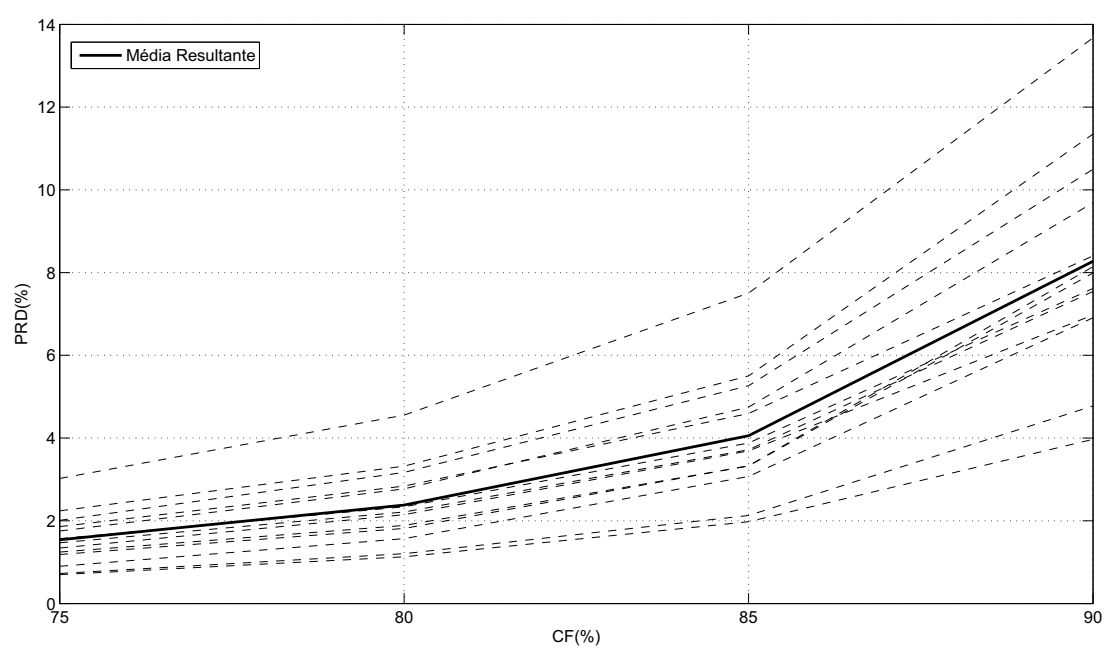

(a)

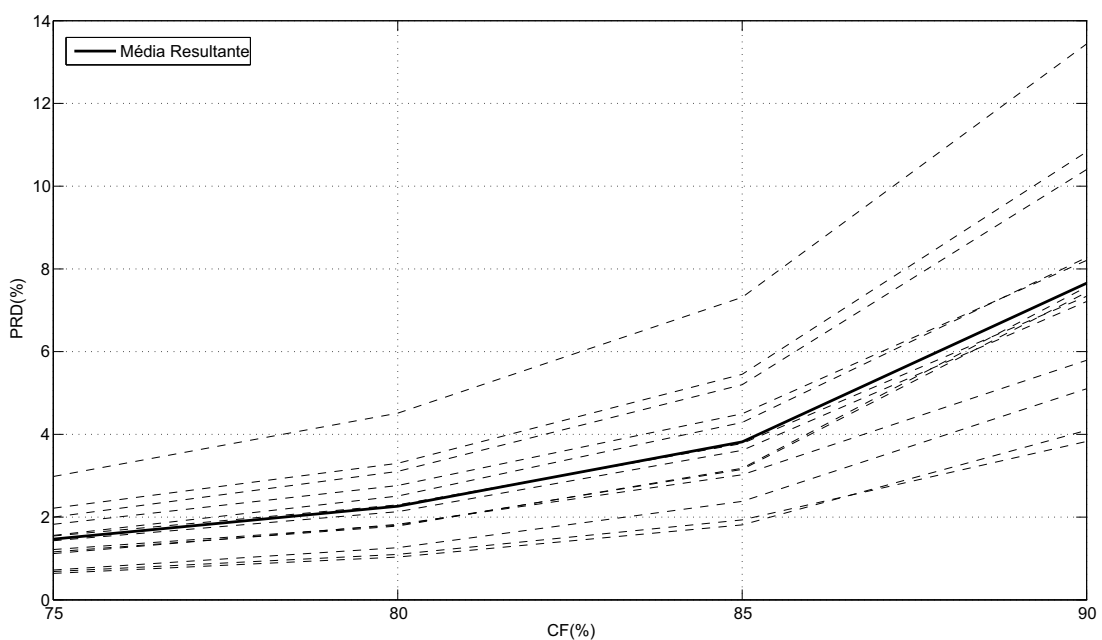

(b)

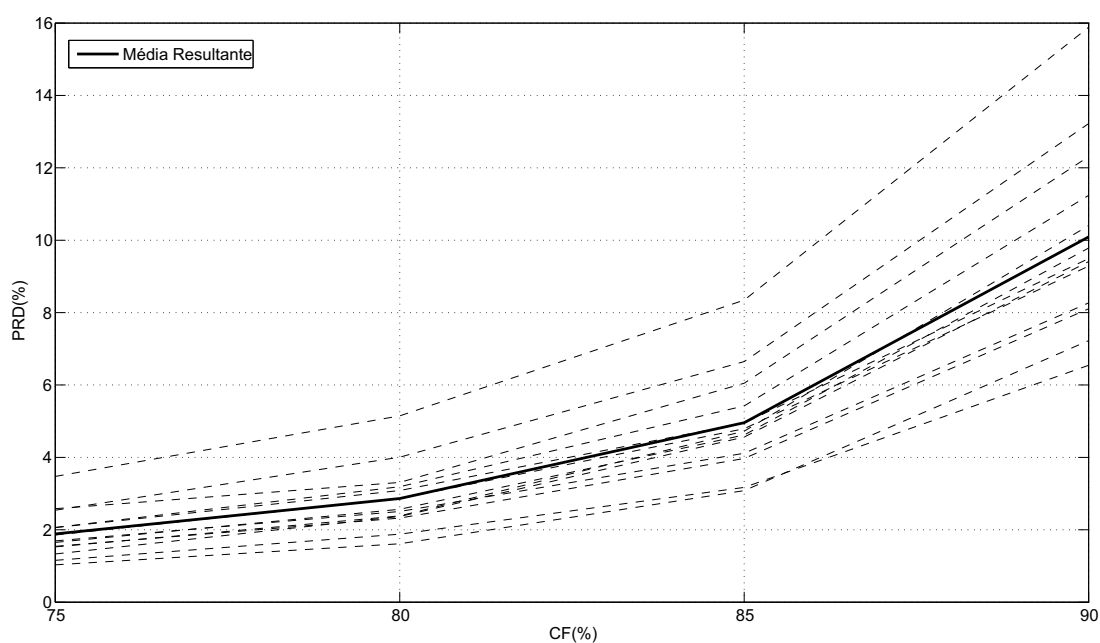

(c)

Figura 6.1: Resultados experimentais para o codificador JPEG2000: (a) sem técnica de pré-processamento, (b) com a ordenação por diferença percentual e (c) com a segmentação por similaridade. 


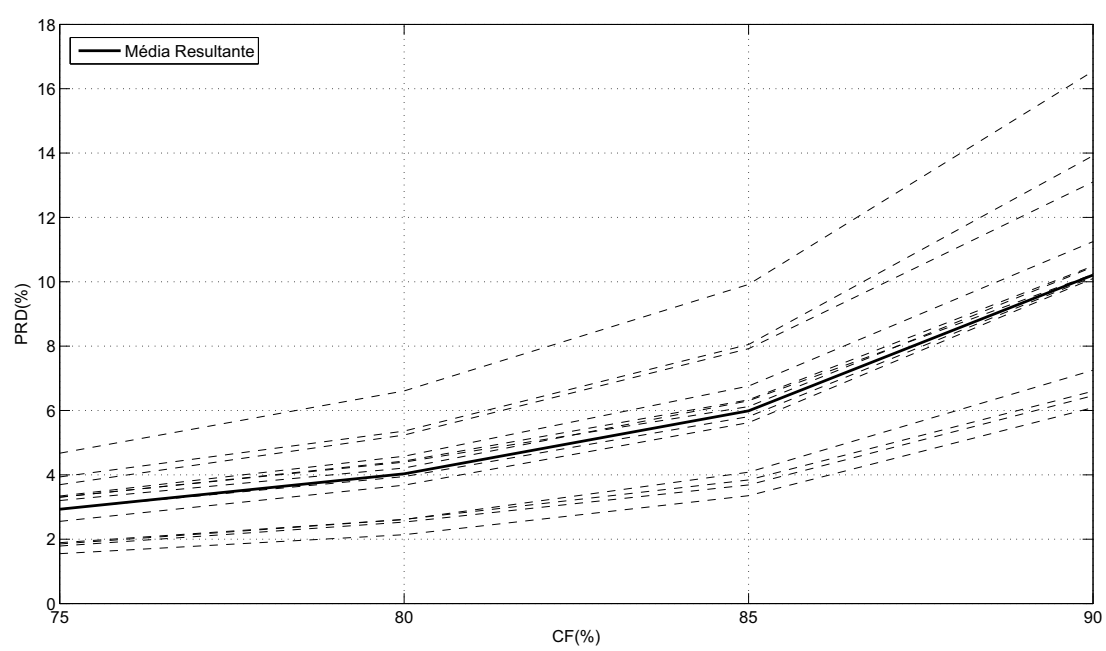

(a)

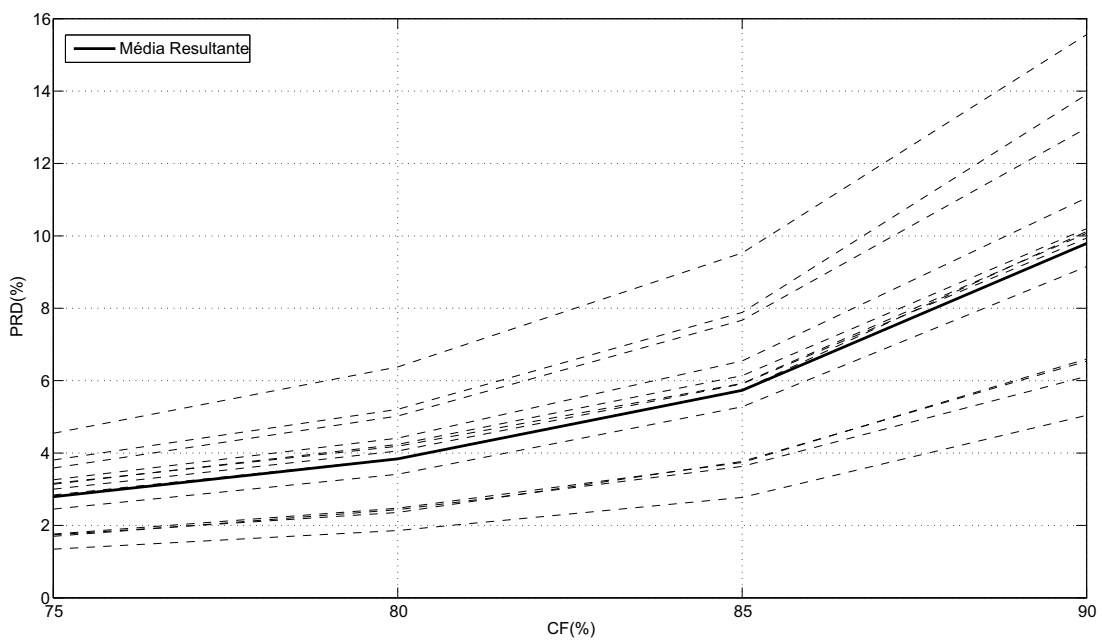

(b)

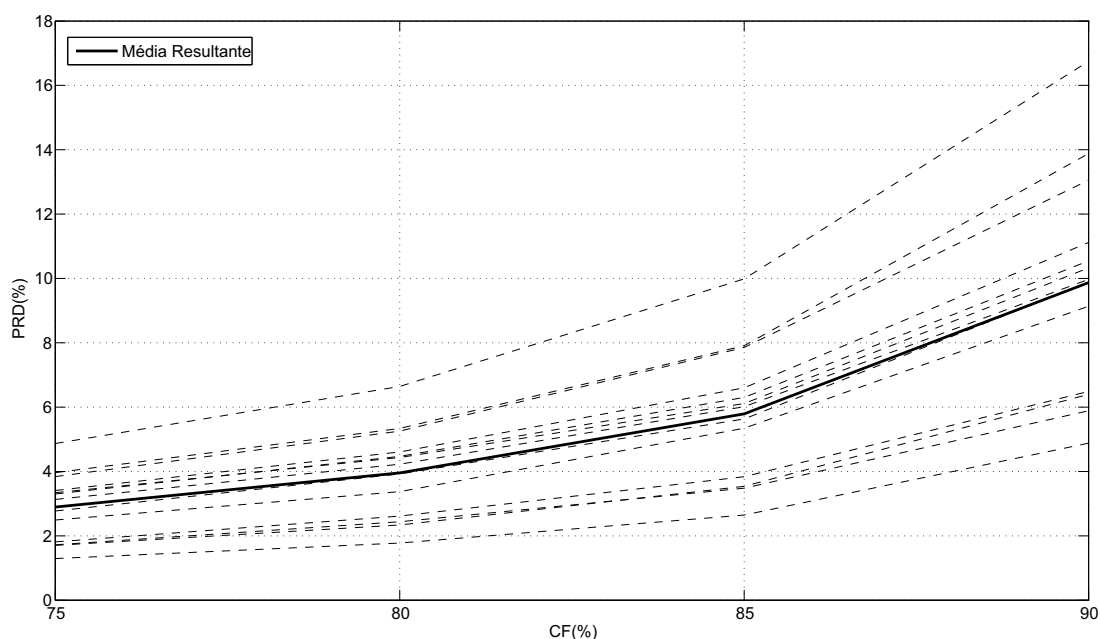

(c)

Figura 6.2: Resultados experimentais para o codificador H.264/AVC: (a) sem técnica de pré-processamento, (b) com a ordenação por diferença percentual e (c) com a segmentação por similaridade. 


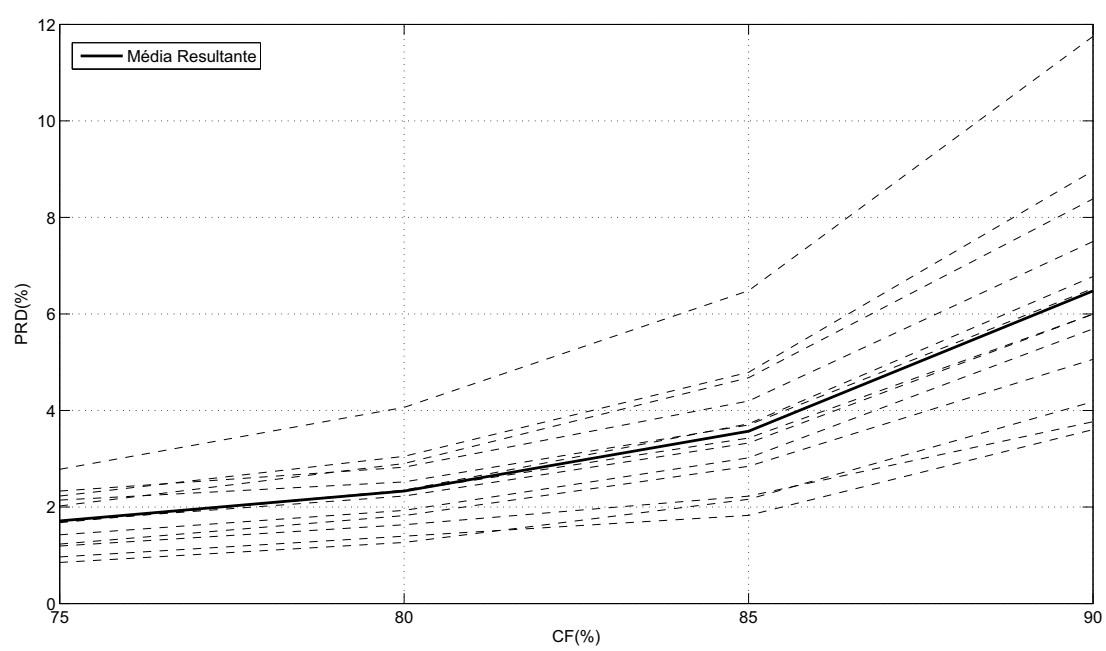

(a)

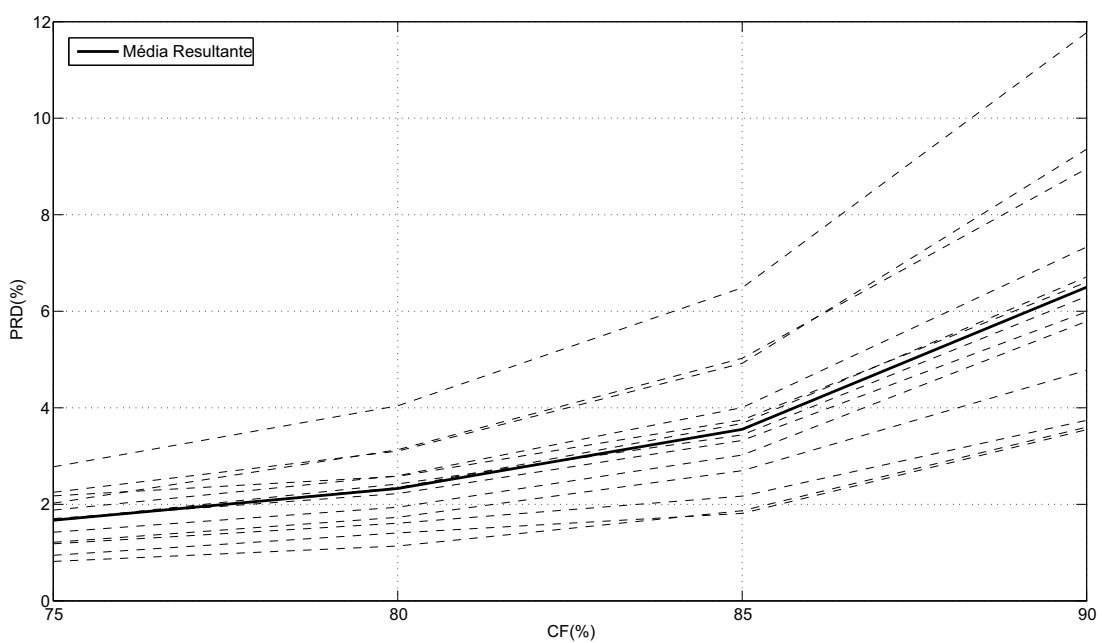

(b)

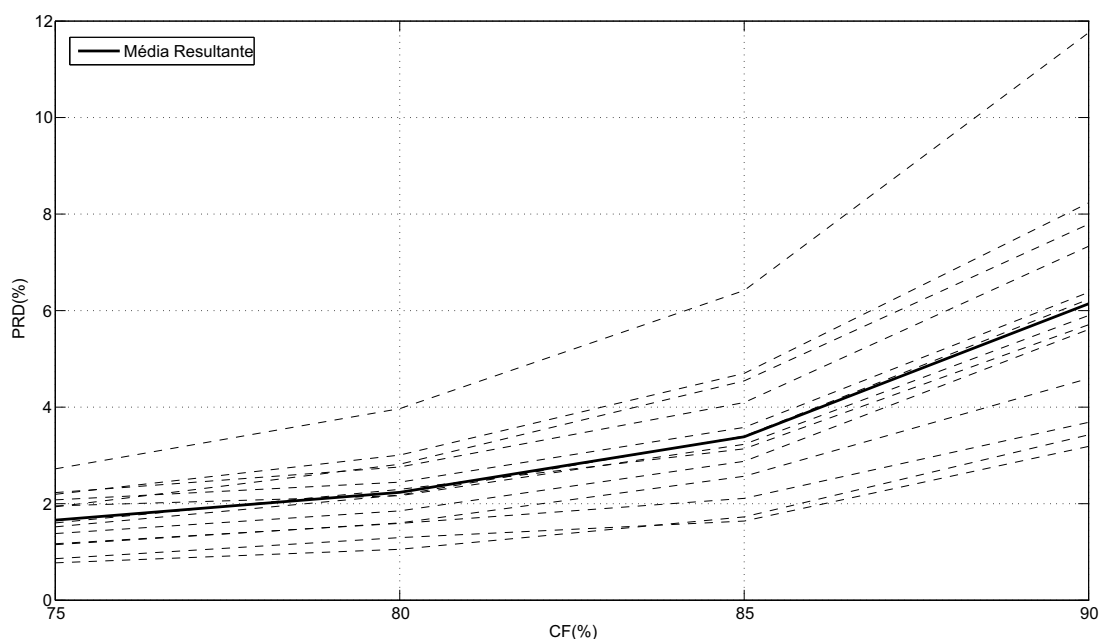

(c)

Figura 6.3: Resultados experimentais para o codificador HEVC: (a) sem técnica de pré-processamento, (b) com a ordenação por diferença percentual e (c) com a segmentação por similaridade. 


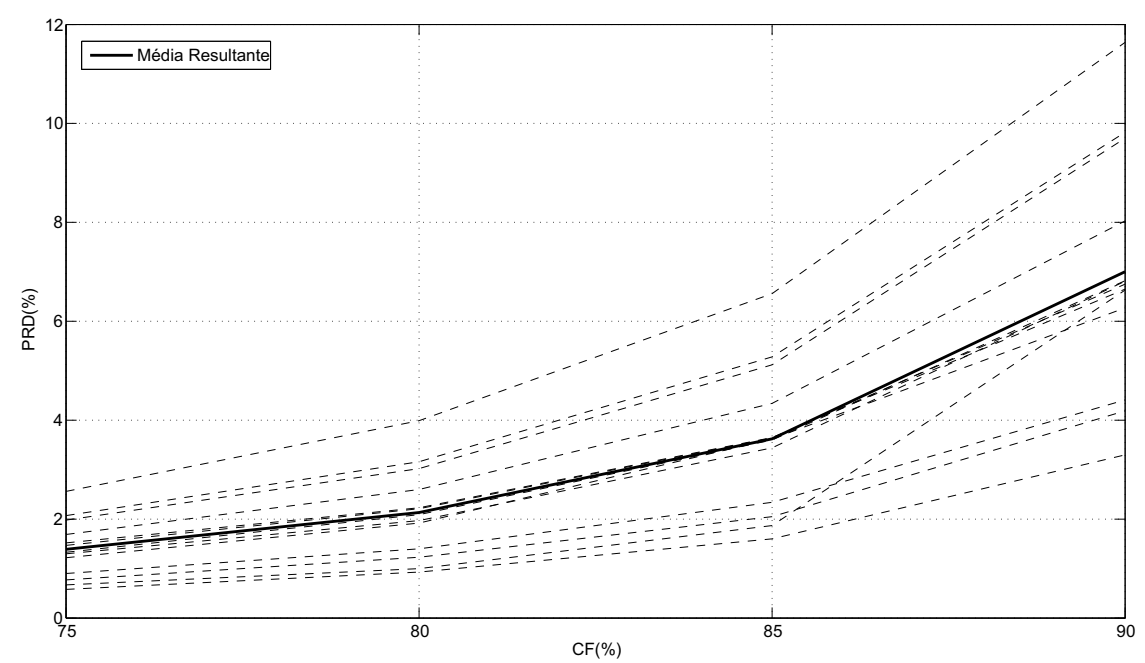

Figura 6.4: Resultados experimentais para o codificador MMP-Bio.

de compressão.

Os resultados com a técnica de segmentação por similaridade apresentam aumento no desempenho dos codificadores empregados, com exceção do codificador JPEG2000. Estes resultados indicam que a técnica possui o potencial de favorecer compressores de imagens que realizam segmentação do sinal de entrada.

Quando se analisa a técnica que proporciona o maior aumento na eficiência de cada codificador, observa-se desempenho superior nos codificadores JPEG2000 e H.264/AVC quando combinados com a técnica de ordenação por diferença percentual, enquanto o codificador HEVC apresenta melhor desempenho com a técnica de segmentação por similaridade.

Tabela 6.1: Valores de $P R D(\%)$ médios para metodologia proposta

\begin{tabular}{ccccc}
\hline \hline Fator de Compressão & $75 \%$ & $80 \%$ & $85 \%$ & $90 \%$ \\
\hline JPEG2000 & 1.53 & 2.38 & 4.05 & 8.27 \\
o.d.p+JPEG2000 & 1.46 & 2.26 & 3.81 & 7.65 \\
s.s.+JPEG2000 & 1.88 & 2.86 & 4.95 & 10.09 \\
H.264/AVC & 2.93 & 4.03 & 5.99 & 10.21 \\
o.d.p+H.264/AVC & 2.79 & 3.83 & 5.73 & 9.79 \\
s.s.+H.264/AVC & 2.89 & 3.95 & 5.78 & 9.87 \\
HEVC & 1.71 & 2.33 & 3.56 & 6.47 \\
o.d.p+HEVC & 1.67 & 2.32 & 3.55 & 6.49 \\
s.s.+HEVC & 1.65 & 2.23 & $\mathbf{3 . 3 8}$ & $\mathbf{6 . 1 4}$ \\
MMP-Bio & $\mathbf{1 . 3 8}$ & $\mathbf{2 . 1 3}$ & 3.62 & 7.00 \\
\hline \hline
\end{tabular}




\subsubsection{Análise de Desempenho do Codificador HEVC}

Os resultados médios do codificador HEVC são melhores que os do codificador JPEG2000, com exceção de um $C F$ de $75 \%$. Quando se compara o desempenho destes codificadores com as técnicas de pré-processamento, nota-se que o desempenho do codificador HEVC combinado com a técnica de segmentação por similaridade (s.s.+HEVC) é superior, exceto para o mesmo $C F$, em que o codificador JPEG2000 combinado com a técnica de ordenação por diferença percentual (o.d.p+JPEG2000) obteve o melhor resultado. É importante notar que o HEVC é empregado na codificação de sinais de vídeo, ao contrário do codificador JPEG2000 que é empregado na codificação de imagens.

Comparando os resultados do codificador HEVC com os do codificador H.264/AVC, observa-se que o desempenho do codificador HEVC é superior, onde para um $C F$ de $90 \%$ a diferença de $P R D$ é de aproximadamente $4 \%$. Quando estes codificadores são analisados em conjunto com as técnicas de pré-processamento, observa-se que novamente o desempenho do codificador HEVC é superior, onde a combinação (s.s.+HEVC) produz uma diferença de PRD superior a 3,5\%, em um $C F$ de $90 \%$, para qualquer combinação do codificador H.264/AVC. Estes resultados mostram que um esquema mais flexível de particionamento e um número maior de técnicas de predição exploram de forma mais efetiva as redundâncias do sinal.

\subsubsection{Análise de Desempenho do Codificador MMP-Bio}

Os resultados obtidos para todos os 13 sinais de S-EMG com o algoritmo MMP-Bio mantém um PRD inferior a $7 \%$ para valores de $C F$ menores que $85 \%$. É possível notar que para um $C F$ de $70 \%$ todos os valores de $P R D$ são inferiores a $3 \%$, e para um $C F$ de $90 \%$ todos os valores de $P R D$ são inferiores a $12 \%$. Estes valores mostram um bom desempenho do codificador.

Comparando os resultados médios do codificador MMP-Bio apresentados na Tabela 6.1 com os resultados do codificador JPEG2000, observa-se que o codificador proposto é superior em todos os fatores de compressão, onde para um $C F$ de $70 \%$ a diferença é de aproximadamente 1,30\%. Mesmo quando se compara os resultados obtidos pela combinação do codificador JPEG2000 com as técnicas de pré-processamento propostas, nota-se que o desempenho do codificador MMP-Bio 
permanece superior. Com isso, mostra-se que a abordagem baseada em técnicas de predição e casamento de padrões é mais eficiente que a técnica baseada em transformada.

Os resultados médios do codificador H.264/AVC mostram um desempenho inferior deste codificador quando comparado ao codificador MMP-Bio. Pode-se observar que para um $C F$ de $90 \%$ a diferença de $P R D$ é de 3, 21\%. Quando combina-se o codificador H.264/AVC com as técnicas de pré-processamento, o desempenho permanece inferior. Embora os codificadores utilizem segmentação do sinal de entrada e técnicas de predição, o codificador MMP-Bio possui um esquema mais eficiente, favorecendo a utilização do dicionário, o que aumenta o desempenho da compressão.

Quando compara-se os resultados médios do codificador HEVC com o codificador MMP-Bio, pode-se observar que o desempenho dos codificadores é competitivo, onde o codificador MMP-Bio apresenta melhores resultados nos fatores de compressão iguais a $75 \%$ e $80 \%$. Comparando os resultados do codificador proposto com a combinação das técnicas de pré-processamento com o codificador HEVC, observa-se que a competitividade é mantida. Assim como no caso do codificador H.264/AVC, os codificadores utilizam técnicas de predição e segmentação do sinal de entrada, a diferença, basicamente, consiste na estratégia de codificação do resíduo, onde no MMP-Bio a codificação é realizada através do casamento de padrões, enquanto que no HEVC é empregado um método baseado em transformada. Embora, a abordagem seja distinta os seus desempenhos mantiveram-se similares.

\subsubsection{Análise de Desempenho com outros Métodos}

Os valores médios de $P R D$ do esquema proposto são comparados com resultados de outros métodos, dos quais alguns representam o estado da arte presente na literatura, na Tabela 6.2. O método em [48] é baseado em wavelets e em um esquema de alocação dinâmica de bits, o esquema em [16] emprega uma modificação do algoritmo EZW, e a técnica utilizada em [19] é baseada em codificadores JPEG2000 e H.264/AVC com técnica de pré-processamento. Como pode ser visto, o algoritmo MMP-Bio supera esses métodos, mostrando que o paradigma baseado em casamento de padrões e dicionário adaptativo é eficiente na codificação de sinais de S-EMG. 
Tabela 6.2: Valores de $P R D(\%)$ médios para sinais de EMG codificados com diferentes esquemas de compressão

\begin{tabular}{ccccc}
\hline \hline Fator de Compressão & $75 \%$ & $80 \%$ & $85 \%$ & $90 \%$ \\
\hline Norris et. al. [48] & 3.8 & 5 & 7.8 & 13 \\
Berger et. al. [16] & 2.5 & 3.3 & 6.5 & 13 \\
Filho et. al. [51] & 1.61 & 2.51 & 4.13 & 7.36 \\
Chaffim et. al. (JPEG2000) [19] & 3.50 & 4.48 & 6.92 & 13.44 \\
Chaffim et. al. (H.264/AVC) [19] & 5.37 & 6.90 & 9.93 & 16.62 \\
o.d.p+JPEG2000 & 1.46 & 2.26 & 3.81 & 7.65 \\
o.d.p+H.264/AVC & 2.79 & 3.83 & 5.73 & 9.79 \\
s.s.+H.264/AVC & 2.89 & 3.95 & 5.78 & 9.87 \\
s.s.+HEVC & 1.65 & 2.23 & $\mathbf{3 . 3 8}$ & $\mathbf{6 . 1 4}$ \\
MMP-Bio & $\mathbf{1 . 3 8}$ & $\mathbf{2 . 1 3}$ & 3.62 & 7.00 \\
\hline \hline
\end{tabular}

O método proposto por Filho et. al. emprega a versão unidimensional do MMP, onde cada sinal de EMG é dividido em segmentos com 64 amostras, e cada segmento é aproximado por elementos de um dicionário adaptativo. O algoritmo MMP-Bio possui uma abordagem bidimensional com técnicas de predição e controle de redundância do dicionário. Os resultados mostram melhor desempenho do algoritmo proposto. O motivo é que o algoritmo adapta-se melhor ao sinal de S-EMG, consequentemente, o uso do dicionário é mais eficiente.

Por fim, compara-se o desempenho dos codificadores JPEG2000 e H.264/AVC combinados com as técnicas de pré-processamento introduzidas neste trabalho, com o método proposto por Chaffim et. al., que utiliza os mesmos codificadores, porém com técnicas de pré-processamento distintas. Pode-se perceber que o desempenho da metodologia proposta é superior, mostrando uma maior eficiência das técnicas de pré-processamento propostas. Além disso, observe que os resultados da ordenação por diferença percentual com o JPEG2000 foram superiores aos dos outros métodos encontrados na literatura, com exceção do método proposto por Filho et. al. a um CF de $90 \%$.

\subsubsection{Análise do Envelope do Sinal Reconstruído}

Como a codificação de sinais biológicos possui a restrição de preservar a informação clínica presente no sinal, é importante verificar se o envelope do sinal é mantido após a decodificação. Quando o envelope está corrompido, o sinal erro produzido pela diferença entre o sinal original e o reconstruído possui alta energia, 
com isso pode-se analisar o sinal erro gerado após o processo de compressão. A Figura 6.5 apresenta uma comparação do envelope do sinal original e do reconstruído a partir do MMP-Bio para um $C F$ de $87,5 \%$, pode-se observar que não há distorções visíveis no sinal reconstruído e a energia do sinal erro é baixa, o que mostra que a abordagem no domínio espacial realizada pelo MMP-Bio possui o potencial de preservar a forma de onda do sinal de entrada.

Nas Figuras 6.6 até 6.11 são apresentadas comparações entre os resultados do envelope do sinal para cada técnicas de pré-processamento associada com os codificadores aplicados no esquema de compressão proposto. Pode-se observar que visualmente não há diferença entre os sinais originais e os reconstruídos, e como o desempenho de cada associação entre as técnicas de pré-processamento e o codificadores são diferentes, os sinais de erro são distintos, com energia baixa, observe que a escala está 10 vezes menor.

\subsection{Considerações Finais}

Neste capítulo, o esquema de compressão de sinais eletromiográficos proposto foi avaliado por meio de 13 sinais de S-EMG. Os resultados foram obtidos para os codificadores JPEG2000, H.264/AVC, HEVC combinados com as técnicas de pré-processamento propostas. Além disso, empregou-se o codificador MMP-Bio na compressão dos sinais, de modo a investigar o seu desempenho. Os resultados mostram que as técnicas de pré-processamento aumentam o potencial da exploração das correlações intrasegmento e intersegmento. Embora a segmentação por similaridade não aumente a eficiência do codificador JPEG2000, os seus resultados com os codificadores H.264/AVC e HEVC são bons, indicando que a sua utilização é mais efetiva para codificadores que particionam a imagem de entrada. Os resultados do codificador HEVC foram melhores que os gerados com o codificador H.264/AVC e JPEG2000, além disso, o codificador MMP-Bio também apresentou um desempenho superior aos dos codificadores H.264/AVC e JPEG2000. Por fim, os codificadores HEVC e MMP-Bio superam o desempenho dos métodos presentes na literatura, comprovando a eficiência destes codificadores na compressão de sinais eletromiográficos, e a comparação entre estes codificadores mostra que eles possuem 
um desempenho similar. No próximo capítulo, apresentam-se as conclusões e as propostas de trabalhos futuros desta Dissertação.

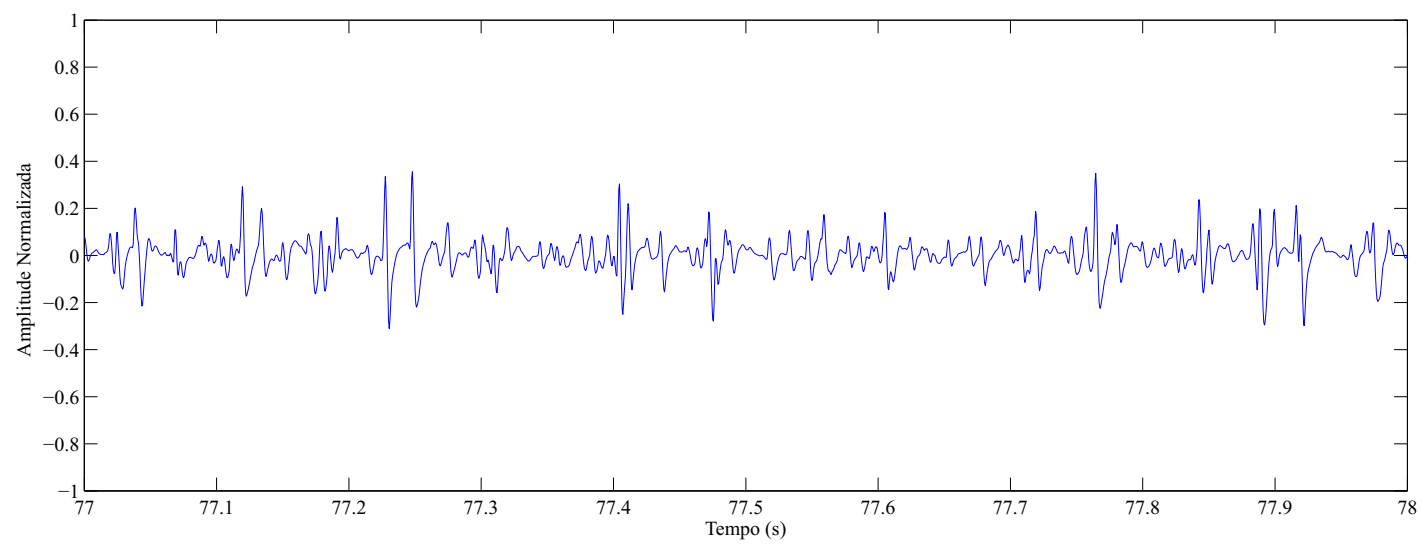

(a)

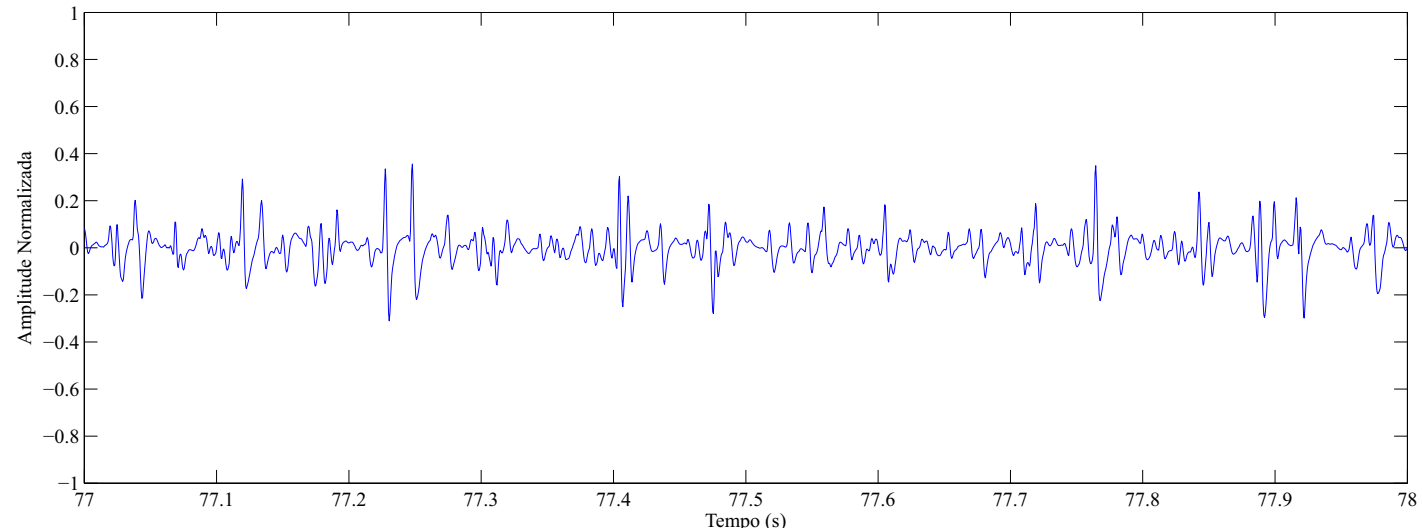

(b)

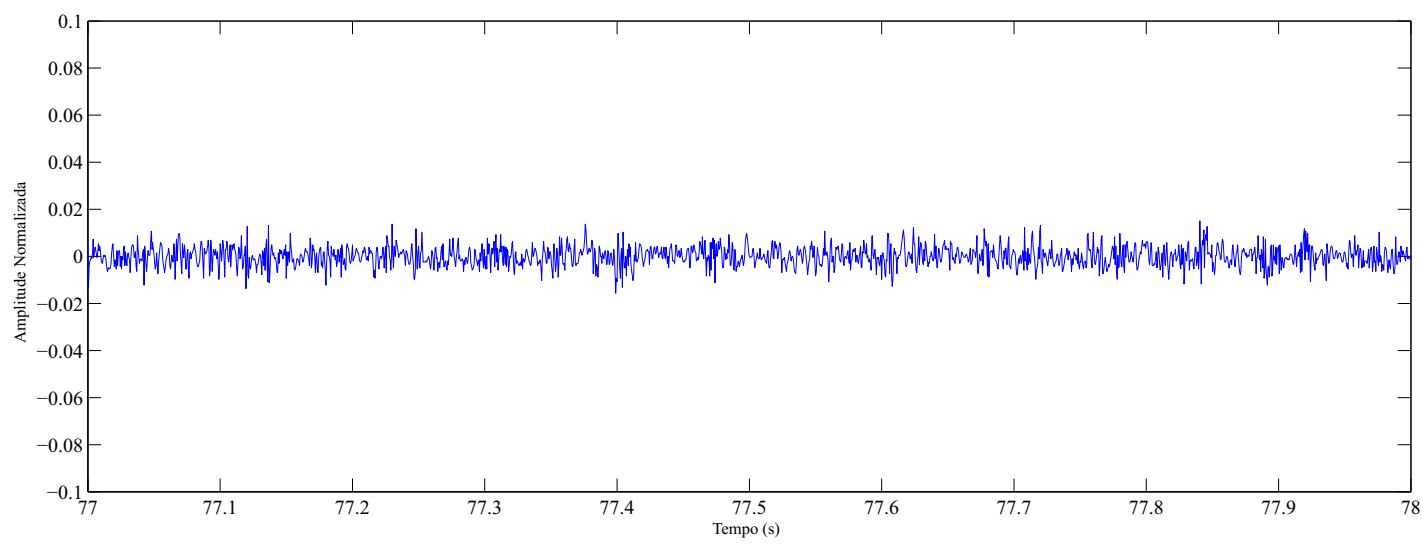

(c)

Figura 6.5: Inspeção visual da qualidade do sinal reconstruído a partir do codificador MMP-Bio: (a) sinal original, (b) sinal reconstruído a um $C F$ de 87, 5\% e (c) diferença entre sinal original e o reconstruído. 


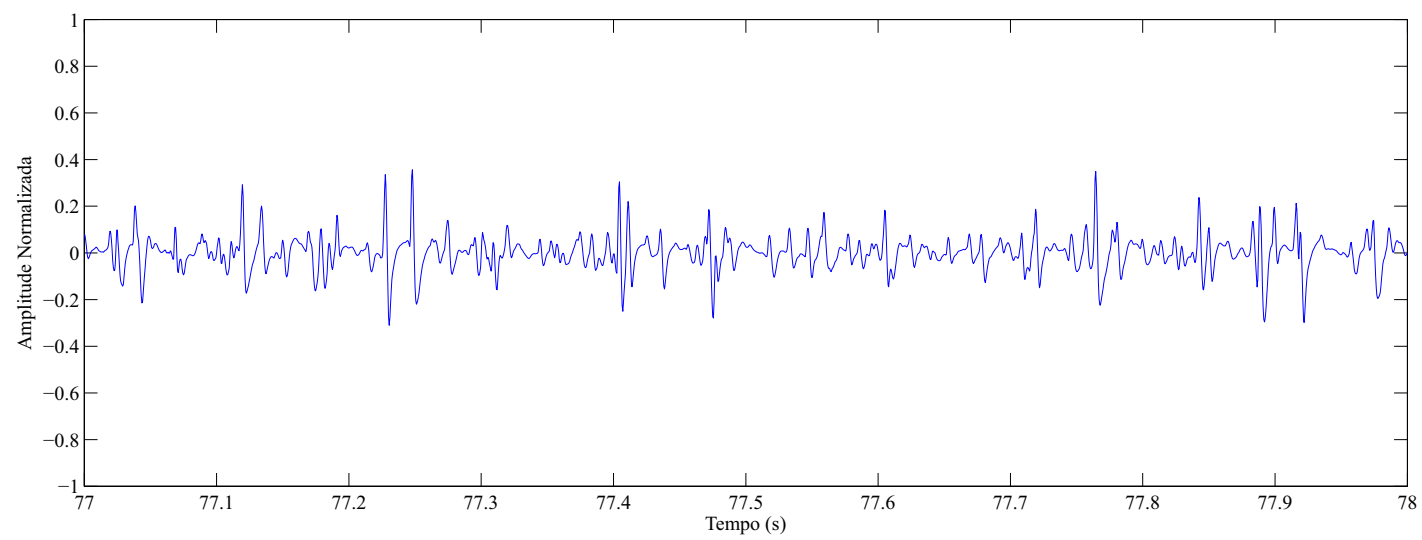

(a)

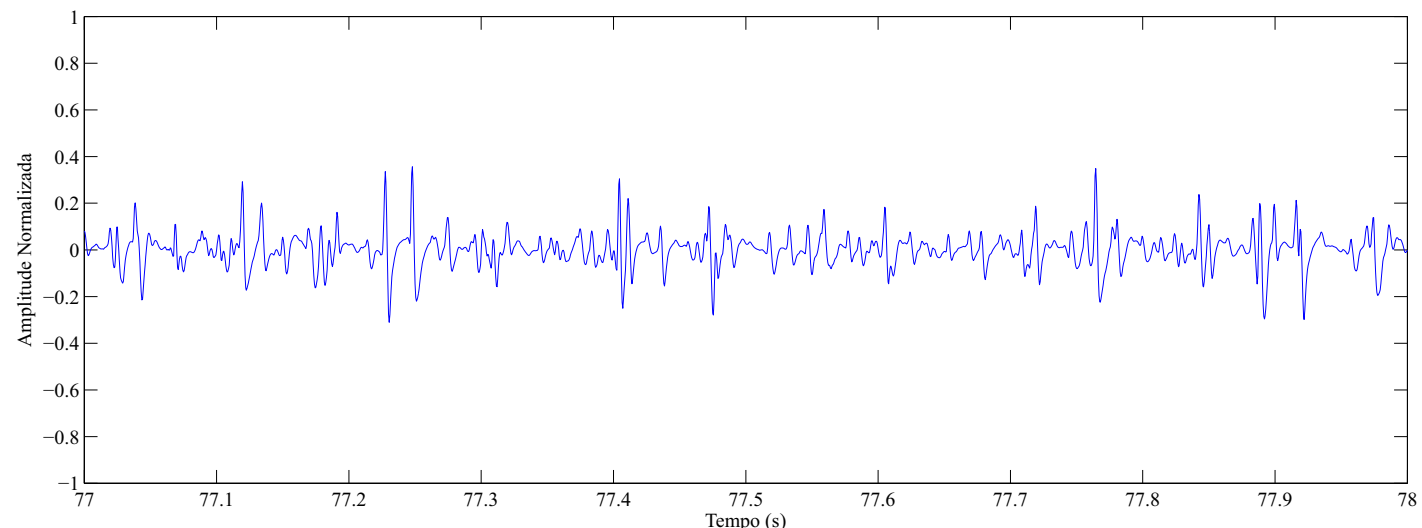

(b)

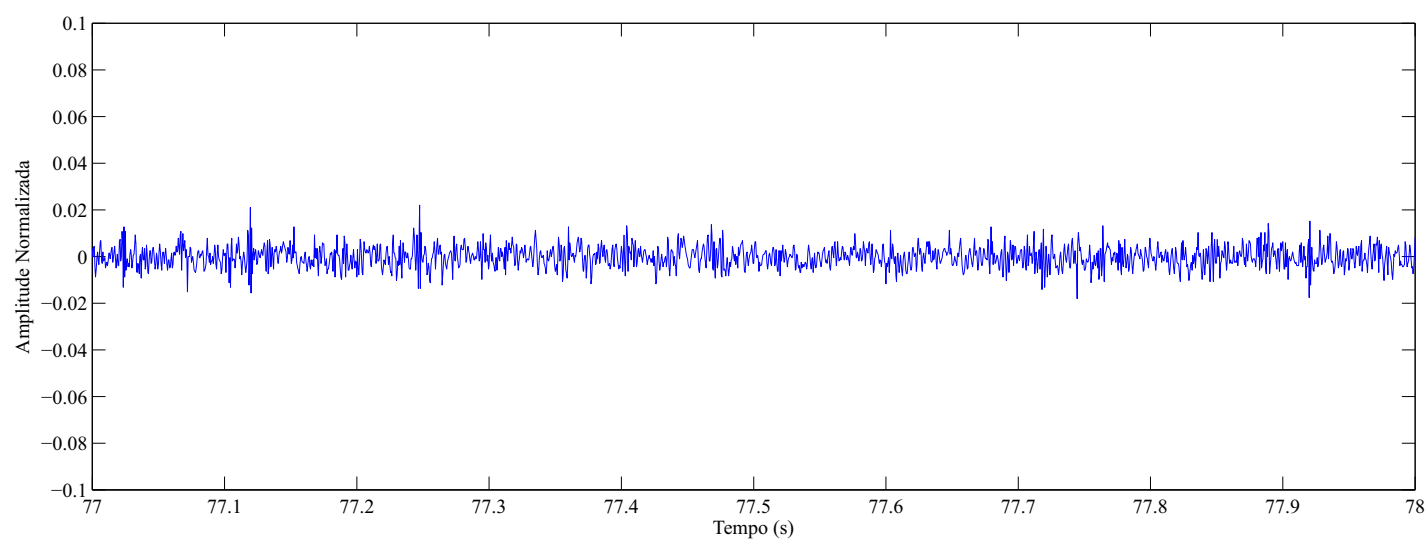

(c)

Figura 6.6: Inspeção visual da qualidade do sinal reconstruído a partir da s.s.+HEVC: (a) sinal original, (b) sinal reconstruído a um $C F$ de $87,5 \%$ e (c) diferença entre sinal original e o reconstruído. 


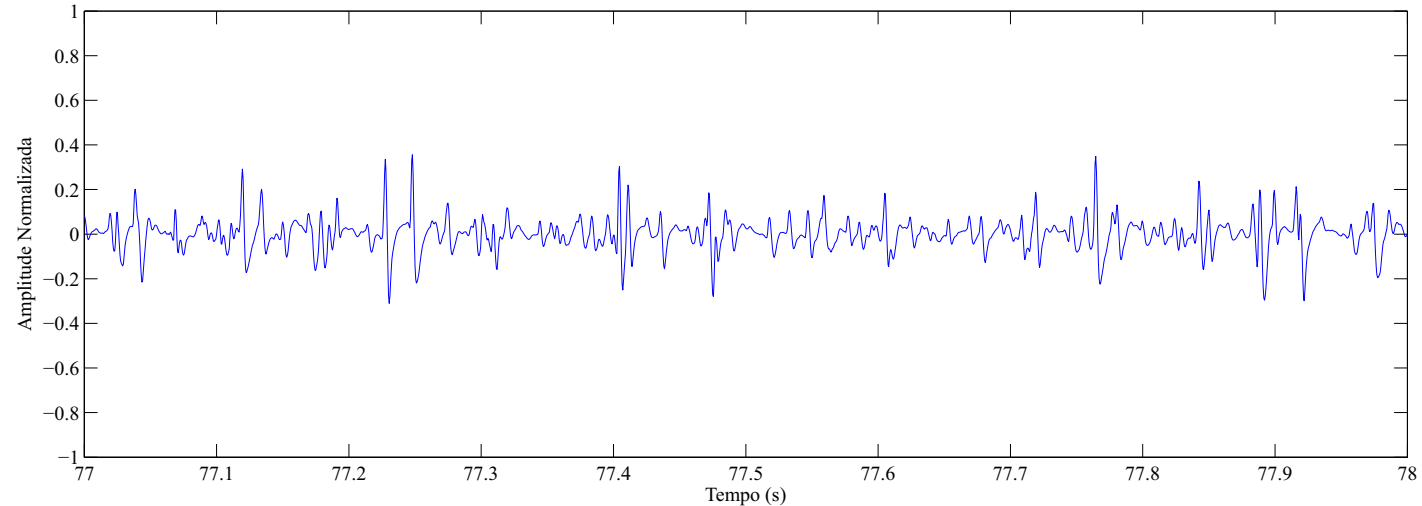

(a)

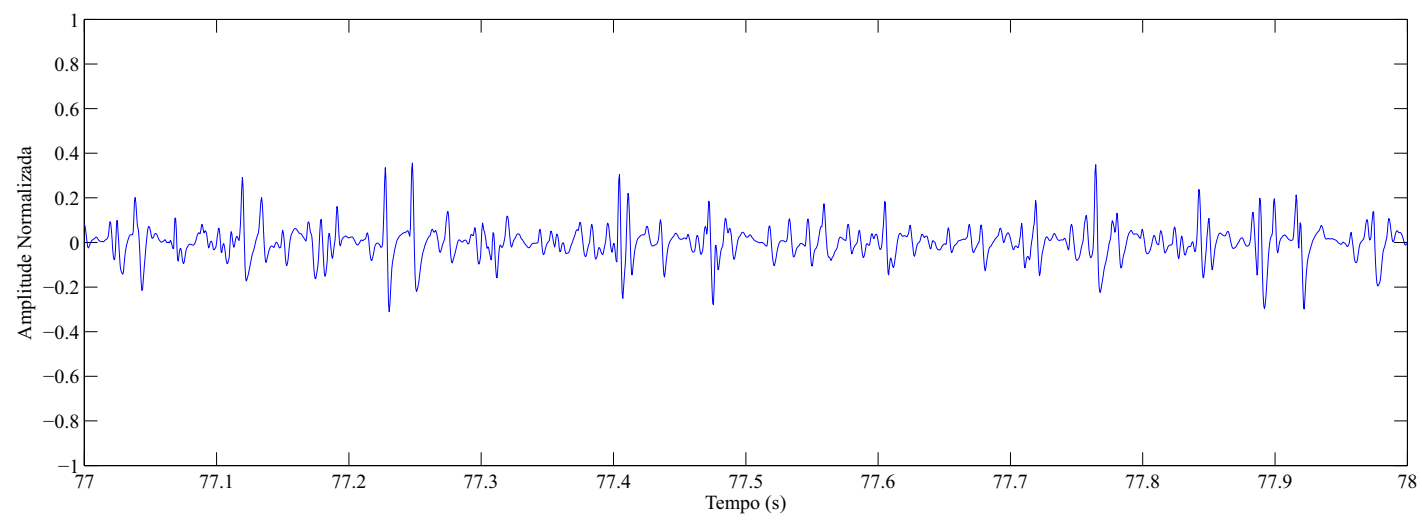

(b)

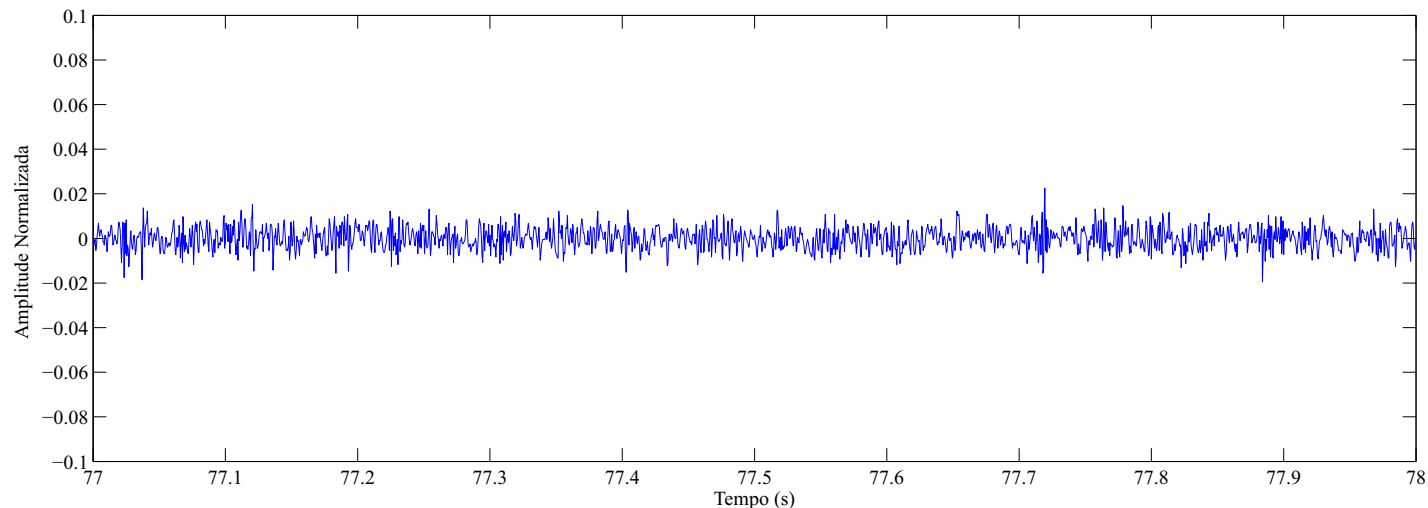

(c)

Figura 6.7: Inspeção visual da qualidade do sinal reconstruído a partir da o.d.p.+HEVC: (a) sinal original, (b) sinal reconstruído a um $C F$ de $87,5 \%$ e (c) diferença entre sinal original e o reconstruído. 


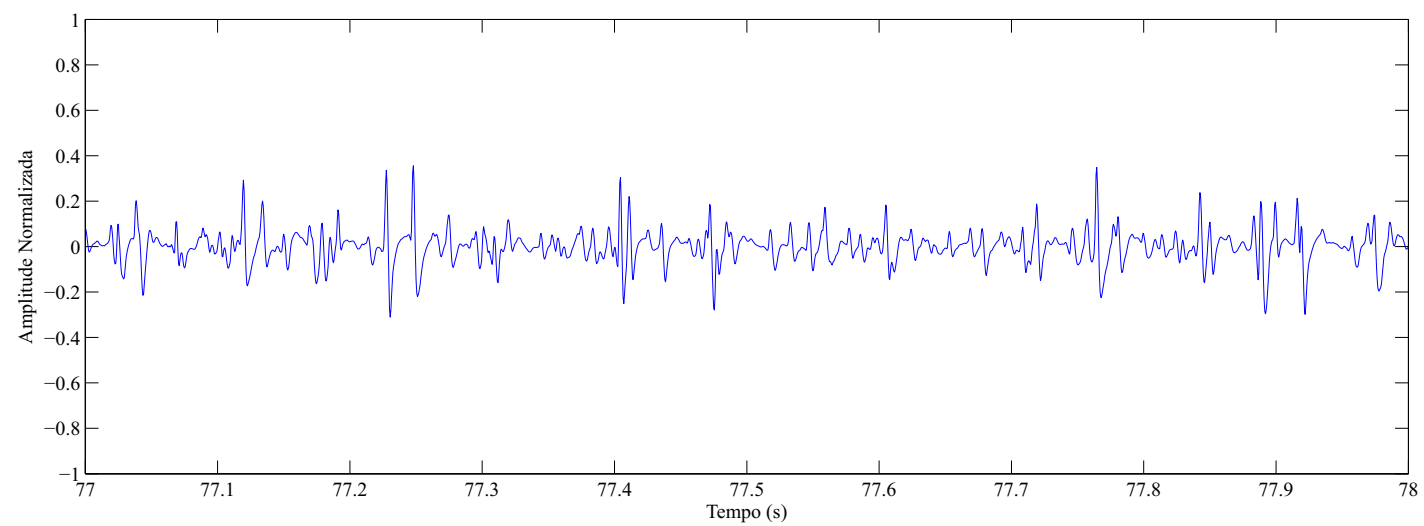

(a)

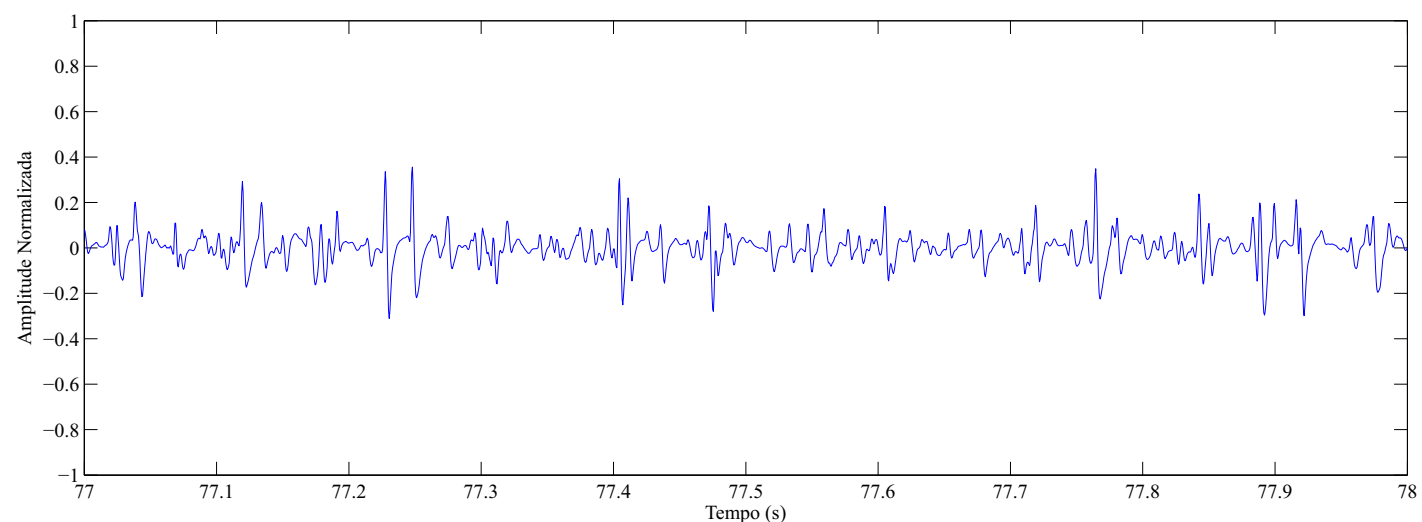

(b)

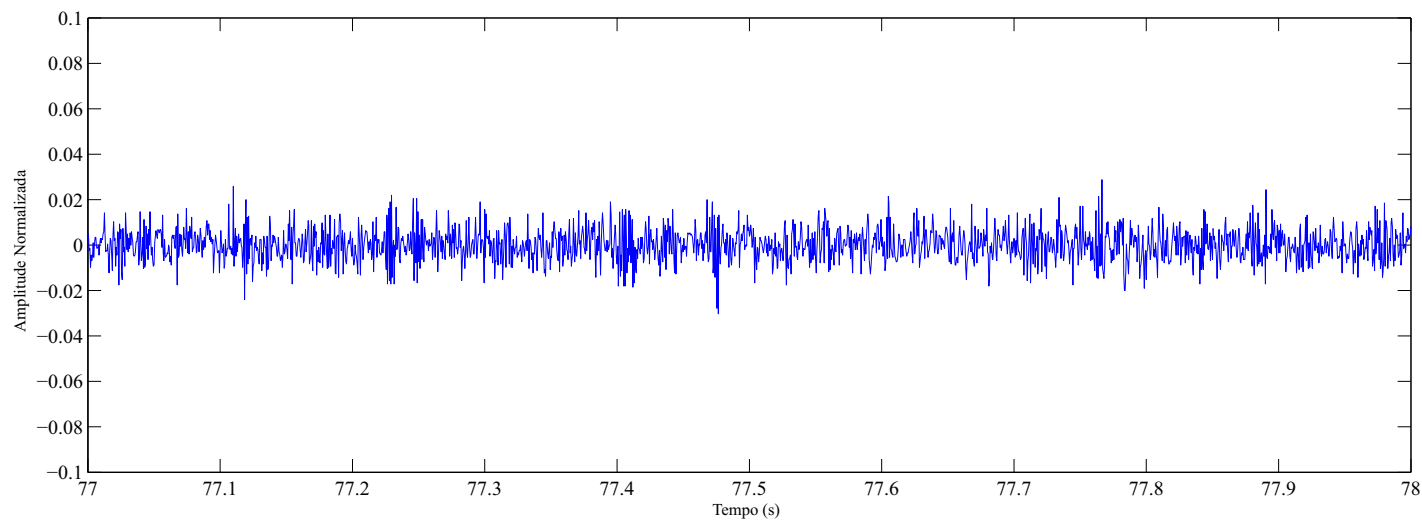

(c)

Figura 6.8: Inspeção visual da qualidade do sinal reconstruído a partir da s.s.+H264: (a) sinal original, (b) sinal reconstruído a um $C F$ de $87,5 \%$ e (c) diferença entre sinal original e o reconstruído. 


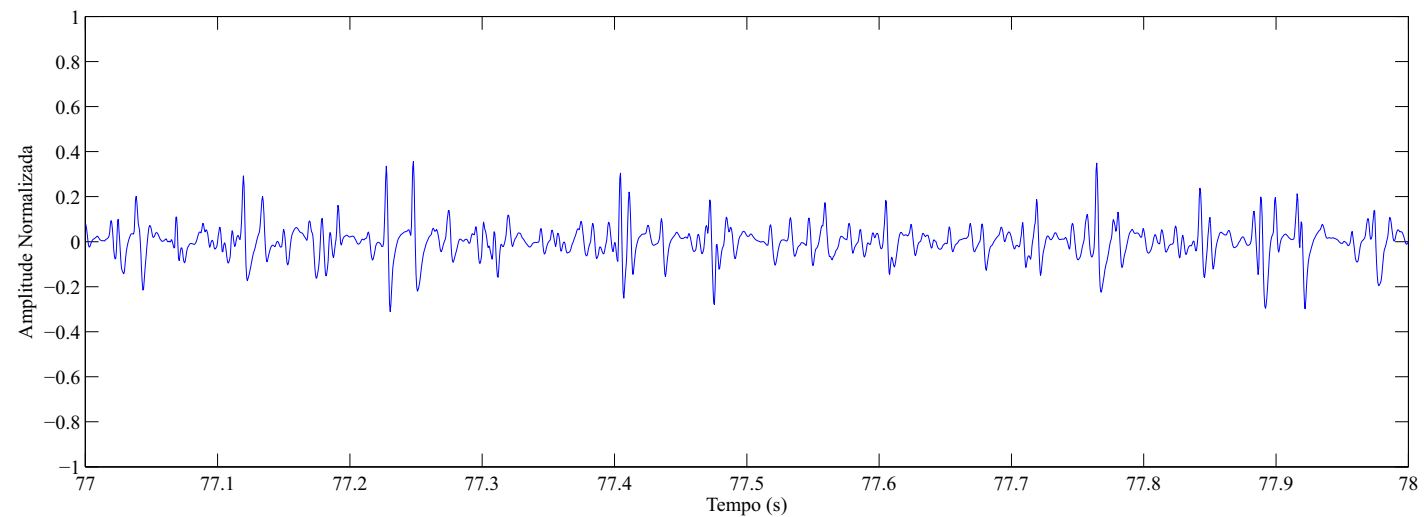

(a)

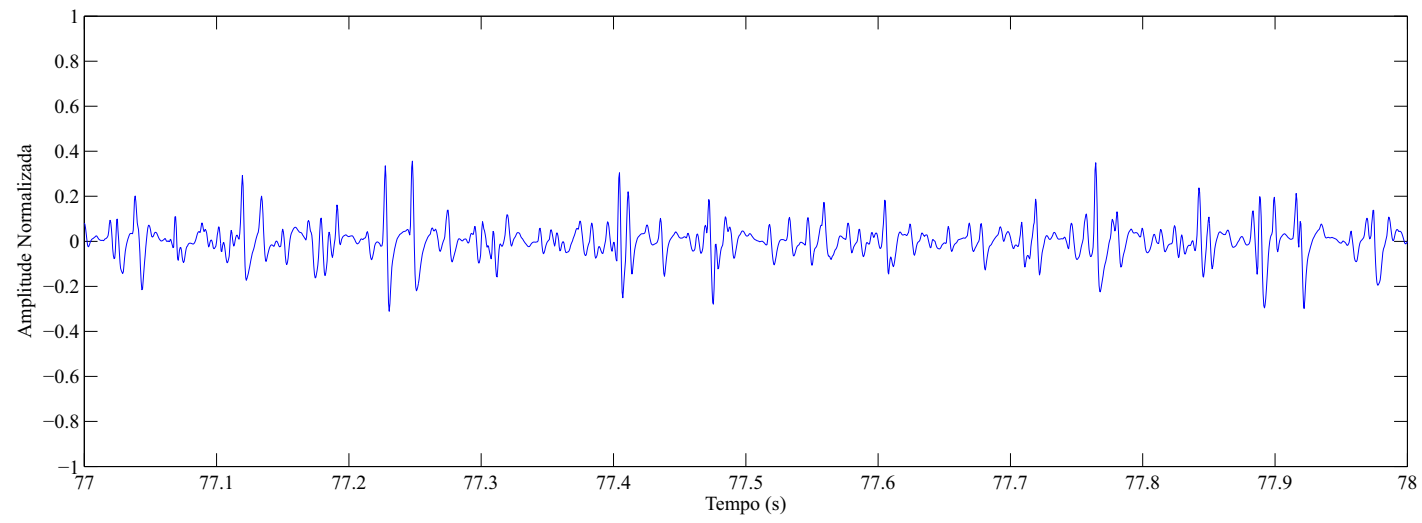

(b)

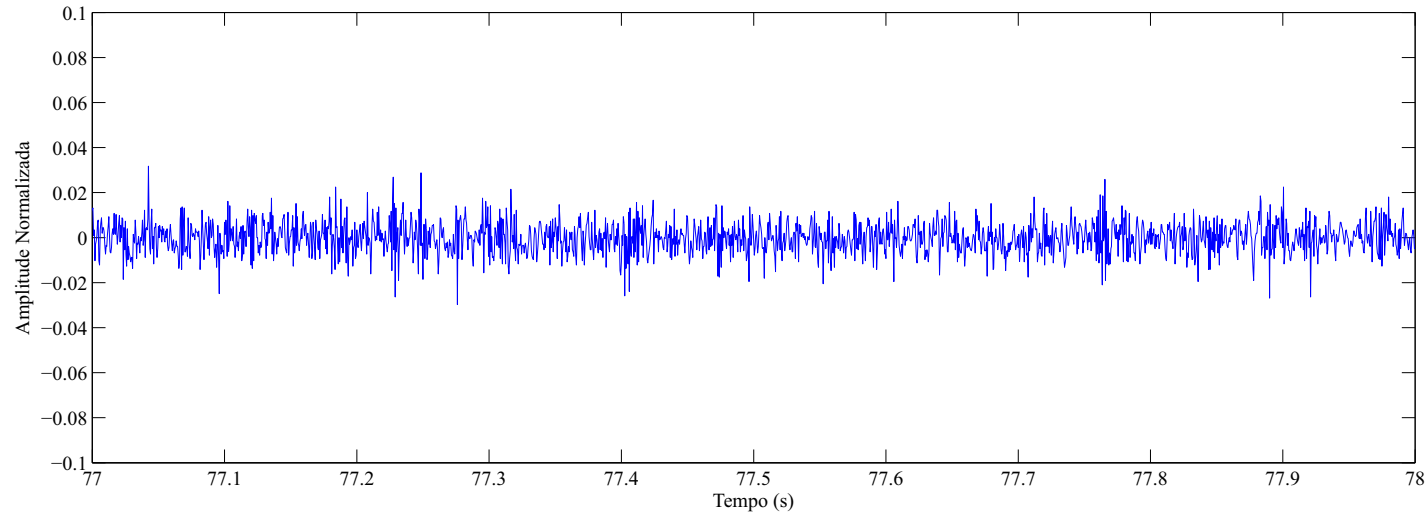

(c)

Figura 6.9: Inspeção visual da qualidade do sinal reconstruído a partir da o.d.p.+H264: (a) sinal original, (b) sinal reconstruído a um $C F$ de $87,5 \%$ e (c) diferença entre sinal original e o reconstruído. 


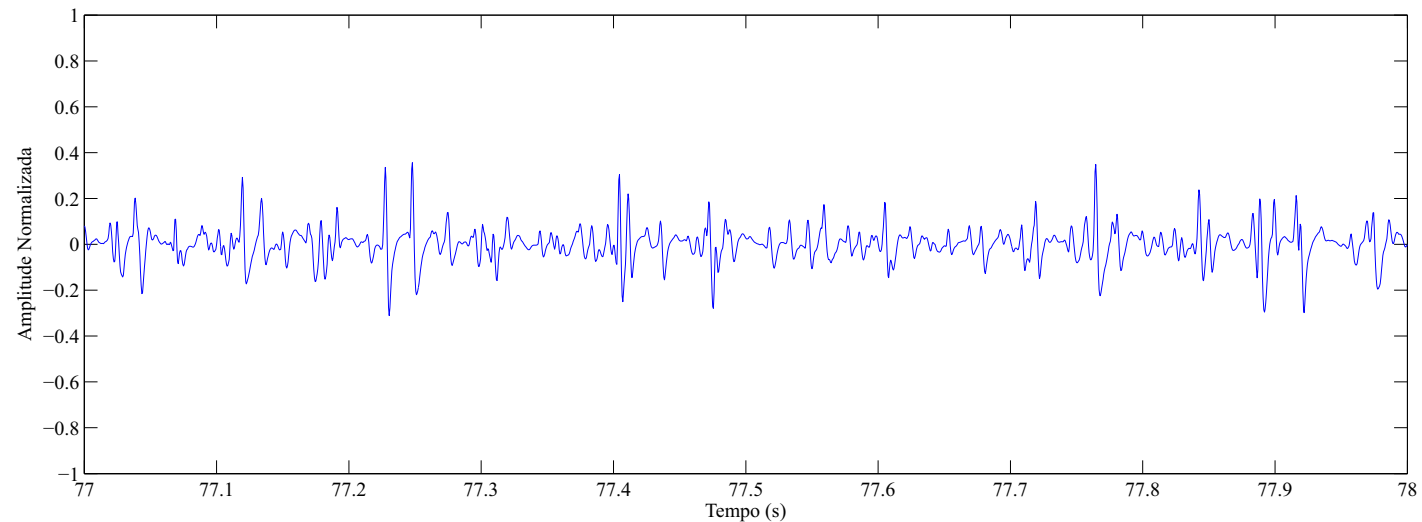

(a)

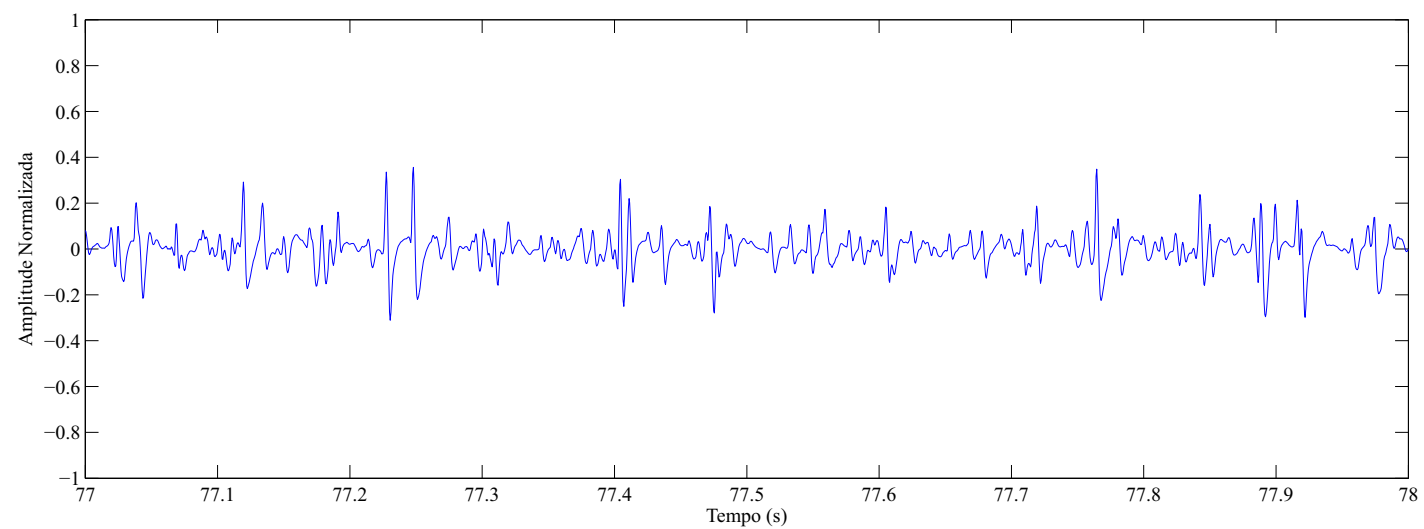

(b)

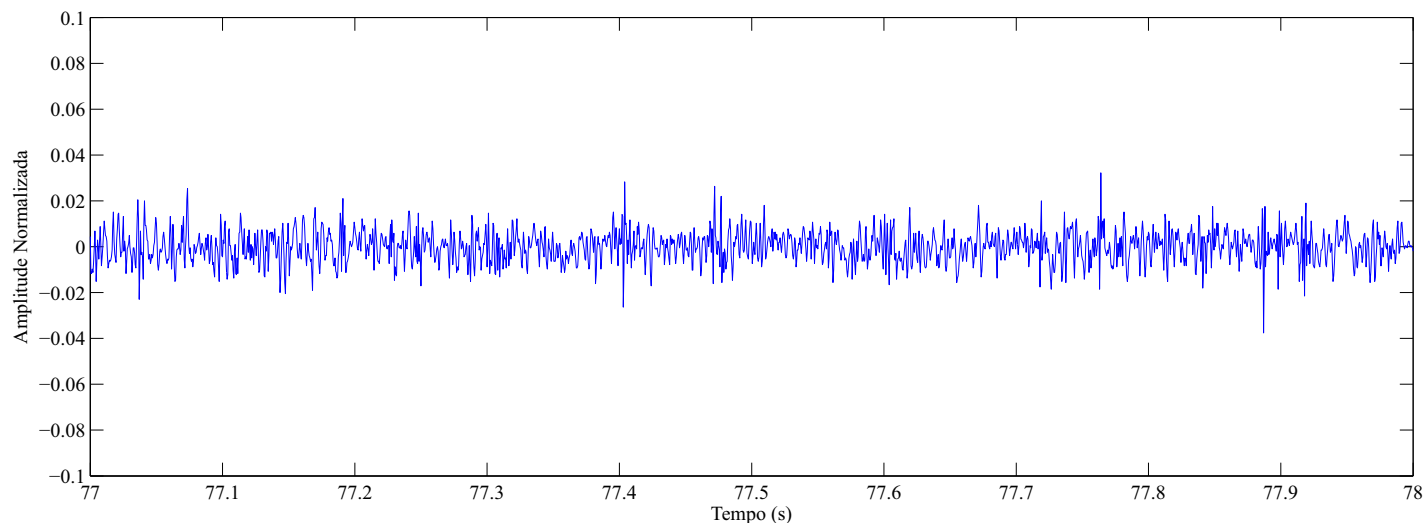

(c)

Figura 6.10: Inspeção visual da qualidade do sinal reconstruído a partir da s.s.+JPEG2000: (a) sinal original, (b) sinal reconstruído a um $C F$ de $87,5 \%$ e (c) diferença entre sinal original e o reconstruído. 


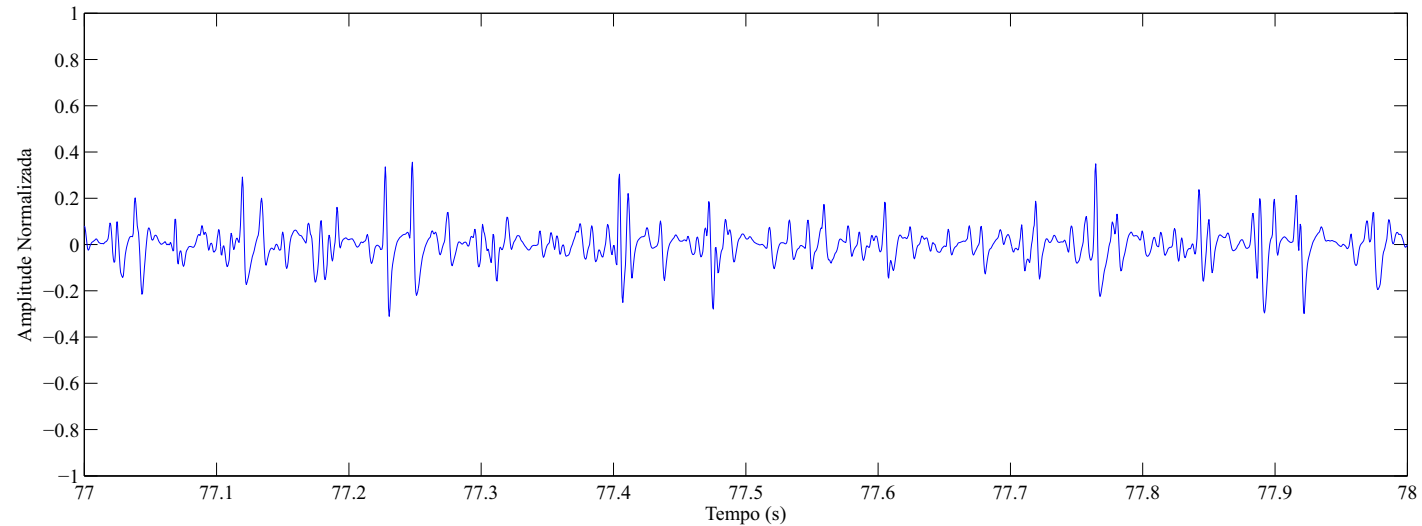

(a)

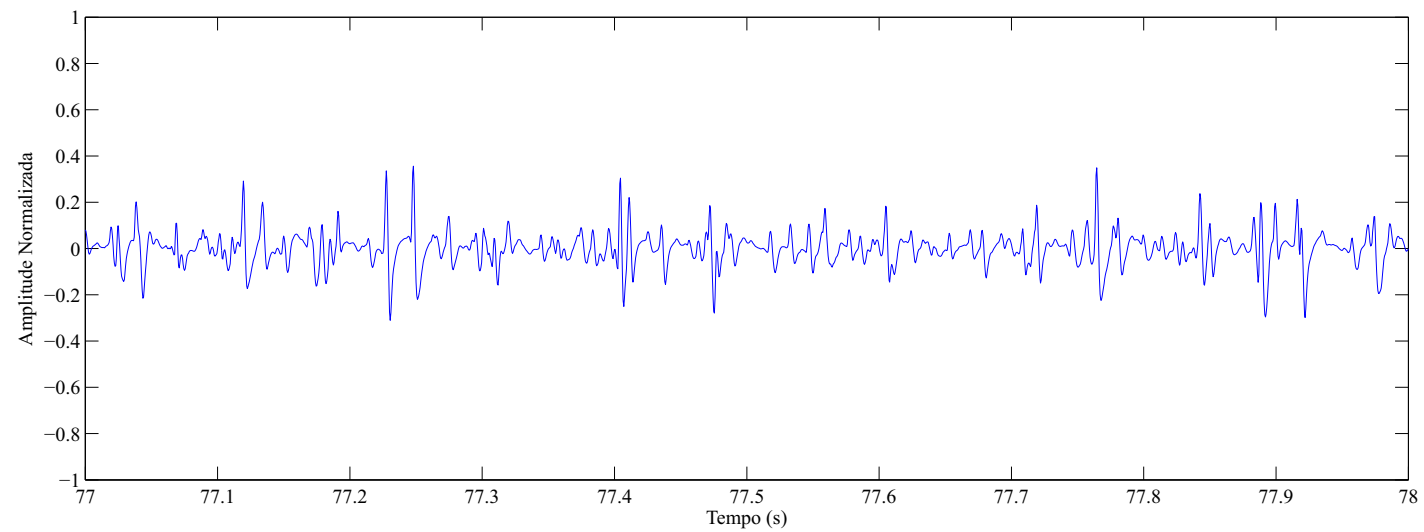

(b)

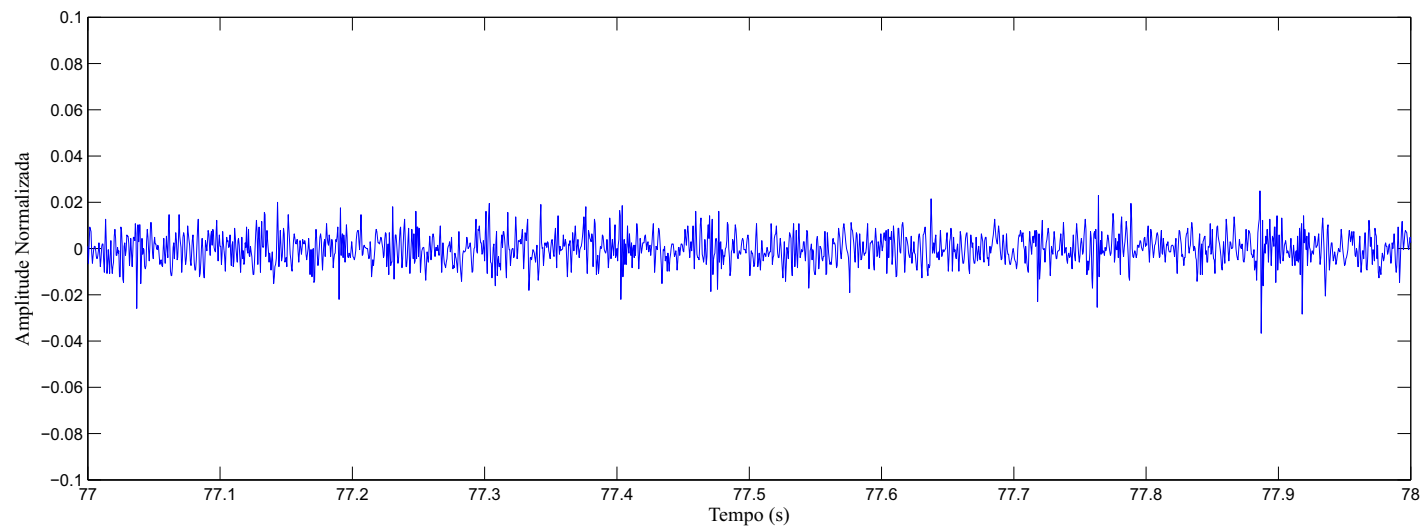

(c)

Figura 6.11: Inspeção visual da qualidade do sinal reconstruído a partir da o.d.p.+JPEG2000: (a) sinal original, (b) sinal reconstruído a um $C F$ de 87,5\% e (c) diferença entre sinal original e o reconstruído. 


\section{Capítulo 7}

\section{Conclusões}

\subsection{Considerações Finais da Dissertação}

Nesta dissertação, investigou-se novas técnicas de compressão de sinais eletromiográficos. Foram propostos métodos nos diferentes estágios do esquema adotado para codificação de sinais. Embora os sinais de testes empregados sejam os de eletromiografia, o esquema pode codificar qualquer sinal biológico. A seguir, menciona-se as principais contribuições deste trabalho.

As técnicas de pré-processamento introduzidas no Capítulo 5 foram aplicadas na compressão de sinais de S-EMG formatados como imagens. A técnica de ordenação por diferença percentual melhorou o desempenho dos codificadores empregados. A técnica de segmentação por similaridade proporcionou maior eficiência dos codificadores, com exceção do compressor JPEG2000, mostrando que esta técnica funciona bem com codificadores que fazem particionamento da imagem. Entretanto, não se deve descartar a combinação do compressor JPEG2000 com esta técnica, pois é necessário verificar os resultados para outros sinais biológicos. Comparando-se as técnicas propostas com as existentes na literatura, observa-se melhores desempenhos dos codificadores, quando associados com as técnicas propostas. Portanto, as técnicas possuem o potêncial para melhorar a exploração das dependências do sinal, podendo até serem incorporadas em esquemas existentes, levando a uma melhoria na qualidade do sinal reconstruído.

O codificador HEVC mostrou-se eficiente na compressão de sinais de S-EMG. O seu desempenho superou os dos codificadores JPEG2000, com exceção de um fator 
de compressão igual a 75\%, e H.264/AVC. A combinação deste codificador com a técnica de segmentação por similaridade gerou resultados que superam o estado da arte presente na literatura. Com isso, o codificador HEVC estabelece-se como uma boa opção para compressão de sinais eletromiográficos.

No Capítulo 4, adaptou-se o compressor MMP-II para codificar sinais eletromiográficos. O algoritmo passou a comprimir de acordo com a profundidade de bits do sinal biológico e o dicionário teve seus limites de amplitude alterados. Para melhorar a exploração das correlações intrasegmento e intersegmento, as técnicas de predição foram substituídas pelas técnicas adotadas no codificador HEVC. Essas alterações deram origem ao codificador MMP-Bio. Os resultados gerados com o novo codificador superaram a versão unidimensional do MMP e o estado da arte presente na literatura. Comparado com o codificador HEVC, o MMP-Bio apresenta resultados melhores para um fator de compressão igual a $75 \%$ e $80 \%$. Estes fatos consolidam o codificador MMP-Bio como uma alternativa eficiente, de paradigma diferente, para compressão de sinais eletromiográficos.

Um avaliação visual do sinais de S-EMG codificados com o esquema proposto foi realizada. Os resultados, para um fator de compressão igual a 87,30\%, mostram que o envelope do sinal reconstruído é preservado. Uma vez que a informação clínica não é perdida, o esquema pode ser embarcado e utilizado na compressão de sinais biológicos, com a ressalva do codificador MMP-Bio que possui uma alta latência.

\subsection{Propostas para Trabalhos Futuros}

Neste seção, apresenta-se algumas propostas para desenvolvimentos futuros relacionados às técnicas de compressão de sinais eletromiográficos propostas nesta dissertação. Estas propostas podem ser divididas em duas categorias. Na primeira, considera-se modificações que podem ser realizadas nas técnicas de préprocessamento e no codificador MMP-Bio e, na segunda, indica-se potenciais aplicações do esquema proposto. Assim, as propostas futuras são: 


\section{Quanto a modificações das técnicas:}

- As técnicas de pré-processamento possuem o potencial de favorecer a exploração das dependências do sinal bidimensional. Neste sentido, pode-se investigar diferentes técnicas de ordenação. Por exemplo, pode-se analisar a combinação da técnica de ordenação por diferença percentual e a segmentação por similaridade, desta forma obtém-se um particionamento que aumenta as correlações do sinal, e posteriormente, a exploração das dependências intersegmento é favorecida com a ordenação por diferença percentual.

- O algoritmo MMP-Bio utiliza basicamente todos os modos de predição para cada escala do bloco de entrada. Com o objetivo de melhorar a entropia dos símbolos que são codificados aritmeticamente, pode-se investigar quais modos são mais relevantes para cada escala. Além disso, pode-se investigar métodos para diminuir a latência do codificador.

- O codificador MMP-Bio apresenta um bom desempenho na compressão de sinais de S-EMG. As técnicas de pré-processamento possuem o potencial para melhorar a eficiência da compressão. Com base neste fatos, pode-se investigar a combinação das técnicas propostas com o MMP-Bio, como o codificador realiza particionamento da imagem de entrada, a segmentação por similaridade pode ser uma boa escolha.

\section{Quanto a potenciais aplicações:}

- Os resultados experimentais obtidos com o sinais de S-EMG são bons. O esquema pode ser avaliado com outros sinais biológicos, como o eletroencefalograma (EEG) e o eletrocardiograma (ECG).

- Os sinais eletromiográficos podem ser de múltiplas derivações. Neste contexto, pode-se avaliar a codificação destes sinais pelo esquema proposto, onde formatam-se os sinais como um único sinal bidimensional. 


\section{Referências Bibliográficas}

[1] MCBRIDE, J., ZHAO, X., MUNRO, N., et al., "Scalp EEG Signal Reconstruction for Detection of Mild Cognitive Impairment and Early Alzheimer's Disease". In: Proceedings of the Biomedical Sciences and Engineering Conference, pp. 1-4, Oak Ridge, Tennessee, USA, May 2013.

[2] DOUlah, A. B. M. S. U., IQBAL, M. A., JUMAnA, M. A., "AlS Disease Detection in EMG Using Time-Frequency Method". In: Proceedings of the International Conference on Informatics, Electronics Vision, pp. 648-651, Dhaka, Bangladesh, May 2012.

[3] GRADL, S., KUGLER, P., LOHMUller, C., et al., "Real-Time ECG Monitoring and Arrhythmia Detection Using Android-Based Mobile Devices". In: Proceedings of the Annual International Conference of the IEEE Engineering in Medicine and Biology Society, pp. 2452-2455, San Diego, Califórnia, USA, Aug 2012.

[4] PARK, S.-H., LEE, S.-P., "EMG Pattern Recognition Based on Artificial Intelligence Techniques", IEEE Transactions on Rehabilitation Engineering, v. 6, n. 4, pp. 400-405, Dec 1998.

[5] INOUE, K., SUGIOKA, K., ISHII, K., et al., "Pattern Recognition of EEG Signals During Right and Left Motor Imagery". In: Proceedings of the Society of Instrument and Control Engineers Annual Conference, v. 3, pp. 2432-2437, Fukui, Japão, Aug 2003.

[6] HE, L., HOU, W., ZHEN, X., et al., "Recognition of ECG Patterns Using Artificial Neural Network". In: Proceedings of the Sixth International Confe- 
rence on Intelligent Systems Design and Applications, v. 2, pp. 477-481, Jinan, Shandong, China, Oct 2006.

[7] ANG, K. K., GUAN, C., PHUA, K. S., et al., "Transcranial Direct Current Stimulation and EEG-Based Motor Imagery BCI for Upper Limb Stroke Rehabilitation". In: Proceedings of the Annual International Conference of the IEEE Engineering in Medicine and Biology Society, pp. 4128-4131, San Diego, Califórnia, USA, Aug 2012.

[8] BAI, F., CHEW, C.-M., LI, J., et al., "Muscle Force Estimation Method with Surface EMG for a Lower Extremities Rehabilitation Device". In: Proceedings of the IEEE International Conference on Rehabilitation Robotics, pp. 1-6, Seattle, Washington, USA, June 2013.

[9] SÖRNMO, L., LAGUNA, P., Electrocardiogram (ECG) Signal Processing. Wiley Encyclopedia of Biomedical Engineering, 2006.

[10] PARKER, P., MERLETTI, R., Electromyography:Physiology, Engineering, and Noninvasive Applications. John Wiley \& Sons, Inc., 2005.

[11] SANEI, S., CHAMBERS, J., EEG Signal Processing. John Wiley \& Sons Ltd, 2007.

[12] GAUTHAAM, M., KUMAR, S., "EMG Controlled Bionic Arm". In: Proceedings of the National Conference on Innovations in Emerging Technology, pp. 111-114, Erode, Tamilnadu, Índia, Feb 2011.

[13] HOShino, T., SUZUKI, T., TOMONO, M., et al., "Development of a Motion Support System by Using an Electromyogram”, v. 5, pp. 4432-4437, 2004.

[14] ZHEN, Z., HONG-LIANG, F., "Prosthetic Controlled System Based on Signal Pattern Recognition of Electroencephalogram". In: Proceedings of the International Seminar on Future BioMedical Information Engineering, pp. 287-290, Wuhan, Hubei, China, Dec 2008.

[15] DOULAH, A. B. M. S. U., IQBAL, M. A., "An Approach to Identify Myopathy Disease Using Different Signal Processing Features with Comparison". In: 
Proceedings of the 15th International Conference on Computer and Information Technology, pp. 155-158, Chittagong, Bangladexe, Dec 2012.

[16] Berger, P. A., NASCimento, F. A. O., CARMO, J. C., et al., "Compression of EMG Signals With Wavelet Transform and Artificial Neural Networks", Institute of Physics Publishing: Physiological Measurement, v. 27, n. 6 , pp. 457-465, June 2006.

[17] LICHTER, P. A., LANGE, E. H., RIEHLE, T. H., et al., "Rechargeable Wireless EMG Sensor for Prosthetic Control". In: Proceedings of the Annual International Conference of the IEEE Engineering in Medicine and Biology Society, pp. 5074-5076, Buenos Aires, Argentina, Aug 2010.

[18] Filho, E. B. L., RODRIGUES, N. M. M., DA SILVA, E. A. B., et al., "ECG Signal Compression Based on Dc Equalization and Complexity Sorting", IEEE Transactions on Biomedical Engineering, v. 55, n. 7, pp. 1923-1926, July 2008.

[19] Costa, M. V. C., CARvalho, J. L. A., BerGer, P. A., et al., "Two-dimensional compression of surface electromyographic signals using column-correlation sorting and image encoders". In: Proceedings of the Annual International Conference of the IEEE Engineering in Medicine and Biology Society, pp. 428-431, Minneapolis, Minnesota, USA, Sept 2009.

[20] HIGGINS, G., MCGINLEY, B., JONES, E., et al., "Efficient EEG Compression Using JPEG2000 with Coefficient Thresholding". In: Proceedings of the IET Irish Signals and Systems Conference, pp. 59-64, Cork, Irlanda, June 2010.

[21] TAUBMAN, D. S., MARCELLIN, M. W., JPEG2000: Image Compression Fundamentals, Standards and Practice. Kluwer Academic Publishers, 2001 .

[22] WIEGAND, T., SUllivan, G. J., BJONTEGAARD, G., et al., "Overview of the H.264/AVC video coding standard", IEEE Transactions on Circuits and Systems for Video Technology, v. 13, n. 7, pp. 560-576, July 2003. 
[23] SUllivan, G. J., OHM, J. R., HAN, W. J., et al., "Overview of the High Efficiency Video Coding (HEVC) Standard", IEEE Transactions on Circuits and Systems for Video Technology, v. 22, n. 12, pp. 1648-1667, Dec 2012.

[24] POurazad, M. T., DOUtre, C., AZIMI, M., et al., "HEvC: The New Gold Standard for Video Compression: How Does HEVC Compare with H.264/AVC?" IEEE Consumer Electronics Magazine, v. 1, n. 3, pp. 3646, July 2012.

[25] NGUYEN, T., MARPE, D., "Performance Analysis of HEVC-Based Intra Coding for Still Image Compression". In: Picture Coding Symposium, pp. 233-236, Krakow, Polônia, May 2012.

[26] Rodrigues, N. M. M., DA SILVA, E. A. B., DE CARVAlHO, M. B., et al., "On Dictionary Adaptation for Recurrent Pattern Image Coding", IEEE Transactions on Image Processing, v. 17, n. 9, pp. 1640-1653, Sept 2008.

[27] NAZARPOUR, K., SHARAFAT, A. R., FIROOZABADI, S. M., "Negentropy Analysis of Surface Electromyogram Signal". In: Proceedings of the 13th IEEE Workshop on Statistical Signal Processing, pp. 974-977, Bordeaux, França, July 2005.

[28] SHANNON, C. E., "A mathematical theory of communication", The Bell System Technical Journal, v. 27, n. 4, pp. 623-656, Oct 1948.

[29] JAYANT, N. S., P., N., Digital coding of waveforms - Principles and Application to Speech and Video. Prentice Hall: Englewood Cliffs, Nj, USA, 1984.

[30] HUFFMAN, D. A., "A Method for the Construction of Minimum Redundancy Codes". In: Proceedings of the Institute of Radio Engineers, v. 40, pp. 1098-1101, 1951.

[31] WITTEN, I., NEAL, R., CLEARY, J., "Arithmetic coding for data compression", Communications of the ACM, v. 30, n. 6, pp. 520-540, 1987.

[32] ZIV, J., LEMPEL, A., "A universal algorithm for sequential data compression", IEEE Transactions on Information Theory, v. 23, n. 3, pp. 337-343, May 1977. 
[33] ZIV, J., LEMPEL, A., "Compression of individual sequences via variable-rate coding", IEEE Transactions on Information Theory, v. 24, n. 5, pp. 530536, Sep 1978.

[34] DE lima filho, E. B., DA SIlva, E. A. B., DE CARvalho, M. B., et al., "Electrocardiographic Signal Compression Using Multiscale Recurrent Patterns", IEEE Transactions on Circuits and Systems I: Regular Papers, v. 52, n. 12, pp. 2739-2753, Dec 2005.

[35] JAlalEDDine, S. M. S., HUTCHENS, C., STRATTAN, R., et al., "ECG Data Compression Techniques-A Unified Approach", IEEE Transactions on Biomedical Engineering, v. 37, n. 4, pp. 329-343, April 1990.

[36] BAZÁN-PRIETO, C., BLANCO-VELASCO, M., CÁRDENAS-BARRERA, J., et al., "Retained energy-based coding for EEG signals", Medical Engineering and Physics, pp. 892-899, Nov 2011.

[37] COVER, T. M., THOMAS, J. A., Elements of Information Theory. John Wiley e Sons, Inc., 2006.

[38] PALANIAPPAN, R., Biological Signal Analysis. Ramaswamy Palaniappan and Ventus Publishing Aps, 2010.

[39] SUBHA, D. P., JOSEPH, P. K., ACHARYA U, R., et al., "EEG Signal Analysis: A Survey", Journal of Medical Systems, v. 34, n. 2, pp. 195-212, 2010.

[40] SOURINA, O., LIU, Y., "EEG-Enabled Affective Applications". In: Proceedings of the Humaine Association Conference on Affective Computing and Intelligent Interaction, pp. 707-708, Geneva, Suíça, Sept 2013.

[41] ASO, S., SASAKI, A., HASHIMOTO, H., et al., "Driving Electric Car by Using EMG Interface". In: Proceedings of the IEEE Conference on Cybernetics and Intelligent Systems, pp. 1-5, Bangkok, Tailândia, June 2006.

[42] CISI, R. R. L., JUNIOR, E. F. C., "Human Gait Analyzed by an Artificial Neural Network Model". In: Proceedings of the Brazilian Conference on Neural Networks, pp. 148-151, São José dos Campos, Brasil, July 1999. 
[43] BELTRAmini, L. M., Elementos de Histologia e Anátomo-fisiologia Humana. Serviço Gráfico do Instituto de Física de São Carlos-USP, 1999.

[44] NIKOLIC, M., Detailed Analysis of Clinical Electromyography Signals EMG Decomposition: Findings and Firing Pattern Analysis in Controls and Patients with Myopathy and Amytrophic Lateral Sclerosis, Ph.D. Thesis, University of Copenhagen, Faculty of Health Science, 2001.

[45] DE LUCA, C., "Surface Electromyography: Detection and Recording ,Delsys Incorporated", 2002, http://www.delsys.com/Attachments_pdf/WP_ SEMGintro.pdf.

[46] NORRIS, J. F., LOVELY, D. F., "Real-Time Compression of Myoelectric Data Utilising Adaptive Differential Pulse Code Modulation", Medical and Biological Engineering and Computing, v. 33, pp. 629-635, September 1995.

[47] CAROTTI, E., DE MARTIN, J., FARINA, D., et al., "Linear Predictive Coding of Myoelectric Signals". In: Proceedings of the IEEE International Conference on Acoustics, Speech, and Signal Processing, v. 5, pp. 629-632, Filadélfia, Pensilvânia, USA, March 2005.

[48] NORRIS, J. A., ENGLEHART, K., LOVELY, D., "Steady-State and Dynamic Myoelectric Signal Compression Using Embedded Zero-Tree Wavelets". In: Proceedings of the 23rd Annual International Conference of the IEEE Engineering in Medicine and Biology Society, v. 2, pp. 1879-1882, Istambul, Turquia, 2001.

[49] GERSHO, A., GRAY, R., Vector Quantization and Signal Compression. New York: Springer, 1991.

[50] JAIN, N., R., V., "Wavelet based vector quantization with tree code vectors for EMG Signal compression". In: Proceedings of the 6th World Scientific and Engineering Academy and Society, International Conference on Signal Processing, v. 6, pp. 117-124, Dallas, Texas, USA, March 2007. 
[51] Filho, E. B. L., DA Silva, E. A. B., DE CARvalho, M. B., "On EMG Signal Compression With Recurrent Patterns", IEEE Transactions on Biomedical Engineering, v. 55, n. 7, pp. 1920-1923, July 2008.

[52] DE CARvalho, M. B., DA SIlva, E. A. B., FinAmORE, W., "Muldimensional Signal Compression Using Multiscale Recurrent Patterns", Elsevier Signal Process, v. 82, pp. 1559-1580, Nov 2002.

[53] LUCAS, L. F. R., RODRIGUES, N. M. M., DA SILVA, E. A. B., et al., "Adaptive Least Squares Prediction for Stereo Image Coding". In: Proceedings of the 18th IEEE International Conference on Image Processing, pp. 20132016, Bruxelas, Bélgica, Sept 2011.

[54] Francisco, N. C., RODrigueS, N. M. M., DA Silva, E. A. B., et al., "Efficient Recurrent Pattern Matching Video Coding", IEEE Transaction on Circuits and System for Video Technology, v. 22, n. 8, pp. 1161-1173, August 2012.

[55] PINAGÉ, F. S., DA SILVA, E. A. B., NETTO, S. L., "Prediction-Based Coding of Speech Signals Using Multiscale Recurrent Patterns". In: International Telecommunications Symposium, Manaus, Brasil, Sept 2010.

[56] ORTEGA, A., RAMCHANDRAN, K., "Rate-Distortion Methods for Image and Video Compression", Signal Processing Magazine, IEEE, v. 15, n. 6, pp. 23-50, Nov 1998.

[57] FRANCISCO, N., RODRIGUES, N. M. M., DA SILVA, E. A. B., et al., "Multiscale Recurrent Pattern Image Coding With a Flexible Partition Scheme". In: Proceedings of the 15th IEEE International Conference on Image Processing, pp. 141-144, San Diego, Califórnia, USA, Oct 2008.

[58] GRAZIOsi, D., RODRIGUES, N., DA SILVA, E. A. B., et al., "Improving Multiscale Recurrent Pattern Image Coding With Least-Squares Prediction Mode". In: Proceedings of the 16th IEEE International Conference on Image Processing, pp. 2813-2816, Cairo, Egito, Nov 2009. 
[59] DE CARvalho, M. B., DA Silva, E. A. B., Finamore, W. A., "Multidimensional Signal Compression Using Multiscale Recurrent Patterns", Signal Processing: Image Video Coding Beyond Stand., v. 82, n. 11, pp. 15591580, Nov 2002.

[60] ROdrigues, N. M. M., DA SILVA, E. A. B., DE CARVAlHO, M. B., et al., "Efficient Dictionary Design for Multiscale Recurrent Pattern Image Coding". In: Proceedings of the IEEE International Symposium on Circuits and Systems, pp. 4939-4942, Ilha de Kos, Grécia, May 2006.

[61] CHEN, J., LEE, T., "Planar Intra Prediction Improvement", JCT-VC-F483, July 2011.

[62] Kakadu Software, http://www.kakadusoftware.com/.

[63] JM software reference, http://iphome.hhi.de/suehring/tml/download/.

[64] HM software reference, https://hevc.hhi.fraunhofer.de/svn/svn_ HEVCSoftware/tags/HM-9.1/. 


\section{Apêndice A}

\section{Sinais de S-EMG}

Neste apêndice, apresentam-se os 13 sinais de S-EMG reais adquiridos em laboratório.

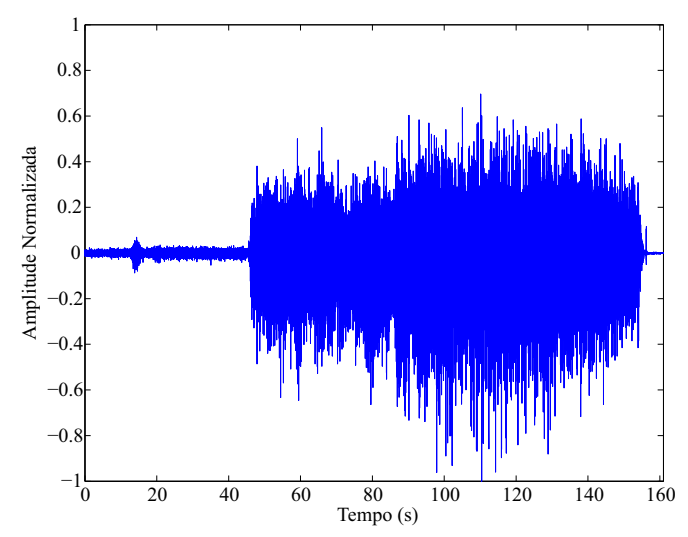

Figura A.1: Sinal teste.01.

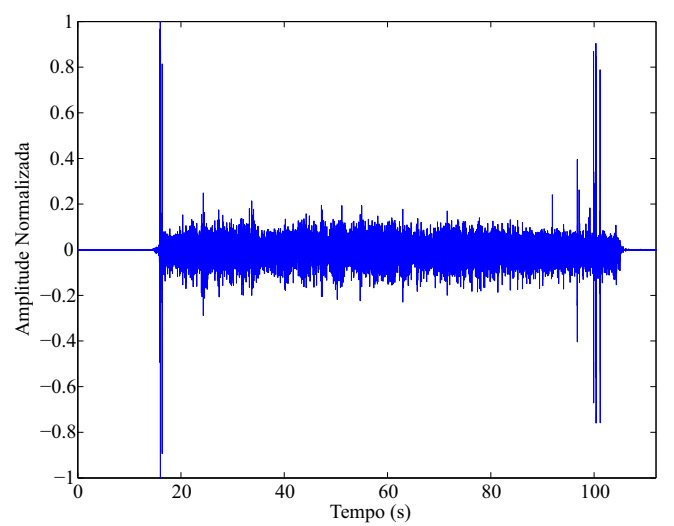

Figura A.2: Sinal teste.02. 


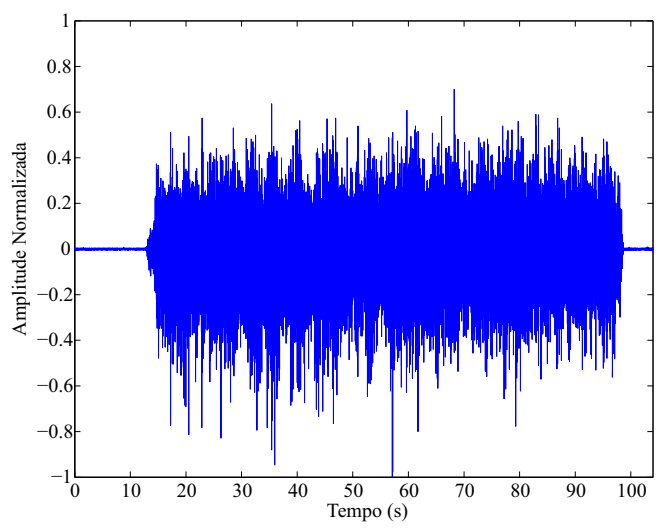

Figura A.3: Sinal teste.03.

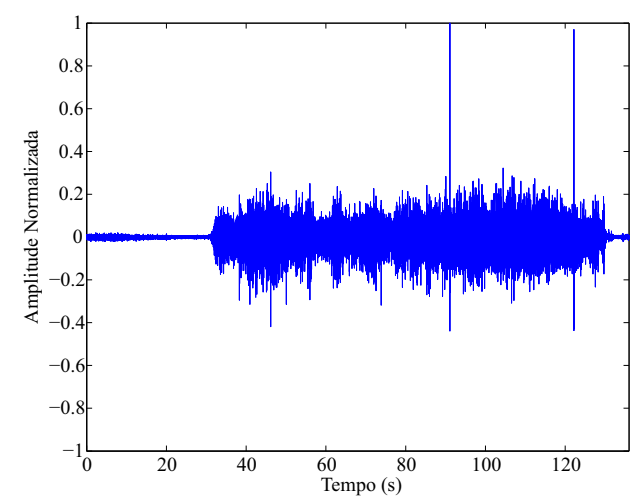

Figura A.4: Sinal teste.04.

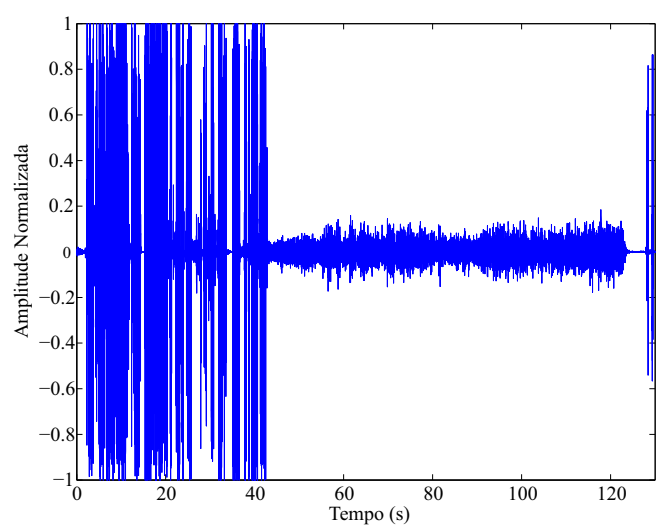

Figura A.5: Sinal teste.05. 


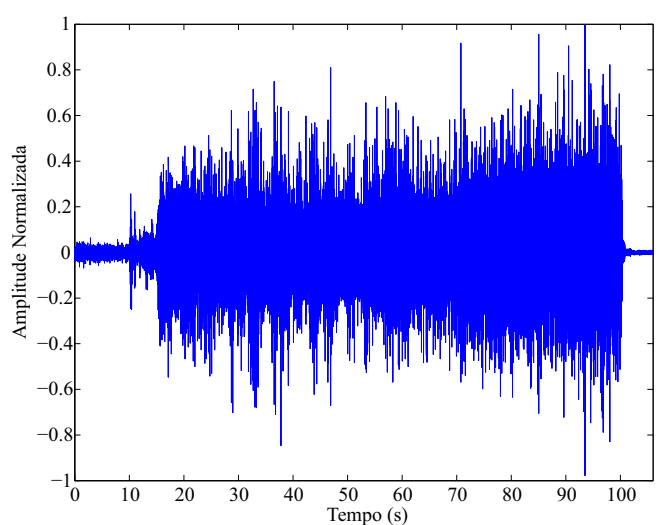

Figura A.6: Sinal teste.06.

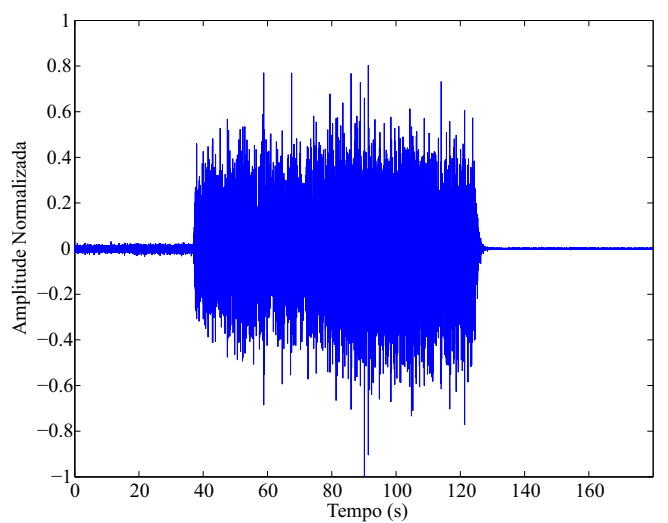

Figura A.7: Sinal teste.07.

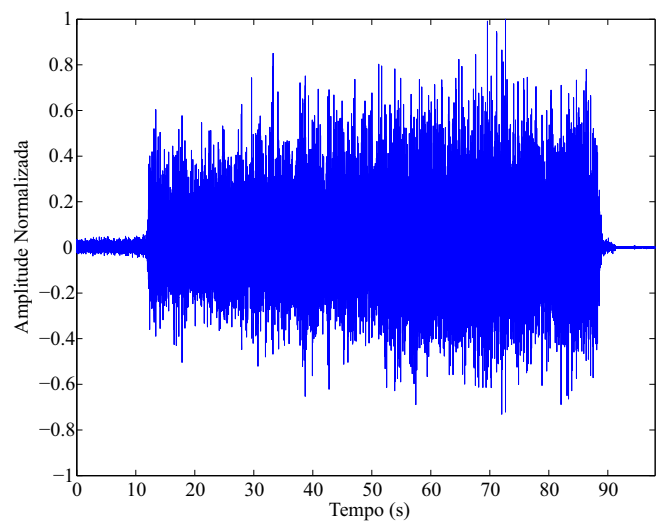

Figura A.8: Sinal teste.08. 


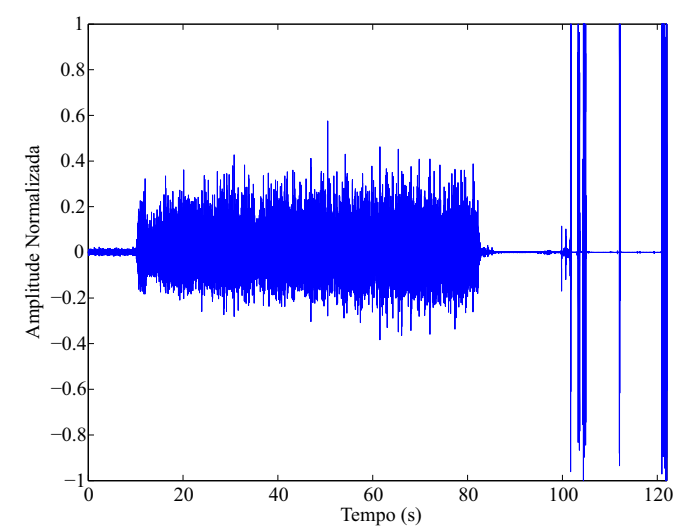

Figura A.9: Sinal teste.09.

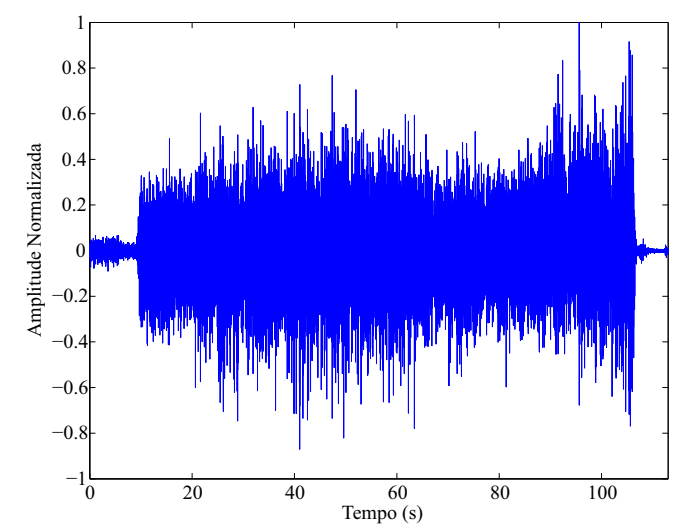

Figura A.10: Sinal teste.10.

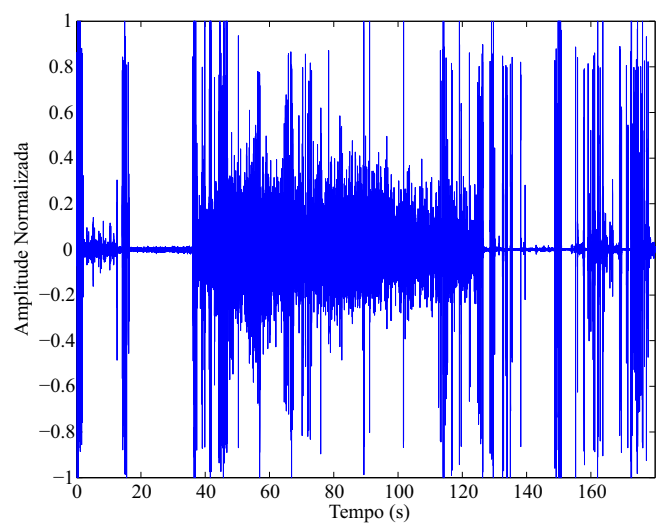

Figura A.11: Sinal teste.11. 


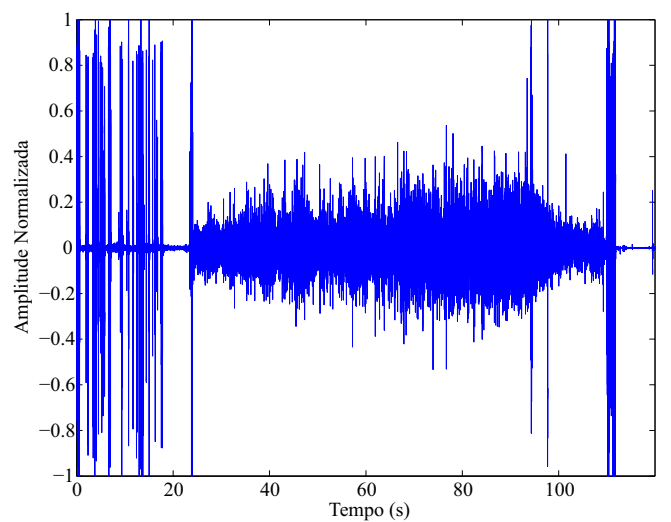

Figura A.12: Sinal teste.12.

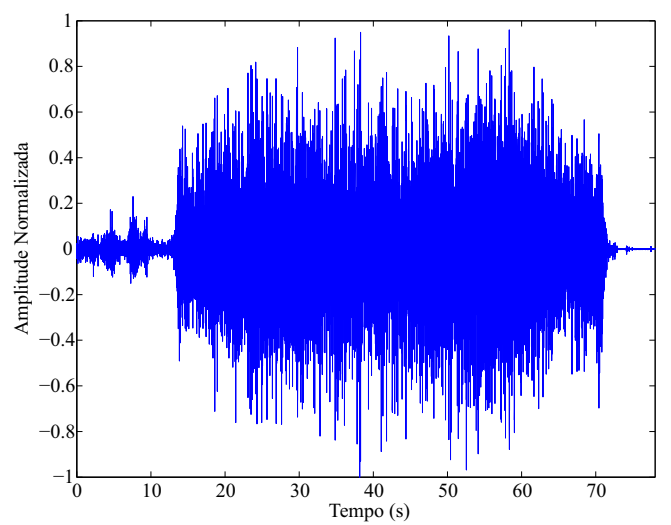

Figura A.13: Sinal teste.13. 


\section{Apêndice B}

\section{Artigos Desenvolvidos nesta \\ Dissertação}

Neste apêndice, apresentam-se os artigos desenvolvidos nesta dissertação.

1. Melo, W. C.; Filho, E. B. L.; JUNIOR, W. S. S. "Compressão de Sinais Eletromiográficos Baseada em Técnicas de Pré-processamento". In: Anais do XXX Simpósio Brasileiro de Telecomunicações, Setembro de 2012, Brasília. SBrT'12, 2012.

1. Melo, W. C.; Filho, E. B. L.; JUNIOR, W. S. S. "Electromyographic signal compression based on preprocessing techniques". In: Engineering in Medicine and Biology Society (EMBC), 2012 Annual International Conference of the IEEE, San Diego, 2012. 